\title{
Plant-INSECT INTERACTIONS IN CHANGING ENVIRONMENTS
}

\author{
Dissertation \\ zur Erlangung des Doktorgrades \\ der Fakultät für Agrarwissenschaften \\ der Georg-August-Universität Göttingen \\ vorgelegt von \\ Dipl.-Biol. David Joachim Gladbach \\ geboren in Köln
}

Göttingen, Mai 2010 
1. Referent: Prof. Dr. Teja Tscharntke

2. Korreferent: Dr. Carsten F. Dormann

Tag der mündlichen Prüfung: 15. Juli 2010 
“..., what good is it to argue about whether HOLISM or REDUCTIONISM is right, when the proper way to understand the matter is to transcend the question, by answering $M U^{\prime \prime}$.

Douglas R. Hofstadter - Gödel, Escher, Bach: An Eternal Golden Braid 


\section{TABLE OF CONTENTS}

CHAPTER 1

General introduction 7

$\begin{array}{lr}\text { INTRODUCTION } & 8\end{array}$

$\begin{array}{ll}\text { CHAPTER OUTLINE AND MAIN RESUltS } & 10\end{array}$

$\begin{array}{ll}\text { ConcLusions } & 12\end{array}$

$\begin{array}{ll}\text { APPENDIX } & 13\end{array}$

CHAPTER 2

Spillover cascades: crops affect trophic interactions on wild plants in surrounding habitats 17

$\begin{array}{ll}\text { ABSTRACT } & 18\end{array}$

$\begin{array}{ll}\text { INTRODUCTION } & 19\end{array}$

$\begin{array}{ll}\text { Methods } & 20\end{array}$

RESULTS $\quad 23$

$\begin{array}{ll}\text { DISCUSSION } & 25\end{array}$

$\begin{array}{ll}\text { APPENDIX } & 28\end{array}$

Chapter 3

Heating up trophic interactions in crops with low vs. high intensity management 35

$\begin{array}{ll}\text { ABSTRACT } & 36\end{array}$

$\begin{array}{ll}\text { INTRODUCTION } & 37\end{array}$

$\begin{array}{ll}\text { METHODS } & 37\end{array}$

$\begin{array}{ll}\text { RESULTS } & 40\end{array}$

DISCUSSION

$\begin{array}{ll}\text { APPENDIX } & 46\end{array}$ 
Chapter 4

Effects of warming, drought and elevated $\mathrm{CO}_{2}$ on performance of an insect herbivore in heathland 51

Abstract

INTRODUCTION

Methods

RESUlts

Discussion

APPENDIX

SUMMARY

ACKNOWLEDGEMENTS

REFERENCES

Publications

Curriculum vitae

89

DeClaration OF ORIGINAL AUTHORSHIP 



\section{Chapter 1}

General introduction

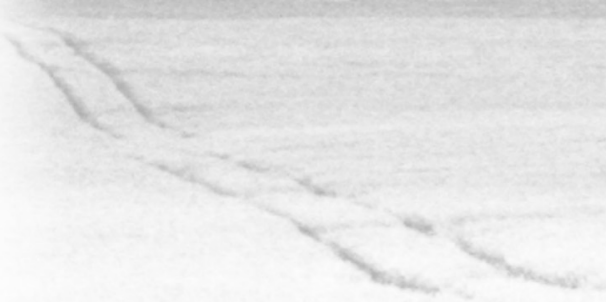

농 


\section{INTRODUCTION}

\section{TROPHIC INTERACTIONS: CENTRAL FOR ECOSYSTEM FUNCTIONING AND SERVICES}

One quarter of all extant organisms are herbivorous insects (Strong et al. 1984; Mayhew 2001), which shape ecosystems in interaction with plants (Weisser and Siemann 2004). Herbivory as ecosystem function can decrease plant biomass and productivity (Matson et al. 1997) and thereby change environmental conditions and diminish resources for species (Jones and Lawton 1995). Fluctuations within herbivore populations are passed to other trophic levels by cascading up and down the food chain. Increasing populations of herbivorous insects may reduce plant biomass on one hand, and at the same time provide sufficient resource for predators (i.e. biocontrol agents). Because herbivorous insects occupy a major trophic position in food chains, (human induced) environmental changes causing fundamental shifts of this trophic level can affect directly linked trophic levels antagonistically and thereby potentially cause instability of ecosystem functioning (Chapin et al. 1997).

Effects of human induced changes to landscape structure, agriculture (intensification), and climate have been identified to affect ecosystem functions with increasing frequency. Publications and citations of these terms in combination with ecosystem function have at least doubled since 2004. For climate change the publication record increased from 30 (2004) to 87 (2009), citations increased from 1100 to 3100 between 2005 and 2009 (Web of Science ${ }^{\circledR}$ Citation Report 2010).

The expansion of agricultural land affects landscape scale patterns (sensu Turner and Gardner 1991) and decreases structural complexity and habitat diversity (Turner 1989; Wrbka et al. 2004). Consequently distribution patterns of insects may alter (Rand et al. 2006) and thereby change ecosystem functions (Kareiva and Wennergren 1995; Hooper et al. 2005).

Locally agricultural intensification includes the application of fertilizers and pesticides that reduce biodiversity within habitats and alters local conditions for insects. Interactions may be more stable in complex agricultural systems (Van Emden and Williams 1974; Balvanera 2001; Gurr et al. 2003; Casula et al. 2006; Schmitz 2009), whereas in intensively managed systems, trophic interactions are often dominated by few species and thereby, susceptible to environmental change (Straub and Snyder 2006; Straub et al. 2008).

Climate change is expected to increase the global mean surface air temperature by 1.8 $5.8^{\circ} \mathrm{C}$ (2090 to 2099 relative to 1980 to 1999 ), with additional changes in other climate change drivers such as increasing $\mathrm{CO}_{2}$ levels or extreme weather events (IPCC 2007). Recent studies, have shown that increases in $\mathrm{CO}_{2}$ may alter plant-insect interactions in various ways (Lincoln et al. 1986; Lincoln and Couvet 1989; Stiling et al. 1999; Stiling and Cornelissen 2007). Elevated temperature is generally assumed to increase herbivory (Bale et al. 2002), while altered water conditions are discussed controversially (Mattson and Haack 1987; Morecroft et al. 2002).

Effects of landscape structure, habitat type and local management, or climate change have been well studied with respect to trophic interactions. However, since the simultaneous 
investigation of different levels of environmental change is difficult, studies are scarce and the interplay of these factors remains hard to predict. While few studies have shown the interaction of landscape and local processes and their effect on patterns of trophic interactions (Cushman and McGarigal 2004; Dauber et al. 2005; Schweiger et al. 2005), I am not aware of studies that investigated interaction effects of different climate change drivers or climate change with landscape or field management on ecosystem functions. Predictions about the quality of future ecosystem functions require mechanistic studies of how trophic interactions respond to interactions of the different types of environmental changes.

\section{BIOTIC ECOSYSTEM SERVICES - THE BESS PROJECT}

The work that is contained in this thesis was integrated in the umbrella project BESS, launched as Helmholtz Young Investigators Group, a cooperation between the Center for Environmental Research -UFZ, Leipzig and the Department of Agroecology, University Göttingen. Ecosystem services in general comprise naturally provided processes that support human life and can be divided into provisioning services (e.g. crops), regulating services (eg. pollination, biocontrol) and cultural services (e.g. recreation, Carpenter et al. 2009). Type, quality and extend of services are a trade off, driven by the characteristics of the service providing ecosystem (Foley et al. 2005). As increasing human requirements push ecosystem services beyond the limits of their
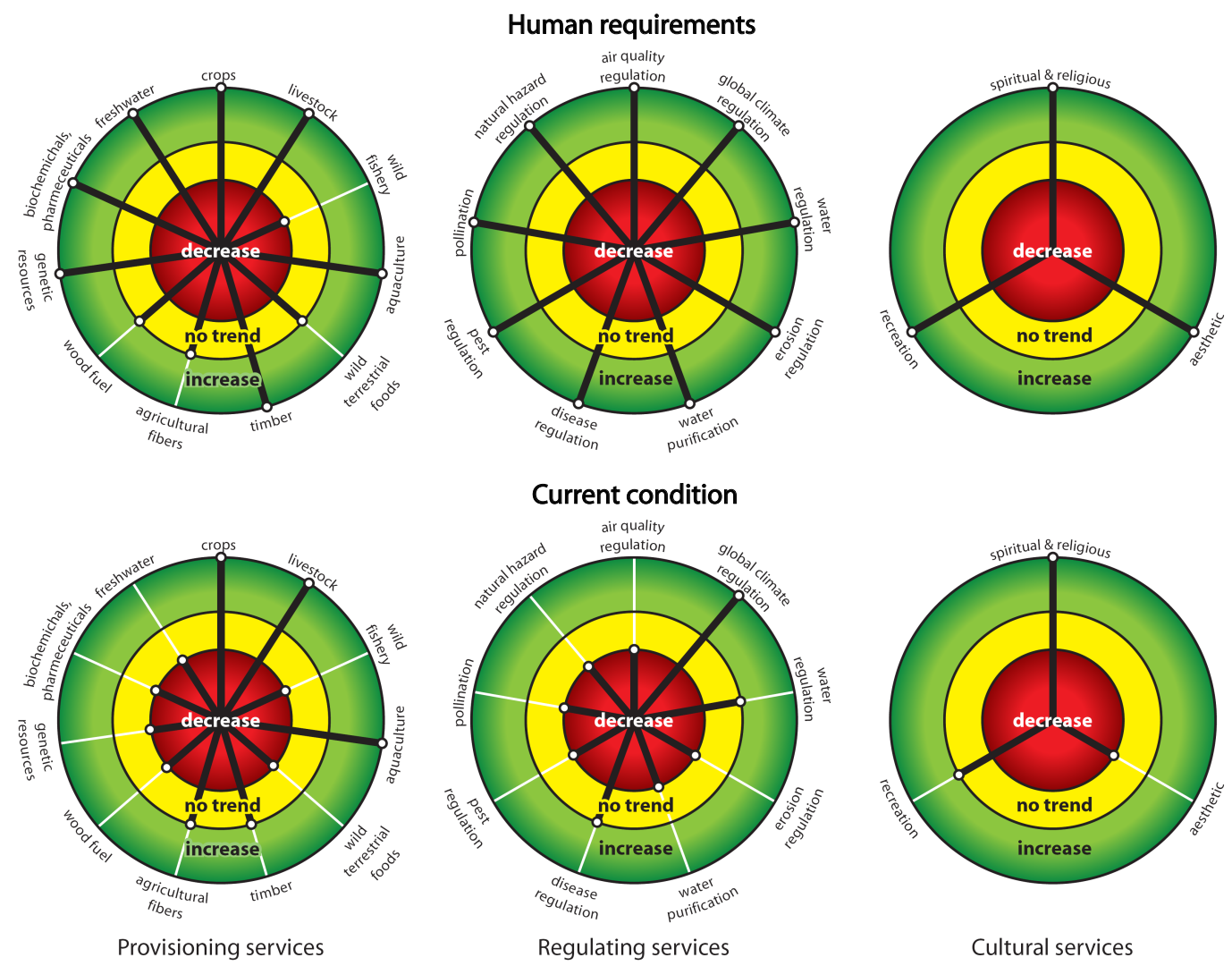

Figure 1.1. Human requirements (top) and current condition (bottom) of ecosystem services. Ecosystem services are split into provisioning, regulating and cultural services (plotted left to right) based on the Millenium Ecosystem Assessment. Black radial lines indicate the tendency of human requirement and condition of the service respectively. Figure adapted from Carpenter et al. 2009. 
capacity, scientists aimed to pinpoint gaps between human requirements and the actual state of ecosystem services in the course of the Millenium Ecosystem Assessment (www.MAweb.org, Fig. 1).

Within this framework BESS focuses on the regulating services - biocontrol and pollination in specific. Both services are related to food production and thus are of major importance for human wellbeing. However, owing to agricultural intensification the condition of pollination and biocontrol services are underperforming with respect to human requirements. In this context the aim of BESS is (1) to acquire the understanding of mechanisms that steer these ecosystem services and subsequently (2) to provide tools and methods to manage and improve these important ecosystem services at a landscape scale. Three sub-projects have been initiated:

i) Pollination of wild bees is investigated with respect to landscape context and source habitats within agricultural landscapes

ii) The work of this thesis constitutes the plant-insect interaction and biocontrol part of the BESS Project. Details are given in the section chapter outline.

iii) A modelling group uses the field data from projects i) and ii) and available information from the literature to compute spatial explicit models. These models serve as a test of how different steering tools may change the services at a landscape scale.

\section{CHAPTER OUTLINE AND MAIN RESULTS}

This thesis comprises three studies approaching the effects of co-acting environmental change factors on trophic interactions. Hereby the focus was on plants and insects with optional inclusion of a predator level. Main questions considered the interaction effects of

i) landscape context and local habitat type on the spillover of pest organisms and biocontrol agents from crop into non-crop habitats.

ii) Climate warming and high vs. low field management on tri-trophic interactions in wheat.

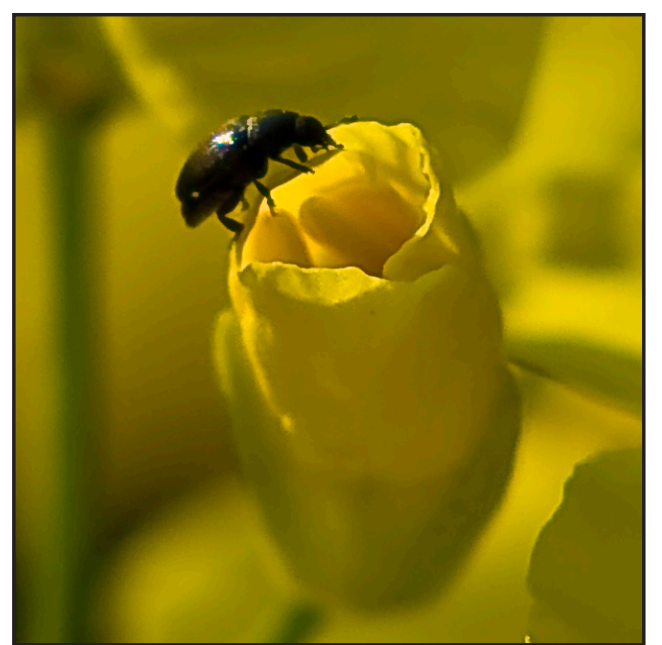

Figure 1.2. Meligethes aeneus iii) Different climate change drivers on the performance of insect herbivores in heathland.

The second chapter deals with the investigation of how spillover of rape pollen beetles (Fig. 1.2) and their parasitoids from oilseed rape fields (Appendix 1.1) into cropland habitats (wheat fields and field margin) and noncrop habitats (fallow, grassland, wood margin) is affected by landscape composition. The study was conducted in the vicinity of Göttingen on a gradient of eight landscape sectors (Fig. 1.3). Within these sectors 

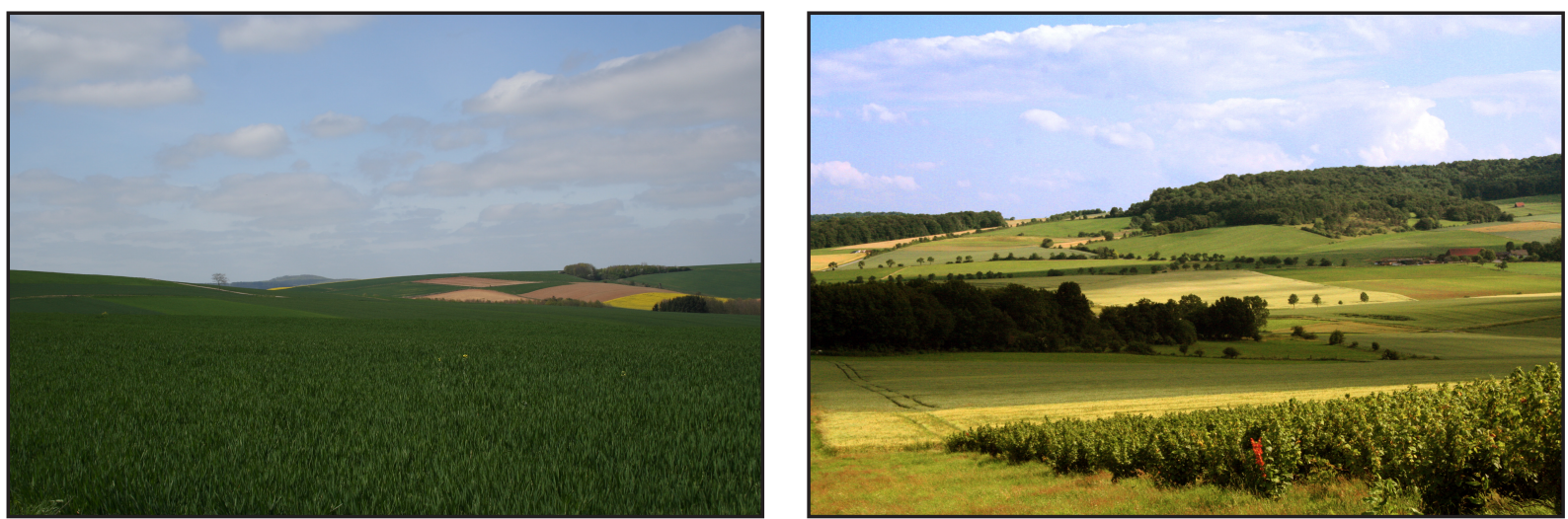

Figure 1.3. Landscape gradient: (left) Homogeneous landscape consisting of large agricultural fields. (right) Heterogeneous landscape caracterized by patchy distribution of crop and non-crop habitats with different landscape elements (hedgerows, woodlots).

we recorded different landscape parameters and the colonization of potted wild mustard plants by rape pollen beetles and parasitoids. Both landscape and local factors affected the abundance of rape pollen beetles and parasitoids. Rape pollen beetle infestation and parasitism rates were lower in noncrop habitats and higher in wheat fields and field margins. In contrast, beetles and parasitoids responded differently to landscape scale parameters. Parasitism rates were not related to landscape simplification, but benefited from increasing proportions of oilseed rape. In contrast, we found more rape pollen beetles on plants in simple landscapes, which we attribute to multi-annual population built-ups resulting from long-term oilseed rape planting (as part of the crop rotation). Parasitoid spillover from cropland affects trophic cascades on wild plants outside cropland, which can be expected to be a widespread effect shaping non-crop food webs.

The third chapter reports of the experimental elevation of temperature (using shields for passive warming) and the resulting effects on tri-trophic interactions in fertilized vs. unfertilized wheat and wheat monocultures vs. mixed cultures (with undersowings). The experiment was designed as a full factorial split-plot, mixed and monocultures were manipulated on the highest level and divided into fertilized and unfertilized strips. Within each of the fertilizer treatments we established the warming treatment, yielding a total of 8 treatments $(8$ treatments, 6 replicates, $n=48$ plots, Appendix 1.2). We measured the number of cereal aphids and their natural enemies (Fig. 1.4) in relation to yield of
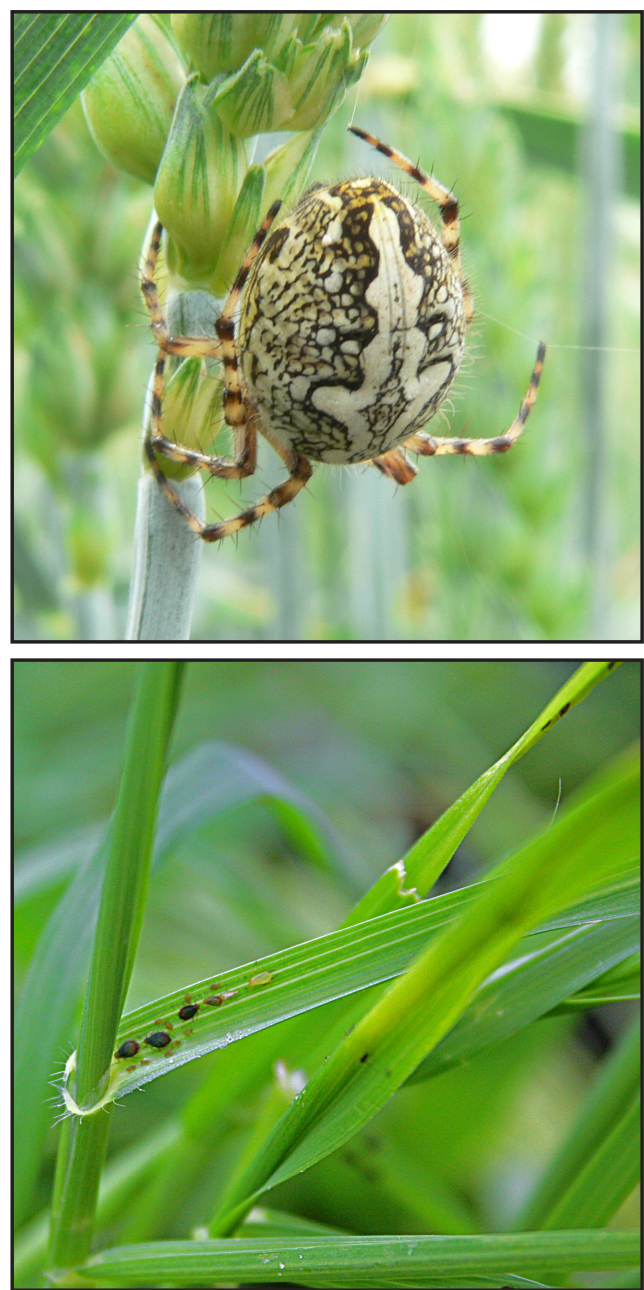

Figure 1.4. Aphids and biocontrol agents in wheat: (top) Araneus spec. (bottom) Metopolophium dirhodum (Walker) 


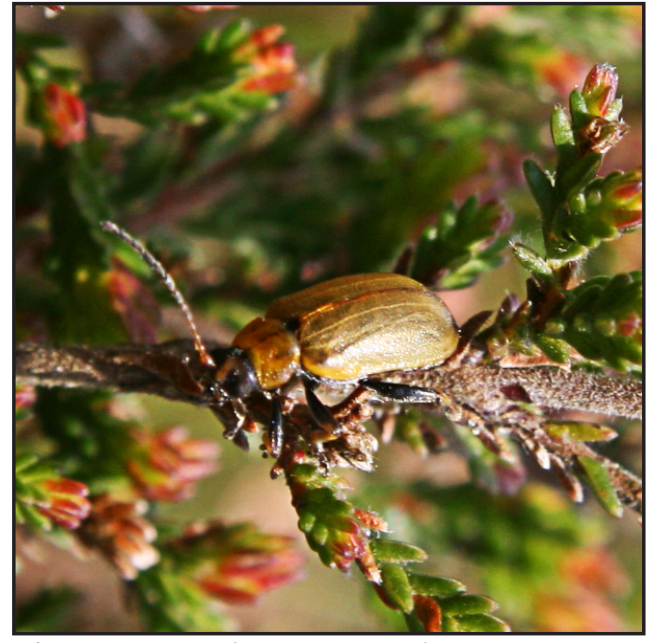

Figure 1.5. Lochmaea suturalis

wheat plants weekly from wheat flowering to dough ripening. Fertilization increased yield, but also aphid density, which negatively affected yield. Predatorprey ratios were highest in diversified wheat and related to reduced aphid population growth. Elevated temperature enhanced aphid growth strongest in fertilized monocultures, leading to reduced yield. Our results show that diversified crops and reduced fertilization may become an important tool to prevent pest outbreaks in future warmer climates.

The fourth chapter contains a report of multiple independently manipulated climate change drivers $\left(\mathrm{CO}_{2}\right.$, temperature, drought) and their effects on herbivorous insects. The study was conducted at the CLIMAITE research facility near Brandbjerg, DK, in heathland ecosystem consisting of a heather (Calluna vulgaris) grassland mosaic. The experiment was designed as a full factorial split-plot with 6 blocks $\times 2 \mathrm{CO}_{2}$ treatments $\times 4$ warming/drought treatments $=$ 48 plots (Appendix 1.3). We exposed a total of $432(\mathrm{n}=9$ per plot) larvae of heather beetle (Lochmaea suturalis Thomson, Appendix 1.4) to ambient vs. elevated drought, temperature and $\mathrm{CO}_{2}$ (plus all combinations) for five weeks. Weight and survival were recorded weekly. Larval growth and survival were significantly reduced by elevated $\mathrm{CO}_{2}$ and drought, which most distinctly affected insect herbivores. Warming had negative effects on growth but not on survival. Combined $\mathrm{CO}_{2}$ and drought significantly reduced growth, while interactions of warming with other global change drivers were inconsistent. Co-acting climate change factors modified each others effects on herbivorous insects, introducing complexity that has to be treated carefully when making predictions. In conclusion insect herbivore populations may respond negatively to future climate.

\section{Conclusions}

In this experimental series shifts within trophic interactions as a result of environmental changes were shown. However, predictions or generalisations about the fate of ecosystems services under environmental change have to be treated with care, because all of the investigated factors of environmental change varied in their effects depending on the responding organism. Insects with different grades of specialisation responded to different aspects on a landscape scale generalists benefited from landscape complexity, while specialist responded to the presence of their preferred food resource. The same was true for habitat diversity on a local scale, specialists did not benefit from diversity but rather from uniform and abundant resource of the crop they are specialized on. Climate change (i.e. temperature) had adverse effects on different insects. Aphids benefited from warming, while others were affected negatively.

Environmental change factors that act in concert caused complex responses of ecosystems. 
We showed that even temperature elevation at the lower scale of predicted change can cause fundamental shifts in established interactions. Extrapolating from local field management effects we may conclude that large scale patterns such as landscape structure may interact with climate change drivers and thus can be used as a tool for insect population management in future. However, species specific responses to experimentally controlled changes highlight the complexity with which future environmental change affects ecosystems.

\section{APPENDIX}

CONTENT

Appendix 1.1. Oilseed rape fields in the vicinity of Göttingen

Appendix 1.2. Experimental field site in Göttingen

Appendix 1.3. CLIMAITE field site at Brandbjerg, DK

Appendix 1.4. Larva of Lochmaea suturalis 


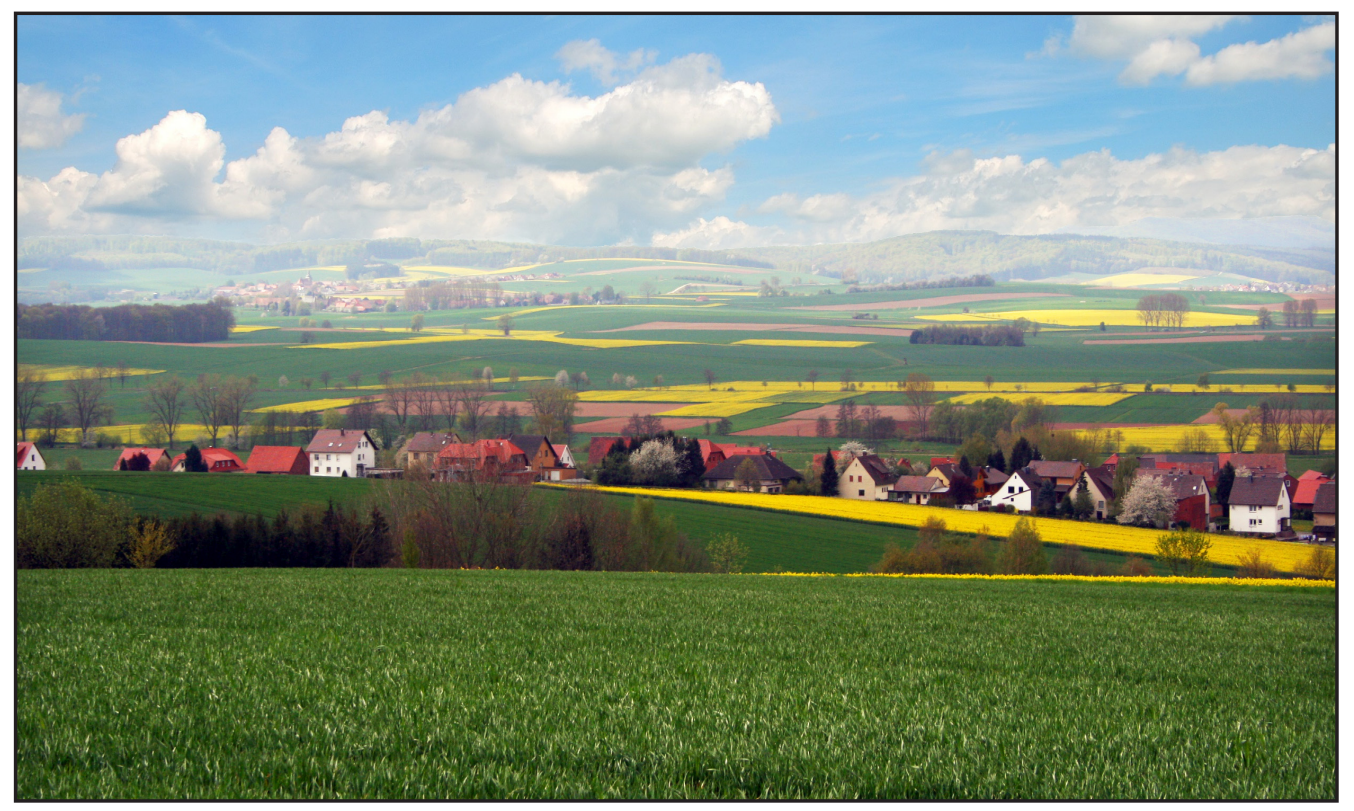

Appendix 1.1. Scattered oilseed rape fields in an agricultural landscape in the vicinity of Göttingen. Spillover effects where investigated from oilseed rape fields into cropland habitats (wheat fields and field margin) and noncrop habitats (fallow, grassland, wood margin).

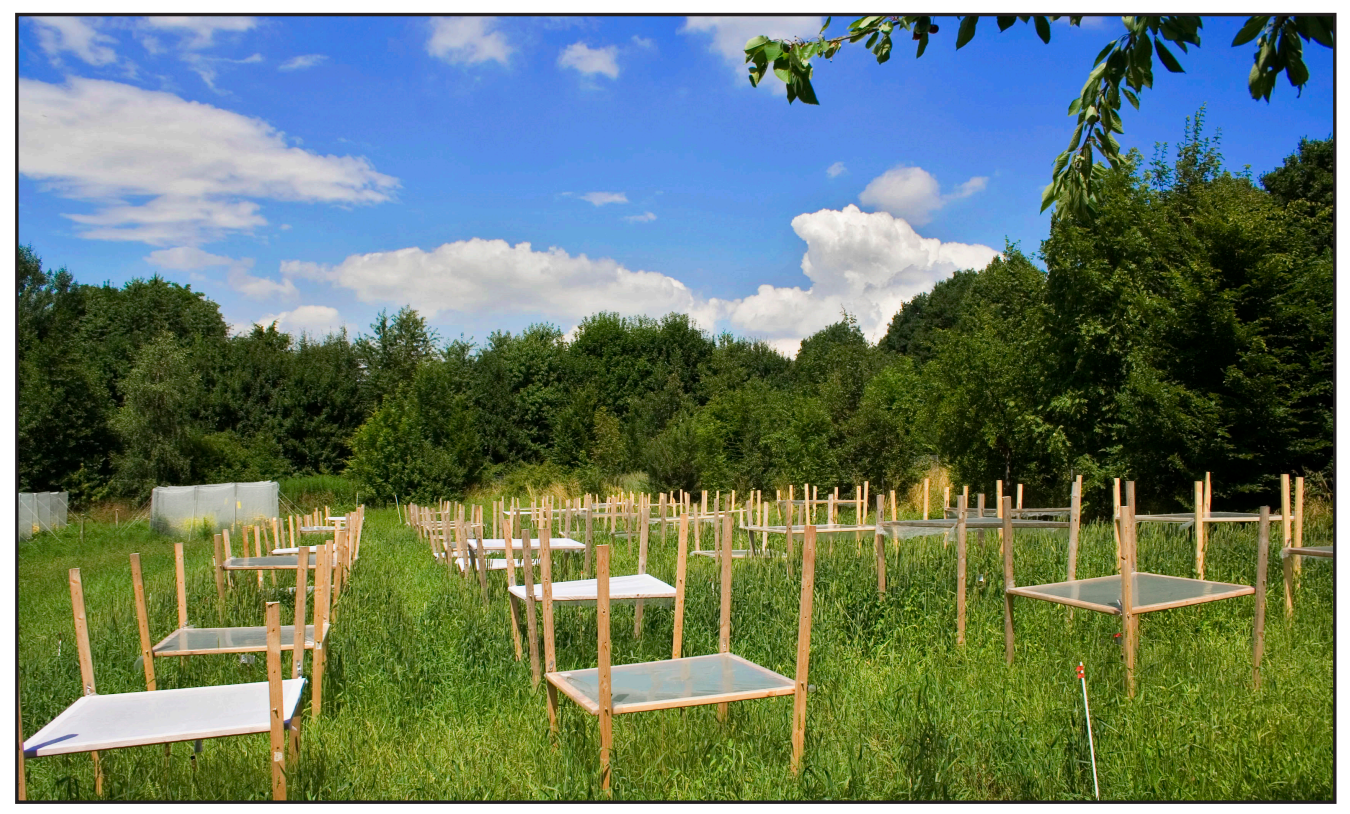

Appendix 1.2. Experimental setup for manipulation of trophic interactions in wheat. Treatments for 48 plots comprise (i) herbicide treatment: monoculture - front left, mixed culture - front right; (ii) fertilizer treatment applied as alternating strips: unfertilized wheat - light green shading: fertilized wheat - dark green shading; (iii) shields for passive warming (greenhouse foil) and control (gauze). Further details are given in chapter 3. 


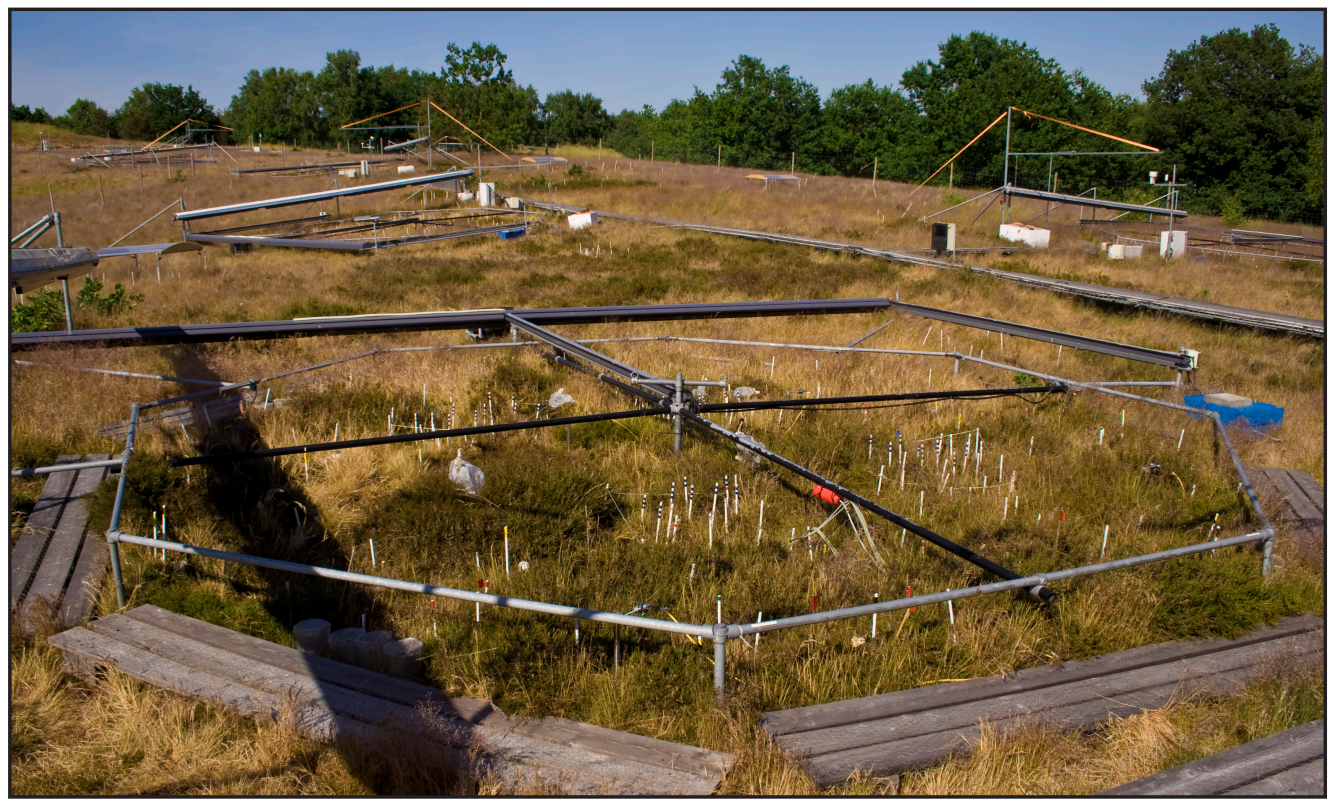

Appendix 1.3. CLIMAITE field site at Brandbjerg, DK. The facility consists of 12 octagons in 6 blocks. The octagon in front is with ambient $\mathrm{CO}_{2}$ treatment; elevated $\mathrm{CO}_{2}$ is applied with plastic tubes tied to the surrounding metal frame and supplied from a $\mathrm{CO}_{2}$ gas tank. Each octagon is divided into 4 plots with single and combined warming and drought treatments. At sunset curtains for passive night time warming are pulled along the guard rails over the two plots at the far end. The drought curtain is drawn along a suspended beam (see distant octagons) over the two plots at the left hand side. Note the white gauze bags for caging the heather beetle larvae during the experiment. White pins indicate subplots of other experiments and locations of sensors for recording of abiotic conditions. Further details and pictures are given in chapter 4 .

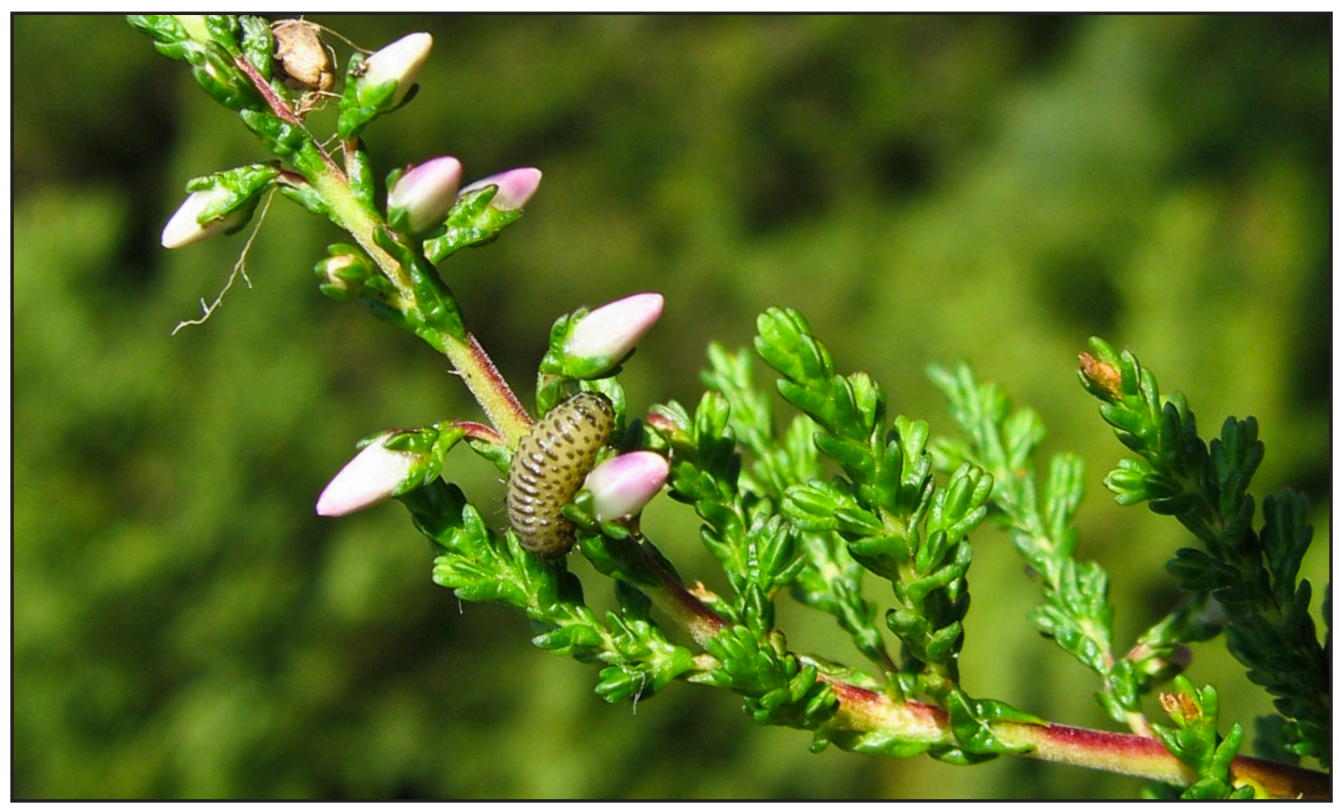

Appendix 1.4. Larval stage II of Lochmaea suturalis feeding on Calluna vulgaris. 



\section{Chapter 2}

Spillover cascades: crops affect trophic interactions on wild plants in surrounding habitats 


\begin{abstract}
Ecosystem processes in agricultural landscapes are often triggered by resource availability in crop and noncrop habitats. We investigated how oilseed rape (OSR, Brassica napus, Brassicaceae) affects noncrop plants in managed systems and semi-natural habitat, using trophic interactions among wild mustard (Sinapis arvensis, Brassicaceae), rape pollen beetles (Meligethes aeneus, Nitidulidae) and their parasitoids (Tersilochus heterocerus, Ichneumonidae). We exposed wild mustard as phytometer plants in two cropland habitat types (wheat field, field margin) and three noncrop habitat types (fallow, grassland, wood margin) across eight landscapes along a gradient from simple to complex (quantified as \% arable land). Both landscape and local factors affected the abundance of rape pollen beetles and parasitoids. Rape pollen beetle infestation and parasitism rates were lower in noncrop habitats and higher in wheat fields and field margins, whereas beetles and parasitoids responded differently to landscape scale parameters. We found the hypothesized spillover from OSR crop onto wild plants in surrounding habitats only for parasitoids, but not for pollen beetles. Parasitism rates were not related to landscape simplification, but benefited from increasing proportions of OSR. In contrast, rape pollen beetles benefited from simple landscape structures, presumably due to multi-annual population built-ups resulting from long-term OSR planting (as part of the crop rotation). In conclusion, we showed that parasitoid spillover from cropland affects trophic cascades on related wild plants outside cropland, which has been not shown so far, but can be expected to be a widespread effect shaping noncrop food webs.
\end{abstract}

Key-words: habitat identity, herbivory, large-scale effects, local effects

Authors:

David J. Gladbach

Andrea Holzschuh

Christoph Scherber

Carsten Thies

Carsten F. Dormann

Teja Tscharntke 


\section{INTRODUCTION}

Landscape-scale patterns (sensu Turner and Gardner 1991) often affect ecosystem processes locally (Kareiva and Wennergren 1995; Hooper et al. 2005). Spatial configuration and composition of ecosystems and habitat diversity (Turner 1989) have been shown to be interwoven with land-use intensity (e.g. Wrbka et al. 2004), and may influence, as landscape effects, important trophic interactions such as biocontrol and herbivory (Gardiner et al. 2009) or pollination (Ricketts et al. 2008). Hence, both ecosystem services and dis-services (Zhang et al. 2007) in different agro-environments are promoted or constrained to various extents depending on landscape effects. Further, local effects such as habitat type and quality (habitat identity) influence diversity and population size of organisms (Matter \& Roland 2002; Haynes et al. 2007; Zaller et al. 2008). Thus, local interactions are triggered by factors such as resource availability at both the landscape and the local habitat scale. However, most studies focus either on just local effects or the distribution of only one habitat type within a landscape (Meyer et al. 2009). Only few studies have shown the interaction of landscape and local processes and their effect on patterns of insect diversity or trophic interactions (Cushman and McGarigal 2004; Dauber et al. 2005; Schweiger et al. 2005). As a simultaneous investigation of local and landscape patterns is difficult, an experimental approach introducing the same study system in a wide range of habitats and landscapes is a suitable, but little explored technique.

Here, we study the rape pollen beetle Meligethes aeneus (Fabricius 1775), which is one of the most important pest organisms in oilseed rape (Brassica napus, L.) (Büchi 2002; Alford et al. 2005). Published studies focus on pollen beetles and their parasitoids on OSR and emphasise that landscape context influences trophic interactions in cropland (e.g. Thies and Tscharntke 1999; Ricketts et al. 2008; Büchi 2002; Bianchi et al. 2006; Thies et al. 2008), whereas wild Brassicaceae have been considered only in their potential role as alternative host plants and not as a substitute resource when OSR fields are not longer available. Thus examples of cropnoncrop spillover are almost absent (Rand et al. 2006). However, spillover may shape trophic interactions and thus we focus on the effect of cropland such as OSR on wild plants in noncrop habitats as well as in crop systems. Although existing theories predict the spillover of insects from crop to non-crop areas (Tscharntke et al. 2005; Rand et al. 2006; Rand and Louda 2006), we are not aware of studies that actually test how the huge and functionally important croprelated populations distribute across different habitats in the landscape shaping food webs,

In the present study we investigated how landscape composition affects crop-noncrop spillover and associated trophic interactions. We quantify flower herbivory by rape pollen beetles and its parasitism by an ichneumonid wasp (Nilsson 2003) in different habitat types across a gradient of landscape complexity. Spillover may vary due to the source capacity as well as the attractiveness of the destination. We hypothesize:

(i) Both habitat type and landscape characteristics influence the spillover of pollen beetles (Meligethes aeneus) and their parasitoids (Tersilochus heterocerus, Thomson 1889) across the crop-noncrop interface. 
(ii) Increasing proportion of oilseed rape as source habitat increases populations of specialised parasitoids more than their generalist hosts (following Thies et al. 2008), thereby affecting parasitism rates.

\section{METHODS}

\section{EXPERIMENTAL SETUP}

The study was conducted after the flowering period of OSR from 1st June to 15th July 2006 in the vicinity of Göttingen, Lower Saxony, Germany $\left(51^{\circ} 32^{\prime} \mathrm{N}, 9^{\circ} 56^{\prime} \mathrm{E}\right)$. The regional landscape pattern varies from intensively managed, simply structured landscapes that undergo a large inter-annual change (arable land up to 90\%) to complex, extensively managed landscapes with a high proportion of near-natural, perennial habitats (i.e. fallow, wood margin; arable land $<20 \%$ ). Eight landscapes (i.e. landscape sectors) were chosen along this gradient of landuse intensity (Appendix 2.1). There was no spatial correlation in the land-use gradient of the landscapes. Within each of the landscapes, we established study plots in five major habitat types (cereal field, field margin adjacent to cereal field, fallow, grassland, wood margin adjacent to crop field), yielding a total of 40 plots.

The locations of the habitats within landscapes were chosen as near to each other as possible, in order to achieve maximum similarity with respect to landscape-scale parameters. Distance of habitats to the nearest OSR crops (mean $197 \pm$ SE 22m) was tested in lme models (described below) and did not vary significantly $\left(\mathrm{F}_{4,21}=1.81, \mathrm{P}=0.147\right)$. In each habitat we established (1st June) a plot of three wild mustard plants (Sinapis arvensis), which is as native rural plant found ubiquitously in agricultural and semi-natural habitats flowering from April to October. Phytometers were grown in pots under standardised conditions in the same soil (standard garden soil, watered every second day), before the start of the experiment. Thus we achieved a maximum of phytometer similarity among habitats and landscapes. Excluding differences in plant quality was particularly important for this study, because it can change the oviposition rate of rape pollen beetles (Hopkins and Ekbom 1996). From the time when rape pollen beetles dispersed from the fading OSR fields the phytometers were freely accessible for rape pollen beetles and their parasitoids, so that differences due to local and landscape effects would be recognizable through population density and parasitism rates.

\section{STUDY SPECIES}

All developmental stages of rape pollen beetle Meligethes aeneus (Coleoptera: Nitidulidae) feed on pollen. M. aeneus is one of the economically most important pest species on OSR, preventing seed development and hence causing loss of yield but the species also feeds on a range of other plant species, such as wild mustard, our phytometer (Ekbom and Borg 1996; Cook et al. 2006). In late April adults start moving into (not yet flowering) OSR crops for maturity feeding and subsequent oviposition. In field conditions the reproductive period usually lasts 2 months, but rape pollen beetles have been shown to exhibit reproductive plasticity in dependence of 
environmental or host plant conditions (Ekbom and Borg 1996; Billqvist and Ekbom 2001). In ideal conditions oviposition may take place until October and also observations of beetles laying eggs in the year of their hatching have been observed (Bromand 1983). Larvae of rape pollen beetles develop in flowers, drop to the ground on maturity, pupate and emerge after one to five weeks. Beetles live on a variety of plants (Hokkanen 2000; Gurr et al. 2003; Lehrman et al. 2008) when OSR crops have faded. Adults of the first generation die after egg laying, second generation beetles move into hibernating sites under herbaceous vegetation or moist woodland debris (Müller 1941; Nilsson 1988; Williams 2004). The larvae of the rape pollen beetle are attacked by the univoltine parasitoids, Tersilochus heterocerus, Phradis interstitialis, and Phradis morionellus (Hymenoptera: Ichneumonidae), of which the last is rare. The parasitoids are specialised on rape pollen beetles and attack host larvae in the first (Phradis spp.) and second (T. heterocerus) instar. After parasitizing the larvae in the flower, both endo-parasitoid species kill their host larvae after they drop to the ground before pupation in the soil (Jourdheuil 1960). Parasitoids peak and start egg deposition in May during OSR flowering (Williams 2006). They overwinter in their hosts in the ground and subsequently emerge from the soil of the last year's OSR crop area.

\section{DATA COLLECTION}

Samples of rape pollen beetles were collected from the phytometers at flowering of wild mustard (27. June 2006) by clipping all flowering stalks and storing them in plastic cups at $-22^{\circ} \mathrm{C}$. The number of parasitized larvae was determined by dissecting the rape pollen beetle larvae under a binocular (Zeiss, Stemi SV 11). Parasitoid eggs were assigned to the parasitoid species by their typical pigmentation (black - T. heterocerus; white - Phradis spp., Foerster 1868). Because we found only 1 - 2 individuals of Phradis spp. in two different landscapes, only T. heterocerus was included to further analyses. After peak ripening, we collected all remaining Sinapis plants and stored them at $1{ }^{\circ} \mathrm{C}$ (15. July 2006). Plant damage to seed set was quantified by counting the number of pods and the podless stalks that remained after rape pollen beetle herbivory.

Landscape parameters were estimated on the basis of the official digital thematic maps (ATKIS - Digitales Landschaftsmodell 25/1; Landesvermessung und Geobasisinformation, Hannover, Germany 1991-1996) containing areal measures of arable land, grassland, forests, hedgerows, garden land and settlement. In addition, we mapped habitat types in the field during the season, allowing a specific classification of land use in the areas with arable land (Appendix 2.4). Data were digitized and analysed in ArcView 3.2 (ESRI Redlands, CA, USA) in a radius of $750 \mathrm{~m}$ around each experimental patch, since this scale has been shown to be appropriate for the studied host-parasitoid interactions (Thies et al. 2003). Habitats were also characterised by vegetation surveys using the Braun-Blanquet scale (Braun-Blanquet, 1964). The surveys were conducted within two weeks at the beginning of the study period on five randomly chosen plots per habitat of 2x2 meters each. Turboveg 2.79 (Hennekens and Schaminée 2001) was used to transform Braun-Blanquet data into plant percentage cover data and to analyse number and abundance of plant species (Appendix 2.2). 


\section{DATA ANALYSES AND STATISTICS}

Variation of adult rape pollen beetle numbers on the sampled phytometer may, in part, be due to diurnal activity patterns. Therefore we included only the rape pollen beetle larvae in our analyses. Missing phytometer plants due to mammalian herbivory, were treated as NA in the statistical analyses. Although being standardized, the phytometers had different numbers of flowering stalks by the time we collected the samples of rape pollen beetles. This variation, however, was not correlated to habitat type (Appendix 2.3) or any landscape parameters (Appendix 2.1). To account for the varying sample size we analyzed our data with the larval abundance divided by the number of flowers in the respective samples. Larvae per flower and parasitism rates in experimetal patches were arcsine square-root transformed and landscape and habitat type effects were tested in linear mixed effects models (lme, Pinheiro et al. 2009) in R 2.9.1 (R Development Core Team 2009). Obtaining normally distributed residuals after the transformation, we could use the more established and widely used lme models instead of generalized linear mixed models for analysing non-normal data, which are more difficult to fit appropriately (Bolker et al. 2009).

Maximal models contained the following landscape-scale predictors: (i) \% arable land, selected a priori based on our experimental design; (ii) \% oil seed rape (OSR), as important predictor due to the focus of spillover from OSR into other habitats; (iii) a small set of additional landscape-scale predictors shown to be important based on inspection of zero-order correlation matrices (Murray and Conner 2009), namely the mean perimeter to area ratio (MPAR) and the number of arable land patches in the landscape (Appendix 2.4). MPAR gives information about the complexity of a landscape (see Bianchi et al. 2006). Low values of MPAR indicate large patches in a landscape whilst landscapes with high MPAR values are characterised by many small patches of fields and habitats, thus the number of different resource types tends to increase with MPAR. Local effects comprised habitat type and the number of larvae per flower. The maximum models were fitted as

$\mathrm{y}=\mathbf{X} \beta+\mathbf{Z b}+\varepsilon$

eqn. 1

where $y$ is the response variable (larvae per flower, parasitism rate), $\beta$ represents the coefficients for local and landscape effects, $\mathrm{b}$ is the random effect term for landscapes $\mathbf{Z}$ and $\varepsilon$ the normally distributed error (Pinheiro and Bates 2000). Two-way interactions were included. The random effect landscape (with eight levels) was included to represent nesting of habitats in landscapes. Landscape measures and habitat type were ordered according to the spatial scale (i.e. largescale effects prior to habitat type).

For each response variable, we used the stepwise AICc function, an informationtheoretical approach for small sample sizes (Burnham and Anderson 2002), to find the minimal adequate model. Two maximum models were calculated for the response variable parasitism rate: first we included conservatively only the design variables (i.e. landscape effects and habitat type); the second included also the number of larvae per flower which is a possible predictor for parasitism rates but was not initially included in the experimental design. 
Seed number, seed weight, fruit set and destroyed buds were estimated per plant. These plant performance measurements were transformed, if necessary, before we fitted lme-models with landscape effects (see above), habitat type, larval infestation, podless stalks and parasitism as explanatory variables. To examine habitats for differences in species richness and evenness we applied an ANOVA with Tukey's HSD post-hoc test (Hothorn et al. 2008). Means were calculated as arithmetic means, unless stated otherwise.

\section{RESULTS}

\section{RAPE POLLEN BEETLE LARVAE}

The minimal adequate model (Appendix 2.5) for the prediction of rape pollen beetle larvae per flower included mean perimeter-area ratio (MPAR) and habitat type as explanatory variables. Rape pollen beetle larvae responded negatively to landscape complexity (MPAR) on the landscape scale $\left(\mathrm{F}_{1,25}=16.36, \mathrm{P}=0.001\right.$, Fig. 2.1). High larval numbers were observed in simple landscapes (MPAR $=0.05)$, whilst observations were low in complex landscapes (MPAR $=0.20$; Appendix 2.1). Other landscape parameters had no significant effect on larval density. Habitat type significantly affected larvae per flower $\left(\mathrm{F}_{4,25}=3.13, \mathrm{P}=0.032\right)$. Cereal fields $(0.34 \pm 0.05)$ and field margins $(0.27 \pm 0.05)$ had higher numbers of larvae per flower than fallow $(0.21 \pm 0.05)$, grassland $(0.16 \pm 0.03)$ and wood margin $(0.14 \pm 0.04$; Appendix 2.3). Significant differences of larvae per flower occurred only between cereal fields and field margins on the one hand and fallow, grassland and wood margin on the other hand (Tukey test, Fig. 2.1).

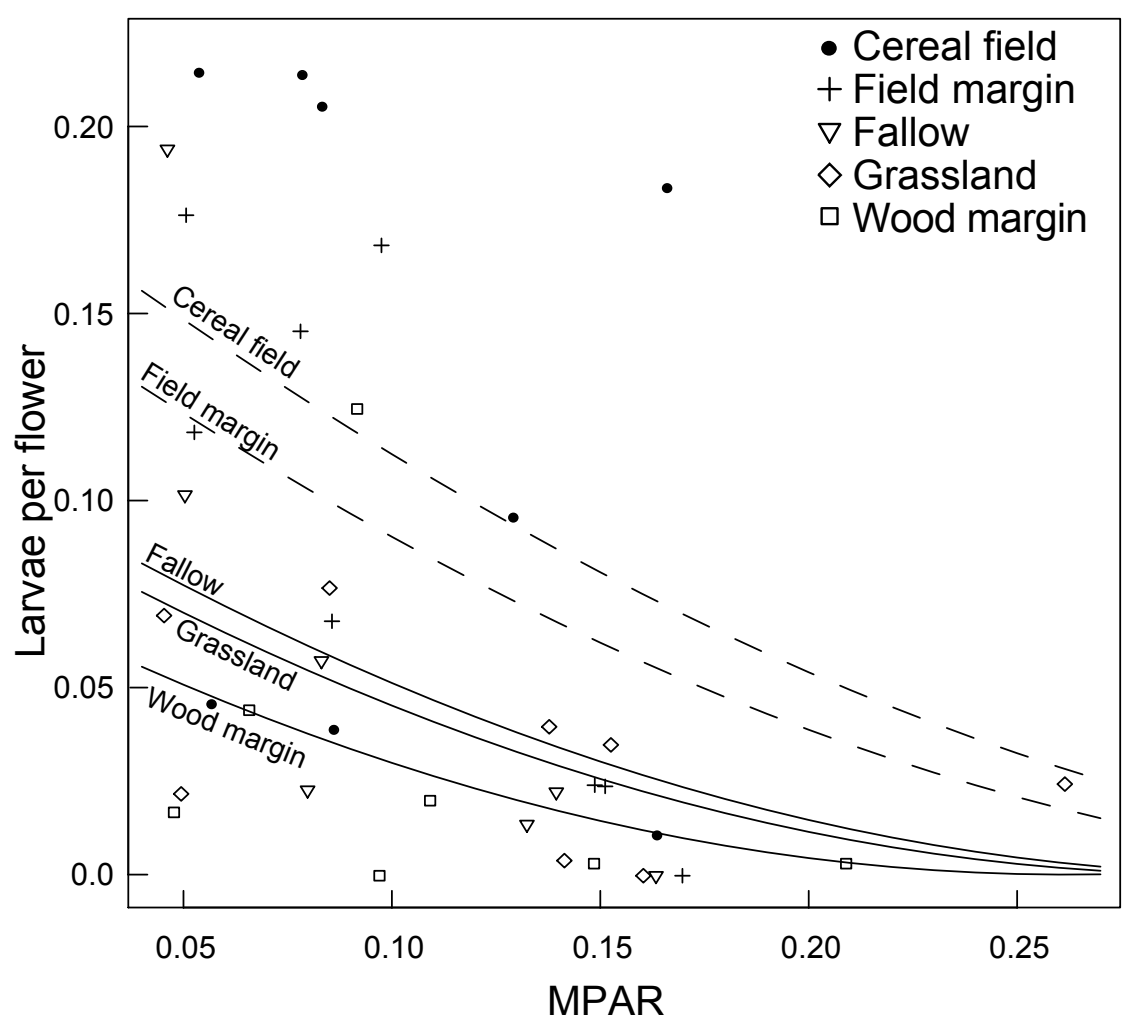

Figure 2.1. The backtransformed data of larvae per flower as a function of the significant mean perimeterarea ratio (MPAR: low values indicate simple, high values complex landscape structure) for each of the five tested habitats. The lines represent model predictions of larval infestation for each of the habitats. Wheat and field margin (dashed lines) had significantly higher larval infestation than grassland, fallow and wood margin (solid lines). Lines of the same type do not differ significantly from each other (Tukey's HSD). 


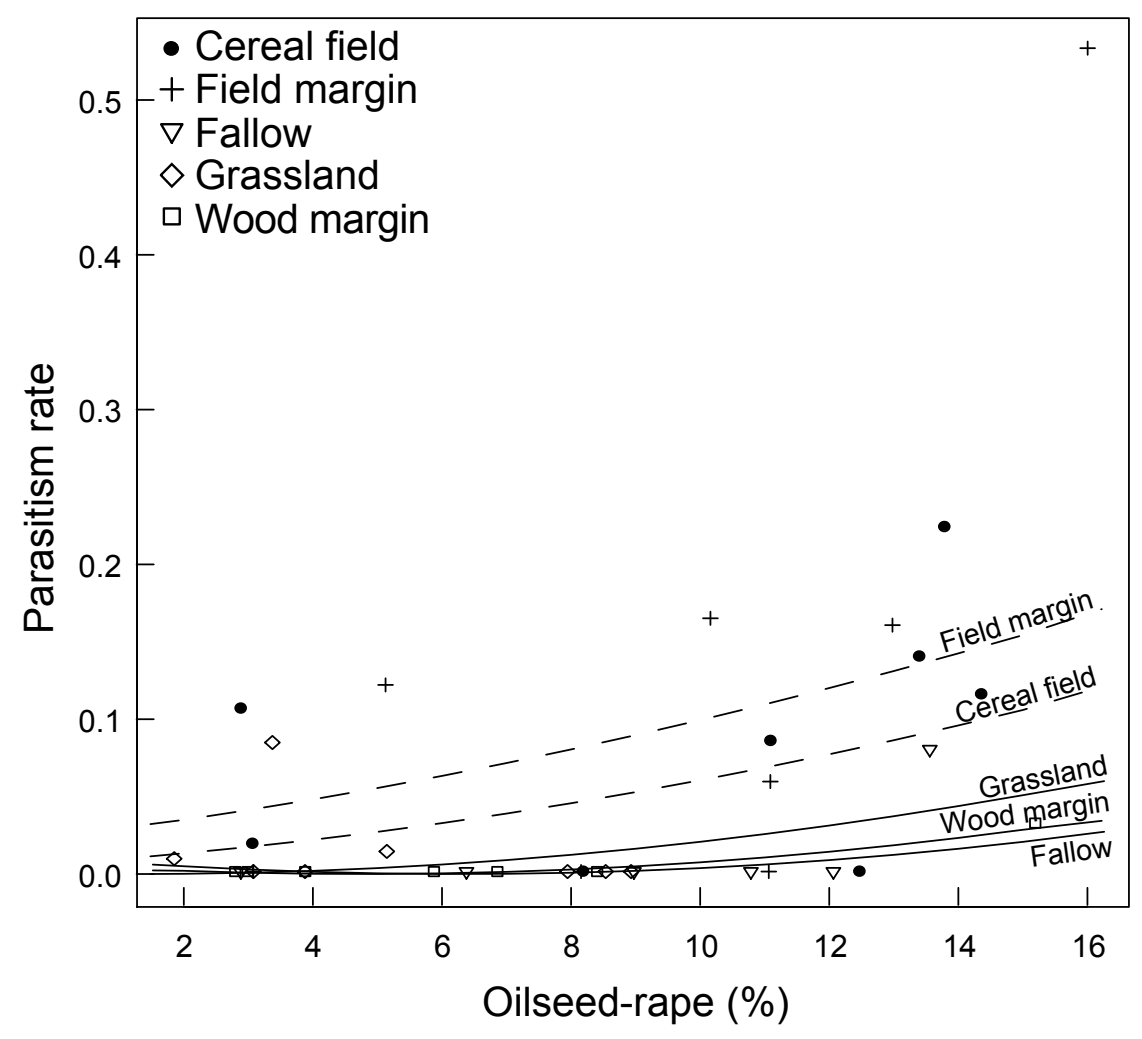

Figure 2.2. Back transformed data of parasitism rates as a function of percentage of oilseed rape crop area for each of the tested habitats. The lines represent model predictions of parasitism rates in each of the habitats. Parasitism rates were significantly higher in wheat fields and field margins (dashed lines) than in grassland, fallow and wood margins (solid lines). Lines of the same type do not differ significantly from each other (Tukey HSD). Also significant was the increase with OSR crop area.

\section{PARASITISM RATES}

At the landscape scale, parasitism rates responded only to \% OSR crop area $\left(\mathrm{F}_{1,23}=13.06\right.$, $\mathrm{P}=0.002$; Fig. 2.2, Fig. 2.3, Appendix 2.5). Locally, host density (i.e. larvae per flower; $\mathrm{F}_{1,2}=.84$, $\mathrm{P}=0.015)$ and habitat type $\left(\mathrm{F}_{4,21}=2.88, \mathrm{P}=0.047\right)$ were significant predictors. Since these two factors correlated with each other, we calculated two different models, the design model with $\%$ OSR and habitat type (Fig. 2.2), and the model that included \% OSR crop area and larvae per flower (Fig. 2.3). Parasitism rates increased stronger with larval density if OSR crop area was high as shown by the interaction between both factors $\left(\mathrm{F}_{1,23}=6.09, \mathrm{P}=0.022\right.$; Fig. 2.3). In landscapes with a low OSR crop area of $2 \%$, parasitism was not observed, or only at rates below $10 \%$. Parasitism rates by $T$. heterocerus increased with larvae per flower and increasing proportion of OSR crops (up to a maximum of 50\%, Fig. 2.3). Plots without parasitism were found in landscapes with an average OSR crop area of 7\%, whereas plots with parasitized rape pollen beetles occurred in landscapes with an average OSR crop area of 9\% (Fig. 2.3).

\section{PLANT PERFORMANCE}

The seed set of $S$. arvensis plants was not significantly influenced by any of the landscape variables nor by habitat type, the minimal adequate model was the null-model (Appendix 2.5). A lme-model including the number of branches as a measure for plant size and podless stalks as a measure for herbivory explained the weight of all seeds of a plant (i.e. yield) best. Total seed weight increased significantly with the number of branches $\left(\mathrm{F}_{1,19}=8.88, \mathrm{P}=0.008\right)$ and decreased with the number of podless stalks $\left(\mathrm{F}_{1,19}=4.77, \mathrm{P}=0.042\right)$. Surprisingly, the amount of rape pollen beetle larvae per flower however could not be linked to the number of podless stalks $(\mathrm{P}=0.633)$. 


\section{Discussion}

We showed that both landscape and local factors affect the abundance of rape pollen beetles (M. aeneus) and its parasitoid (T. heterocerus). Whilst the reaction to habitat type was similar, both species responded to different landscape parameters. We found the hypothesized spillover from OSR crop onto wild plants in surrounding habitats only for parasitoids, but not for pollen beetles, providing one of the first experimental evidence for plant-herbivore cascades triggered by organisms emigrating from cropland.

\section{HABITAT TYPE EFFECTS ON RAPE POLLEN BEETLE LARVAE}

Twice as many rape pollen beetle larvae per flower were found on phytometer plants in cropland habitats such as wheat fields and adjacent field margins in comparison to numbers in the seminatural habitats (grassland, fallow, wood margin). The higher colonisation of phytometers in cropland habitats may be the result of a population built-up of this crop inhabiting species (Rand and Tscharntke 2007). Crop rotation with periodic availability of mass-flowering resources has been shown to change landscape-wide densities of associated organisms (Thies et al. 2008). In contrast near-natural habitats provide resources constantly, but on a lower level, thus preventing the establishment of high pollen beetle abundances.

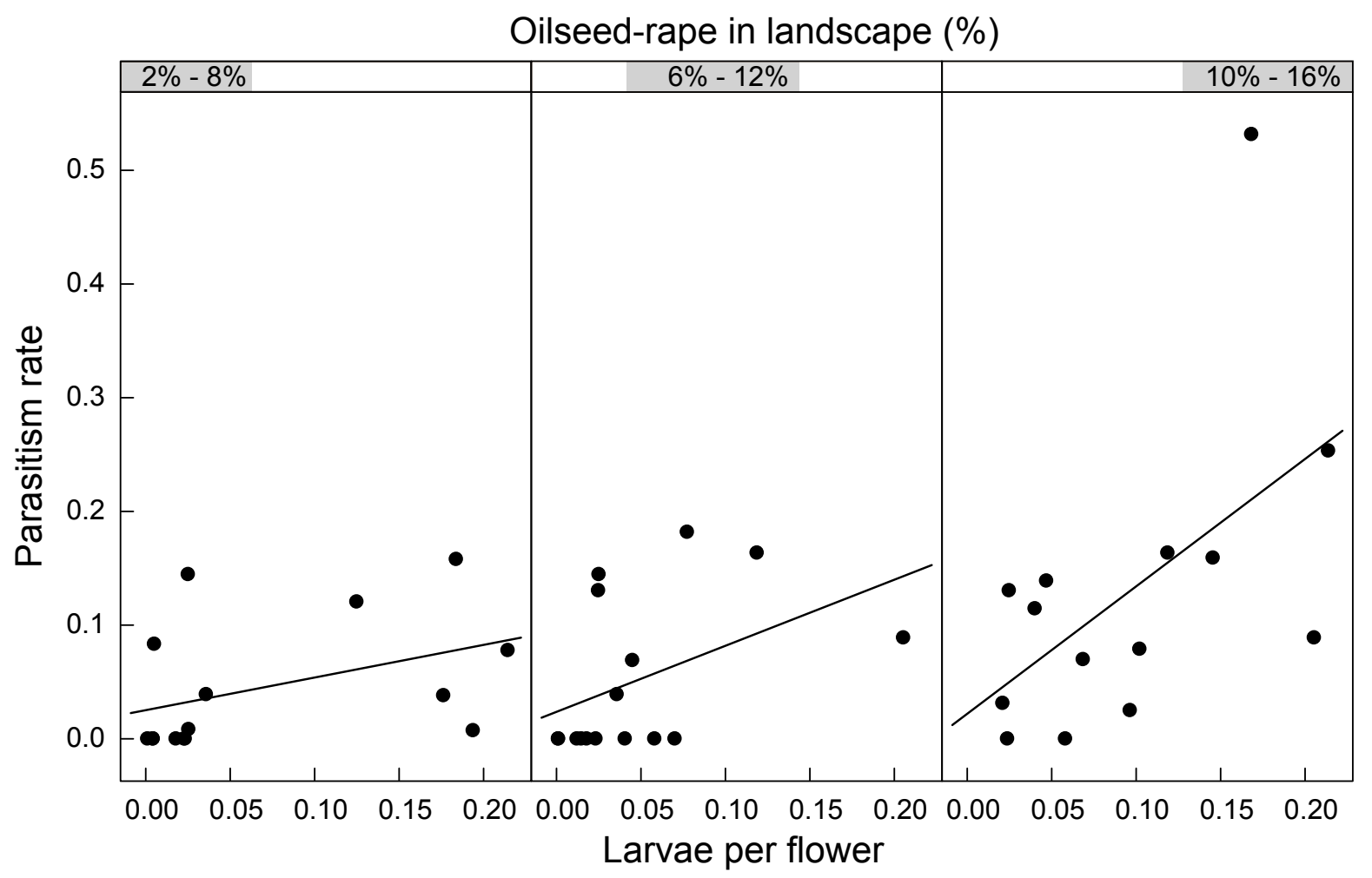

Figure 2.3. Back-transformed parasitism rates as a function of the interaction between larval infestation and three categories of oilseed rape crop area (indicated by the shaded areas and the percentage values at the top). Graphs are overlapping for OSR crop area to avoid too distinct separations of this continuous variable. Parasitism rates responded positively to larval densities and OSR crop area. The synergistic interaction between larvae per flower and rape crop area is apparent in the increasing slope from left to right. 


\section{HABITAT TYPE EFFECTS ON PARASITISM}

Similar to the results for the rape pollen beetle larvae density, parasitism rates were high in wheat fields and field margins and low in the other three habitat types, i.e. parasitoids profited more than their hosts in crop systems. Parasitism rates increased with larval density (as for example in Elzinga et al. 2007), indicating that higher numbers of larvae are easier detectable. Since $T$. heterocerus is highly specific to the olfactory signals of (infected) Brassicaceae (Lewis and Tumlinson 1988; Vet et al. 1995; Renwick 2002; Wackers 2004; Jönsson et al. 2005; Jönsson and Anderson 2007), parasitoids should be less attracted to alternative (i.e. not Brassicacea) host plants infested with rape pollen beetles. As infestation of $S$. arvensis with rape pollen beetle larvae depends on habitat type, concentration of the herbivores on the phytometer are cascading up to parasitoids. Hence, parasitism rates responded to larval density mediating habitat type.

\section{LANDSCAPE-SCALE EFFECTS ON RAPE POLLEN BEETLE LARVAE}

The numbers of rape pollen beetle larvae on the phytometer plants decreased with an increase of landscape complexity, which is in line with some previous studies (Thies and Tscharntke 1999; Thies et al. 2003; but see Zaller et al. 2008b). Simple landscapes may support a population build-up of rape pollen beetles over many years, because they consist of large arable crop patches (including OSR) with uniform resources (Grilli and Bruno 2007). Complex landscapes, in contrast, have scattered small patches of different resource types and thus are likely not to provide enough supply for local mass-populations.

In contrast to our expectation that OSR fields are the main source for spillover of rape pollen beetles, we found no correlation between OSR area and infestation rates of the rape pollen beetle larvae. This is in line with Thies et al. (2008), but in contrast to other studies suggesting pest pressure to increase with cropping area (Jonsen and Fahrig 1997; den Belder et al. 2002; Klug et al. 2003). The lack of response to OSR crop area may be a result of largescale dispersal patterns (Thies et al. 2008), intraspecific larval competition on the phytometers (Nilsson 1988; Ekbom 1998; Hokkanen 2000), or due to abscission of heavily infected buds (Williams 2004).

\section{LANDSCAPE-SCALE EFFECTS ON PARASITISM}

Oilseed rape appeared to be a great source of parasitoids in June. The positive correlation between parasitism rates and OSR crop area indicates that the parasitoids shift from OSR to other (more limited) resources in the landscape after depletion of hosts in OSR fields. This supports similar results of Thies et al. (2008), who showed that reductions of OSR between years enhanced parasitism. Apart from the positive effect on parasitism rates, OSR crop area interacted significantly with the number of rape pollen beetle larvae. The increase of OSR crop area intensified the positive response of parasitism rates on host density, i.e. larvae per flower. This is possibly the consequence of an easier detection at higher host densities combined with a higher availability of parasitoids from larger OSR areas. Despite these spillover and concentration effects on the landscape scale, mean parasitism rates remained at a low level $(<20 \%$, Fig. 2.2 
and 2.3). Two mechanisms may explain this pattern. First, parasitoid populations peak in May (Williams 2006). With a limited lifespan of 1-2 weeks during the summer (Nilsson 2003), the observed parasitism rates may be the result of a declining population. Second, Elzinga et al. (2007) reported that parasitoids occur with lower frequency in small patches compared to larger ones. The three phytometer plants established in the habitats constitute a small patch in contrast to the OSR and this is why the observed parasitism rates ranged below the ones that are usually observed in OSR crops (T. heterocerus parasitation rate 0.2 - 0.3, Thies et al. 2003). Thies et al. (2008) considered the regional population pool (i.e. the pool present within OSR areas) more important for biological control than local management (in their case establishing field margins), and stated that parasitoids in agricultural landscapes can be strongly influenced by inter-annually changing crops. Thus, the lack of response of parasitism to the area of seminatural habitats in a landscape can be best explained with the specialisation of $T$. heterocerus which binds the parasitoid strongly to the area of OSR. Further, the response of parasitoids, but not herbivores, to changes in OSR area with corresponding changes in parasitism rates supports the general idea that parasitoids are more sensitive to disturbances and environmental change than their hosts (Kruess and Tscharntke 1994; Holt et al. 1999; Elzinga et al. 2007).

\section{SEED SET OF SINAPIS ARVENSIS}

The decrease of total seed weight per phytometer plant with an increase of podless stalks indicated that herbivory negatively affected the yield of $S$. arvensis. Podless stalks are a typical sign of herbivory by rape pollen beetles (Thies and Tscharntke 1999). However, the number of rape pollen beetles or their larvae was not related to the number of podless stalks. This may have been caused by the fact that the observed herbivory is not only due to the rape pollen beetle numbers at the time of collection, but also a result of continuous herbivory throughout the experiment. Second, loss of ripe pods due to maturity of the phytometer plants (Bruce et al. 2002) may account for variation that remains unexplained.

\section{CONCLUSIONS}

More than habitat type, landscape-scale factors explained the observed plant-herbivoreparasitoid spillover cascade. Mortality of rape pollen beetles by parasitism was higher in simple landscapes with a high proportion of OSR crops. The response of parasitism to host density profited particularly well from a larger proportion of OSR in the landscape. Positive density dependence in parasitoids is widespread and a basis of successful biological control stabilizing prey populations at low levels (Hassell and May 1974). According to our results, parasitoid spillover from cropland may significantly influence trophic cascades in wild habitats, which is rarely shown, but should be widespread shaping natural food webs. 


\section{APPENDIX}

CONTENT

Appendix 2.1. Dependent and independent variable measures averaged over all habitat types Appendix 2.2. Average vegetation characteristics for habitat types

Appendix 2.3. Dependent and independent variable measures averaged over all landscapes Appendix 2.4. Correlation matrix of model variables and landscape-scale parameters. Appendix 2.5. Maximal and minimal models from the stepwise AICc analysis 


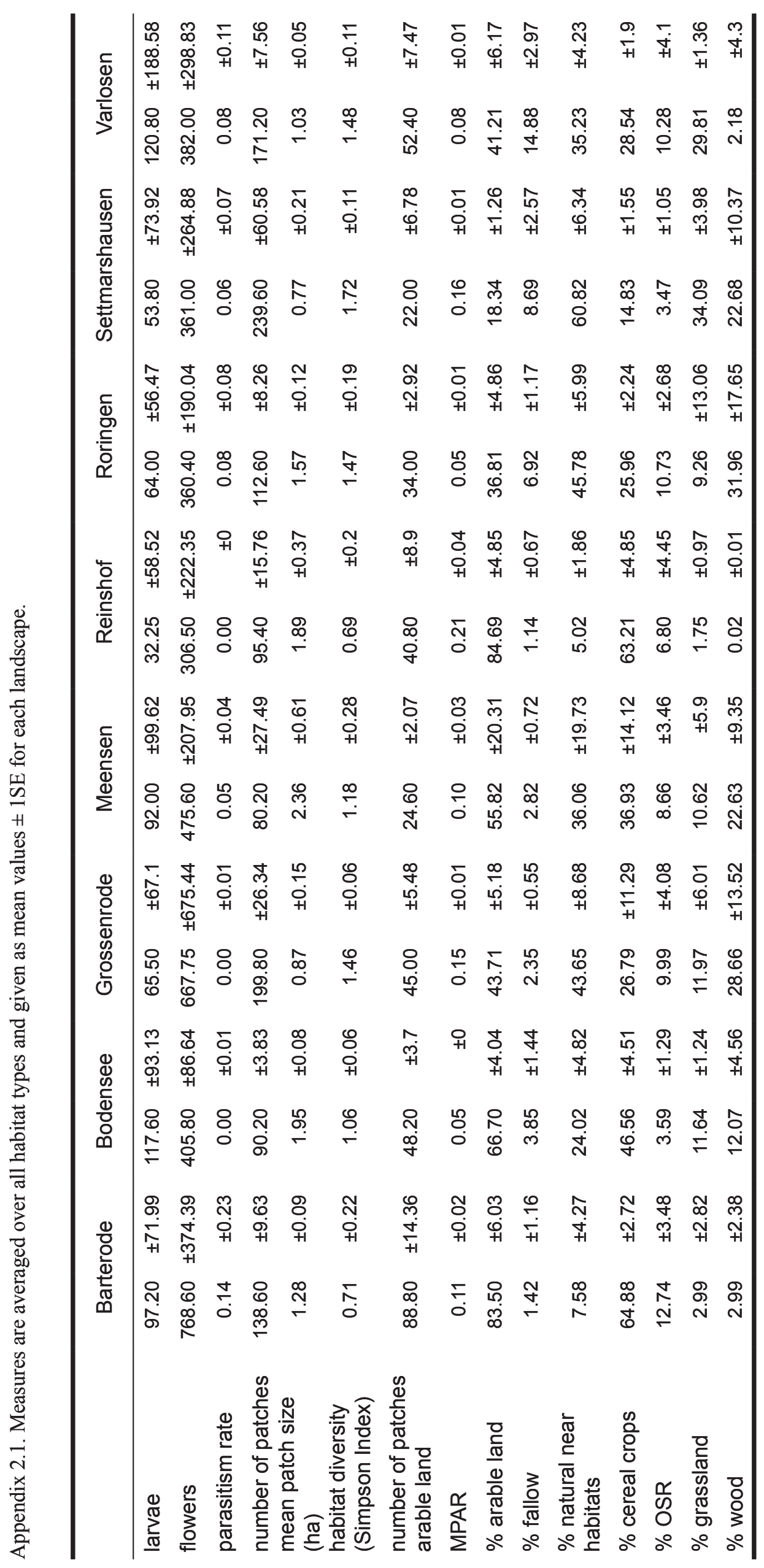




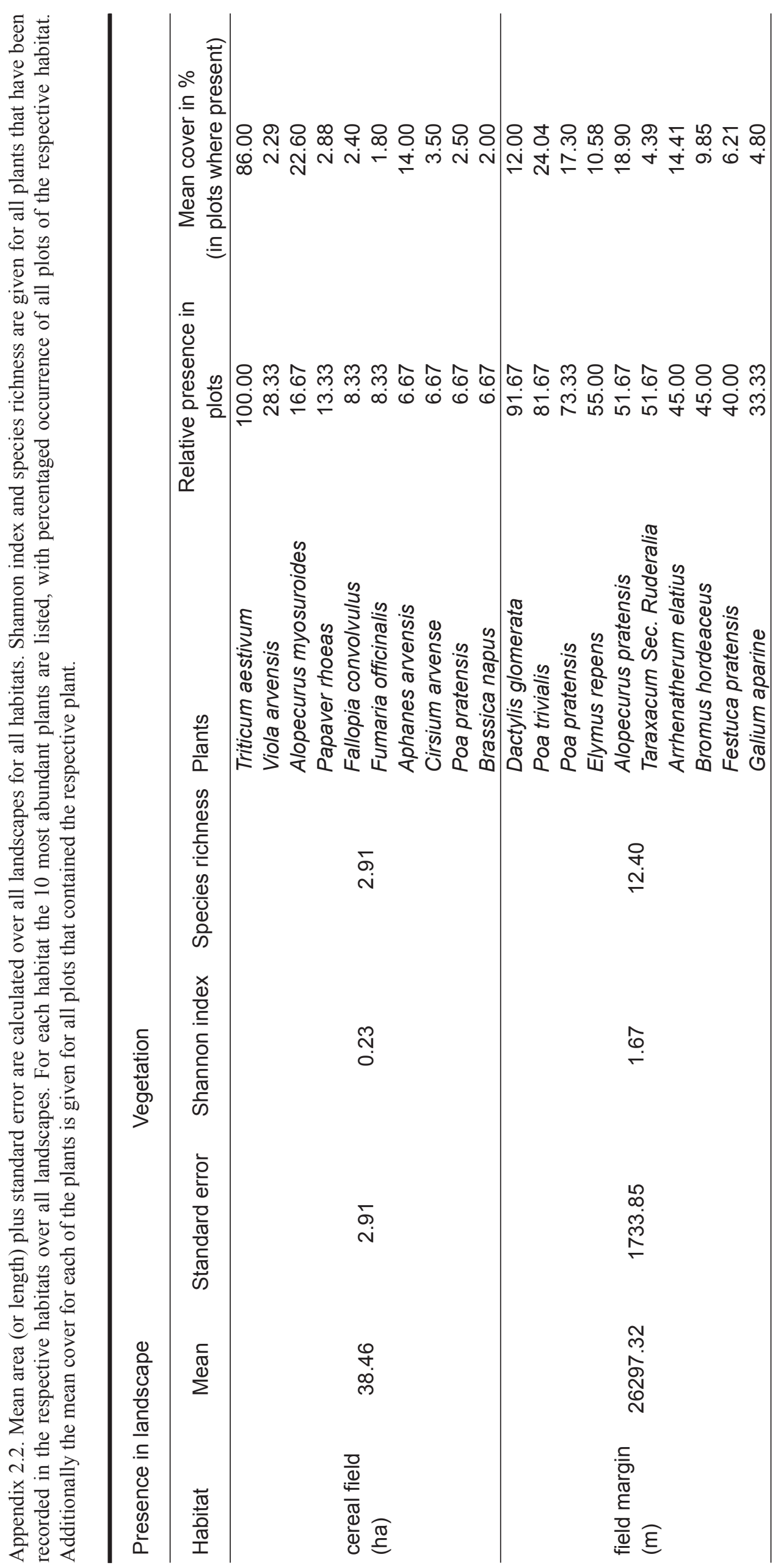




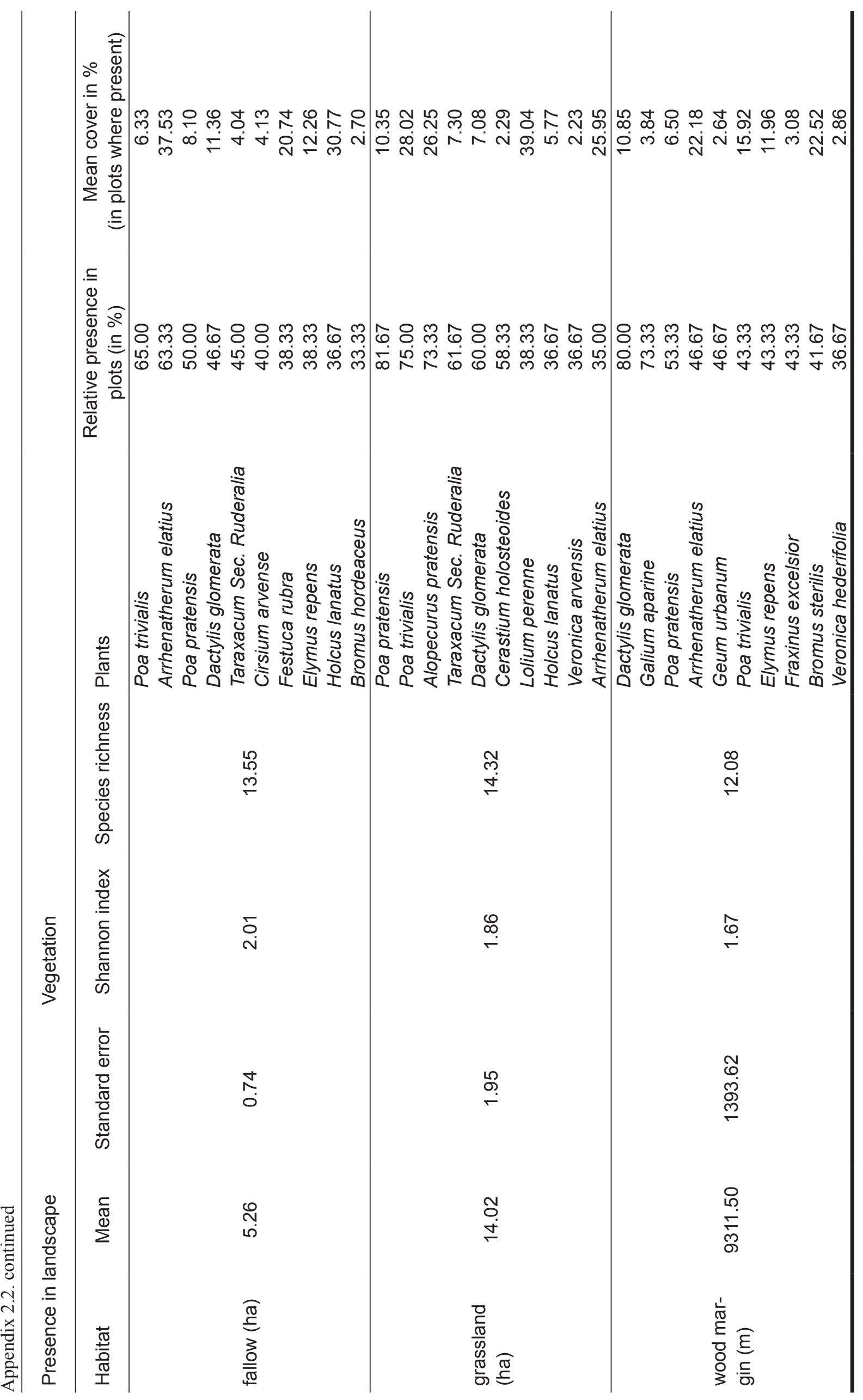




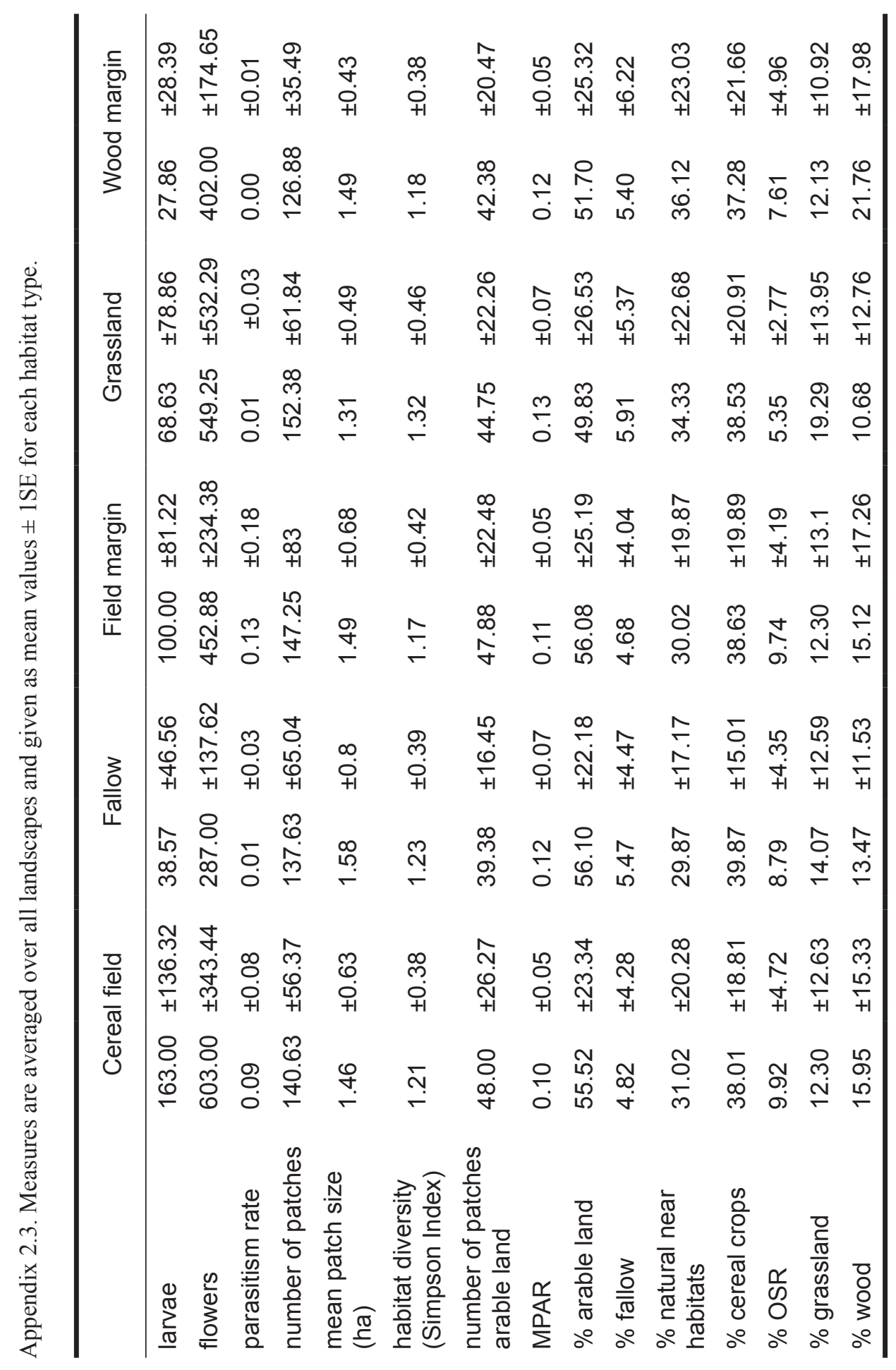


Appendix 2.4. The correlation matrix shows $r^{2}$-values of dependent variables for the most important landscape-scale parameters. Bold values have been used as predictor variables in the maximal models. Landscape-scale parameters were measured in all landscapes on a radius of $750 \mathrm{~m}$.

\begin{tabular}{lcc}
\hline & Larvae/flower & Parasitism rate \\
\hline Landscape structure metrics & & \\
\hline mean edge/patch & & \\
mean edge/patch arable land & -0.044 & -0.041 \\
mean patch size & -0.033 & -0.213 \\
mean patch size arable land & 0.037 & -0.152 \\
MPAR & -0.033 & -0.208 \\
MPAR arable land & $-\mathbf{0 . 3 6 7}$ & -0.131 \\
number of patches & -0.006 & 0.158 \\
number of patches arable land & -0.039 & 0.115 \\
total edge & 0.040 & $\mathbf{0 . 3 6 1}$ \\
total edge arable land & -0.091 & 0.247 \\
wood edge & -0.002 & 0.273 \\
& -0.075 & -0.071
\end{tabular}

Landscape composition metrics

\begin{tabular}{lrr}
\hline \% arable land & -0.05 & 0.092 \\
$\%$ beans & -0.3 & -0.169 \\
$\%$ cereal field & -0.105 & 0.080 \\
\% fallow & 0.250 & -0.025 \\
\% grassland & 0.139 & -0.071 \\
\% maize & 0.192 & -0.14 \\
$\%$ OSR & 0.155 & 0.482 \\
\% orchard & 0.012 & 0.250 \\
$\%$ perennial near-natural habitats & 0.033 & -0.117 \\
$\%$ potatoes & -0.089 & -0.038 \\
\% sugar beet & -0.198 & -0.113 \\
\% urban area & -0.192 & 0.018 \\
\% water & -0.22 & -0.146 \\
\% wood & -0.041 & -0.094 \\
\% shrubs & -0.194 & 0.079 \\
& & \\
crop diversity (Simpson Index) & 0.109 & -0.028 \\
crop evenness & 0.113 & 0.086 \\
habitat diversity (Simpson Index) & 0.064 & -0.148 \\
habitat evenness & 0.077 & -0.114 \\
number of crop types & 0.080 & 0.269 \\
number of habitat types & 0.088 & 0.096 \\
\hline
\end{tabular}



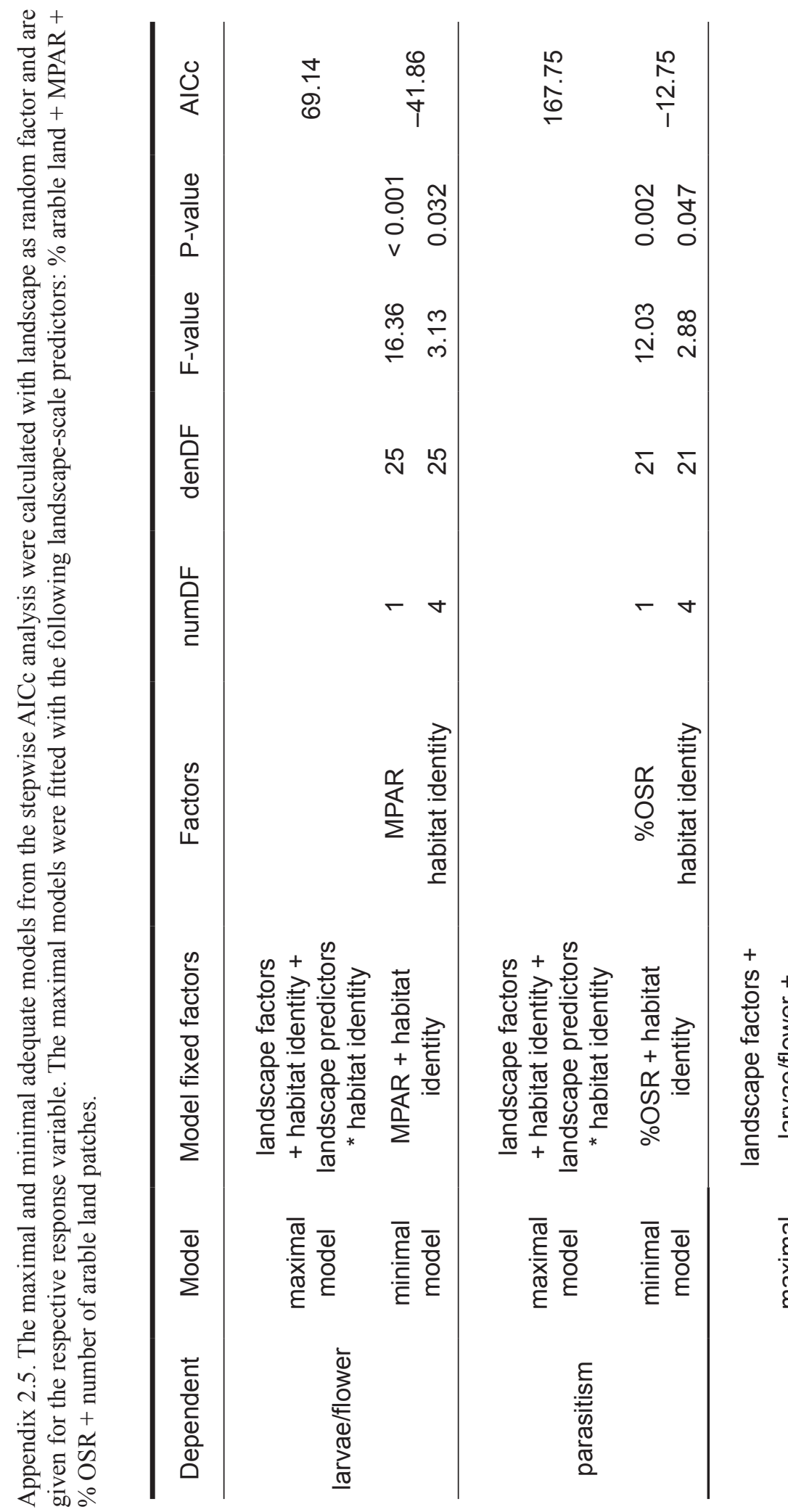

$\stackrel{\infty}{\stackrel{\infty}{+}}$

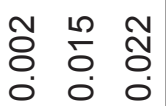

$\begin{array}{lll}9 & + & 8 \\ \text { ले } & 0 & 0 \\ & 0 & 0\end{array}$

$\begin{array}{ll}\dddot{m} & \infty \\ \stackrel{1}{*} & \infty \\ \end{array}$

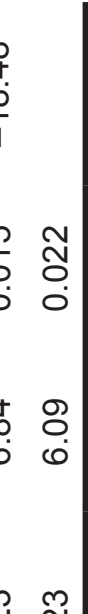

N $ָ$

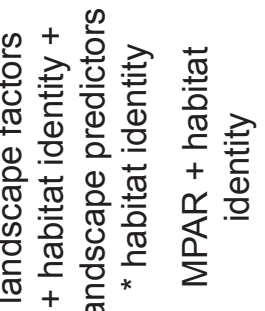

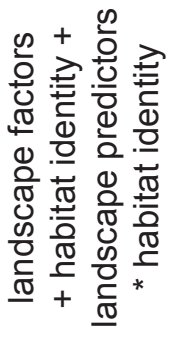

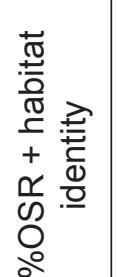

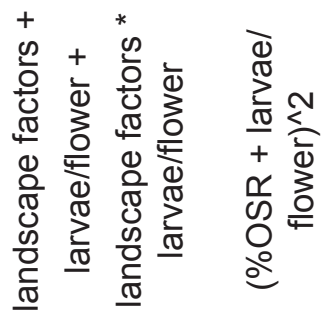

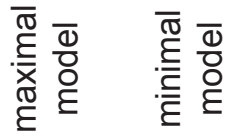

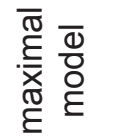

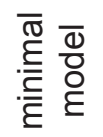

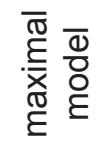

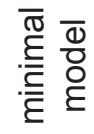

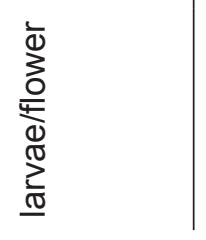

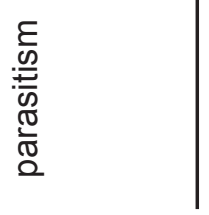

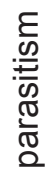




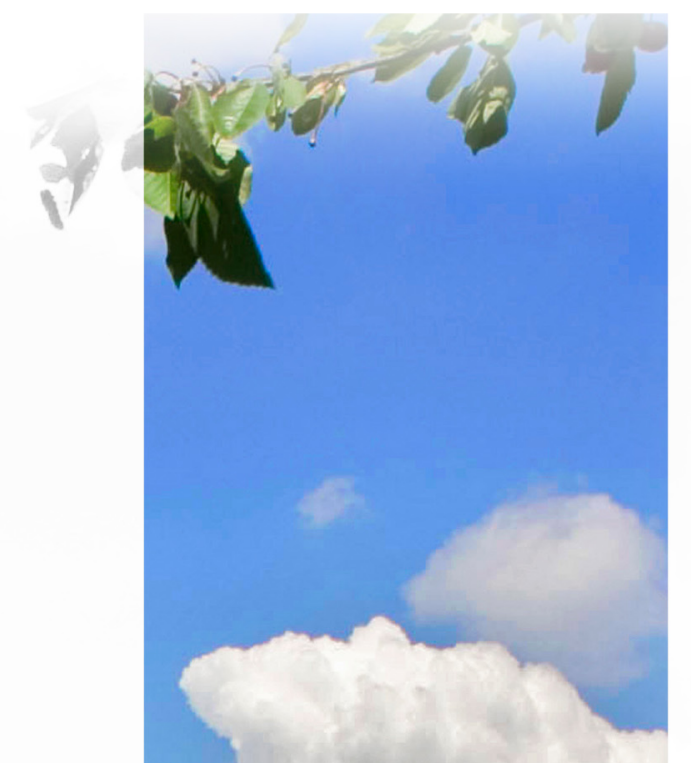

\section{Chapter 3}

Heating up trophic interactions in crops with low vs. high intensity management

in

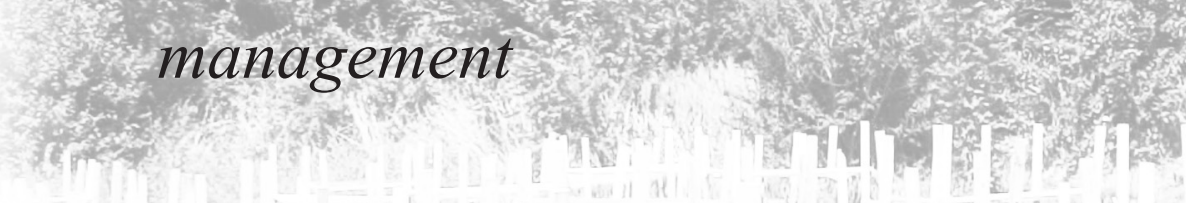




\section{ABSTRACT}

Global warming and agricultural intensification can affect trophic interactions including biological pest control. We tested effects of elevated temperature (using shields for passive warming) in fertilized vs. unfertilized wheat and wheat monocultures vs. wheat diversified with non-crop plants in a full factorial design ( 8 treatments, 6 replicates, $n=48$ plots). We quantified density of cereal aphids and their natural enemies in relation to wheat yield. Fertilization enhanced yield strongly, but also aphid density, which negatively affected yield. Predatorprey ratios were highest in diversified wheat and related to reduced aphid population growth. Warming enhanced aphid growth strongest in fertilized monocultures leading to reduced yields. Our results show that diversified crops and reduced (adapted) fertilization may gain importance as a tool to prevent pest outbreaks in future warmer climates.

Key Words: climate change, intercropping, pest management, Sitobion avenae

Authors:

David J. Gladbach

Carsten Thies

Teja Tscharntke

Carsten F. Dormann 


\section{INTRODUCTION}

Tritrophic interactions can affect functioning of agricultural and natural ecosystems (Holland and Thomas 1997; Matson et al. 1997; Migui and Lamb 2007). Agricultural management such as intercropping compared to monocultural planting and fertilization has been shown to affect yield in agroecosystems (Theunissen 1994; Praslicka and Mistina 2004; Zehnder and Hunter 2008). Changing climate, in interaction with farming practices, will affect tritrophic interactions in the future (e.g. Vandermeer et al. 1998; Bale et al. 2002; Flynn et al. 2006; Adler et al. 2007). Warming as the principal driver of climate change has been reported to shorten insect development times (Bale et al. 2002), reduce larval mortality (Netherer and Schopf 2010) and thus benefit insect abundance and diversity (Wilf and Labandeira 1999). Warming is assumed to increase herbivory (Currano et al. 2008; Delucia et al. 2008), but consequences for agroecosystems are difficult to predict as responses of insects of different trophic positions to warming may interact (Adler et al. 2007). Interactions may be more stable in complex agricultural systems (e.g. Van Emden and Williams 1974; Balvanera 2001; Gurr et al. 2003; Casula et al. 2006; Schmitz 2009), whereas in intensively managed systems, trophic interactions are often dominated by few species and thereby, susceptible to environmental change (Straub and Snyder 2006; Straub et al. 2008).

In the present study we tested how trophic interactions change in differently managed patches of a wheat field (Triticum aestivum) in response to warming. Experimental management included herbicide, fertilizer and temperature manipulation in a full factorial split plot. In the resulting eight treatment combinations we measured numbers of aphids, different biocontrol agents and yield of wheat plants as ecosystem functions. We hypothesise that:

(i) Monocultures in herbicide treated plots support higher aphid densities (Root 1973; Perrin 1976; Risch et al. 1983; Sunderland and Samu 2000), while mixed cultures support higher density of biocontrol agents (Smith 1976). Yield of wheat plants can thus be higher in mixed cultures (Sarker et al. 2009).

(ii) Fertilization effects on to yield will outweigh negative effects of increased aphid growth and population densities (White 1993; Dixon 1997; Zehnder and Hunter 2008).

(iii) Increase of insect population growth rates due to warming (Holopainen J.K. and Kainulainen P. 2004; Netherer and Schopf 2010) leads to particularly large changes of trophic interactions in intensively managed plots.

\section{Methods}

\section{EXPERIMENTAL DESIGN AND TREATMENTS}

The experiment was conducted at a research site of the University, city of Göttingen, Lower Saxony, Germany $\left(51^{\circ} 32^{\prime} \mathrm{N}, 9^{\circ} 56^{\prime} \mathrm{E}\right)$, between $1^{\text {st }}$ and $28^{\text {th }}$ of July 2008 . The average daily temperature in July was $17.9^{\circ} \mathrm{C}$ with a daily maximum of $32.9^{\circ} \mathrm{C}$ and nightly minimum of $8^{\circ} \mathrm{C}$. Prior to the experiment the site was used repeatedly for agricultural experiments, but remained 
unfarmed in 2007. The site was milled and treated with Roundup®UltraMax twice in March to reduce weed pressure. At $10^{\text {th }}$ of April summer wheat (Triticum aestivum forma Passat) was sown with 450 seeds per $\mathrm{m}^{2}$ on an area of $12 \times 40 \mathrm{~m}$. The sown area was irrigated for $2 \mathrm{~h}$ in the evenings at least three times per week, depending on the weather conditions to secure ideal conditions for germination and growth of early wheat seedlings. From jointing stage onwards we watered twice per week in periods of dry weather conditions.

The experiment was designed as a full factorial split plot manipulating herbicide (monocultures vs. mixed cultures), fertilizer (fertilized vs. unfertilized), and temperature (warming vs. no warming). The study contained six blocks (replicates) with 8 plots of one square meter (with one meter spacing), giving a total of 48 plots. Plots were at least one meter from the edge of the wheat field. Each block was half monoculture and half mixed culture. Both, mono- and mixed cultures were split into fertilized and unfertilized strips, which contained a warmed and a non-warmed plot.

The fertilizer treatment was applied in two steps; the first (09.04.2008) was Blaukorn ${ }^{\circledR}$ fertilizer (NPK, 14+7+17) with $500 \mathrm{~kg} / \mathrm{ha}$, the second (22.04.2008) with mineral fertilizer $(27 \% \mathrm{~N}, 330 \mathrm{~kg} / \mathrm{ha})$. The herbicide treatment was also applied in two steps with Accord $\AA$ SuperPack at BBCH 13 - 29 (Biologische Bundesanstalt, Bundessortenamt and Chemical industry, Zadoks et al. 1974; Lancashire et al. 1991) within one week after each of the fertilizer applications. Herbicide treated fields developed into monocultures with few wild herbs, whereas wild herbs grew up in untreated fields (Appendix 3.1). Passive warming with shields that were hung $10-15 \mathrm{~cm}$ above the wheat tillers increased the temperature near the top of the shoots by 1 - 1.5 degrees when compared to ambient plots (Appendix 3.2). Shields were made of greenhouse-foil with regular pinholes (to be permeable for rainwater) clamped on a wooden frame of one square meter. Ambient plots were equipped with a similar construction that had gauze instead of greenhouse-foil to control for treatment artefacts (e.g., heavy rain events might wash insects off the plants). All shields were established on the $29^{\text {th }}$ June. All plots received 500 aphids of the species Sitobion avenae (Fabricius) grown under standardized conditions by the Kaatz Biotech AG at wheat flowering on the $1^{\text {st }}$ of July.

\section{MEASUREMENTS}

Numbers of aphids and biocontrol agents were recorded weekly (four times) for each plot until dough ripening at the end of July, by counting all individuals on 50 tillers. Immigration of additional aphids was negligible, since only single individuals of other cereal aphid species (i.e. Rhopalosiphum padi (L.), Methopolophium dirhodum (Walker)) were encountered. Biocontrol agents included species from the Chrysopidae, Coccinellidae, Dermaptera, parasitic Hymenoptera, Syrphidae, and web-building spiders. All organism groups apart from the parasitoids were used for calculating the predator-prey ratio as a measure of overall biocontrol. Yield of wheat plants was estimated by drying and weighing the seeds of 10 spikes per plot.

For each plot we established a series of additional measurements to evaluate the treatment effects. Temperature was recorded with ibuttons (Thermochron ${ }^{\circledR}$ DS1921) approximately 
$10 \mathrm{~cm}$ below the wheat spikes at a resolution of 8 measures per $24 \mathrm{~h}$ from 01.07.-30.07.2008. Temperature differences between elevated and control plots were calculated for each week. We thus averaged the difference between treatment temperatures and a reference temperature from the experimental field for each measure. The effect of the fertilizer treatment on plants was assessed after two weeks with a Hydro N-Tester, a handheld device that measures the nutritional state (i.e. percent nitrogen) of a plant by light transmittance of chlorophyll (Olivier et al. 2006; Naud et al. 2009) in the leaves (unfertilized plots, $n=24: 336.33 \pm$ SD 19.59; fertilized plots, $\mathrm{n}=24: 497.91 \pm$ SD 19.59). All nitrogen values in this study are given as the corresponding dimensionless transmission values of the Hydro N-Tester, as no correction values for the used wheat variety were available ("Sortenkorrekturwerte": http://www.ages.at). Tiller density, percent wheat and wild herb cover were recorded after the experiment to avoid disturbance of aphid colonies.

\section{ANALYSES AND STATISTICS}

Numbers of aphids are per 100 tillers unless stated otherwise. Aphid population growth was calculated as growth relative to the number of aphids at the first aphid count. Aphid populations showed the typical collapse at dough ripening in time step 4. As this collapse was not related to any of our treatments and thus would have distorted the patterns arising from the experimental treatments, we excluded time step 4 from all statistical analyses. Predator-prey ratios were calculated as the ratio of all predators to aphids. Parasitism rate was calculated as the ratio of parasitized aphids to the sum of parasitized and non-parasitized aphids.

Growth rate, predator-prey ratio and parasitism rate were taken as response variables in linear mixed effects models (lme: Pinheiro et al. 2009) in R 2.10.1 (R Development Core Team 2009). Growth rates were log-transformed, predator-prey ratios and parasitism rates were square root transformed. Obtaining normally distributed residuals after the transformation, we used the more established lme models instead of generalized linear mixed models for analysing non-normal data, which are more difficult to fit appropriately (Bolker et al. 2009). The order of fixed effects was time, herbicide, fertilizer, and temperature, plus three-way interactions between all terms. Because plots were sampled repeatedly over time, we included random intercepts for plots nested in block, herbicide and fertilization treatment and random slopes for time. Variance functions (Pinheiro and Bates 2000; Zuur et al. 2009) were used to account for heteroscedasticity. A modified version of the stepAIC function (Venables \& Ripley 2002), corrected for small sample sizes (Burnham and Anderson 2002), was used to find the minimal adequate model for each response variable. Additional lme models were fitted with the described random effect structure to estimate the effect of biocontrol agents on aphids and of nutritional state and aphids on yield. Structural equation models (Grace and Bollen 2005) were calculated with Amos $^{\mathrm{TM}}$ (Arbuckle 2007). 


\section{RESULTS}

\section{YIELD}

Yield was almost three times higher in fertilized plots $\left(326 \pm 42 \mathrm{~g} / \mathrm{m}^{2}, \mathrm{n}=24\right)$ than in unfertilized plots $\left(110 \pm 21 \mathrm{~g} / \mathrm{m}^{2}, \mathrm{n}=24\right.$, Tab. 3.1a, Fig. 3.1a). While increasing exponentially with the nutritional state of the wheat plants $\left(\right.$ Tab. $\left.3.1 \mathrm{a}^{1}\right)$, yield was reduced by aphids (Tab. 3.1 $\mathrm{a}^{1}$, Fig. 3.2). Warming increased yield in fertilized mixed cultures, but decreased yield in fertilized monocultures, whereas the inverse pattern was observed in unfertilized plots (Tab. 3.1a: herbicide $\times$ fertilizer $\times$ temperature, Fig. 3.1a).

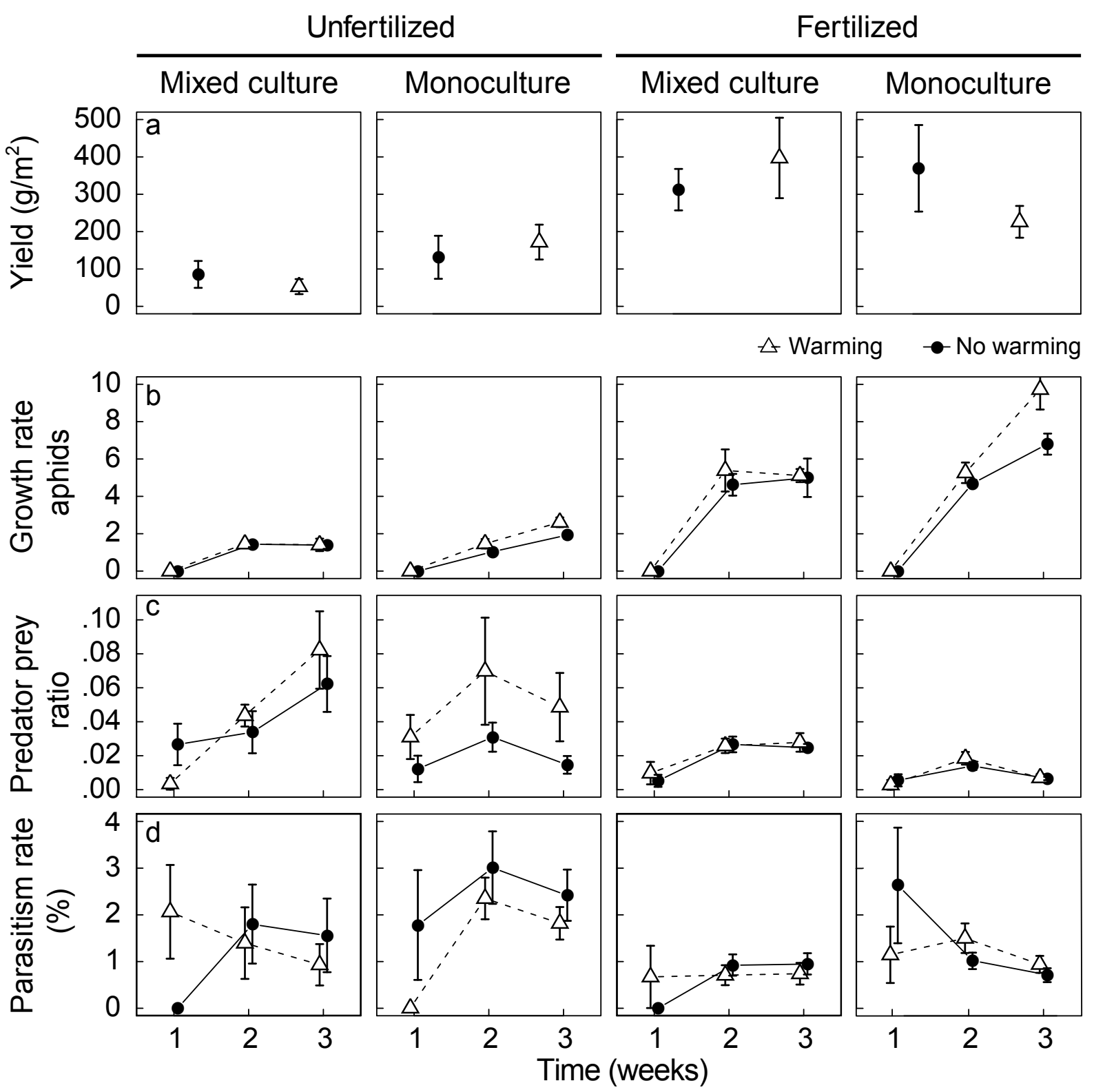

Figure 3.1. Response of the three trophic levels to management type and temperature treatment. Yield (a) was estimated at the end of the experiment and is given in $\mathrm{g} / \mathrm{m}^{2}$. Back-transformed measures of growth rate relative to week 1 (b), predator-prey ratio (c) and parasitism rate (as percent parasitized aphids, d) are plotted over time for the different treatment combinations. Symbols for warming and no warming are the same in all plots. 
APHIDS

Overall aphid numbers increased from wheat flowering in the first week and collapsed after milk ripening in the third week. Highest numbers were reached in the third week in fertilized and warmed monocultures (mean $547 \pm 57, \mathrm{n}=6$, Appendix 3.3), lowest numbers were recorded in unfertilized and non-warmed mixed cultures (mean $54 \pm 7, \mathrm{n}=6$, Appendix 3.3).

Growth rates of aphid populations increased significantly over time (Tab. 3.1b, Fig. 3.1b). Growth was stronger in fertilized and warmed (Tab. 3.1b, Fig. 3.1b) plots. Monocultures had a strong trend of supporting higher aphid growth than mixed cultures, which became significant in the interaction with time (Tab. 3.1b: time $\times$ herbicide, Fig. 3.1b).

\section{BIOCONTROL}

Predator-prey-ratios varied over time (Tab 3.1c, Fig. 3.1c) and increased particularly in mixed cultures (Tab. 3.1c: time $\times$ herbicide, Fig. 3.1c). Unfertilized plots and warmed plots had higher predator-prey ratios (Tab. 3.1c, Fig. 3.1c). The fertilizer effect was slightly stronger in warmed plots (Tab. 3.1c: fertilizer $\times$ temperature, Fig. 3.1c). Predator-prey ratios negatively affected growth rates of aphids in the third time step $\left(\mathrm{F}_{1,23}=4.51, \mathrm{P}=0.04\right)$.

Parasitism rates varied over time and decreased in the third time step (Tab. 3.1d, Fig. 3.1d). In contrast to predator-prey ratios parasitism rates were higher in monocultures (Tab. 3.1d, Fig. 3.1d) and did not respond to warming (and were hence dropped from the minimal model). Unfertilized plots had higher parasitism rates (Tab. 3.1d, Fig. 3.1d). Overall biocontrol (combined predator-prey and parasitism) was best in unfertilized (fertilizer $\mathrm{F}_{1,11}=16.54$, $\mathrm{P}<0.001$ ) and mixed cultures (herbicide $\mathrm{F}_{1,5}=9.49, \mathrm{P}=0.05$ ).

\section{DISCUSSION}

In this study we investigated the effect of warming on a tritrophic system in different field management systems. Warming and field management practices affected aphid density and growth as well as their natural enemies in wheat crops. Monocultures benefited aphids, while mixed cultures supported biocontrol agents (hypothesis i). Positive effect in fertilized plots increased both aphids and yield (hypothesis ii). Warming increased aphid population growth rates, but aphids could only take advantage of warming when nutritive requirements were met in fertilized plots (hypothesis iii).

\section{CROPPING SYSTEMS AT AMBIENT TEMPERATURES}

Wheat plants in fertilized plots were larger, had more tillers, higher yields and possibly higher carrying capacities for aphids (Rotem and Agrawal 2003; Zehnder and Hunter 2008). The enhanced aphid growth in fertilized plots is in line with literature (Weibull 1987; Awmack and Leather 2002) predicting elevated fertility and per capita growth of aphids when plant quality increases in terms of nitrogen availability. Although fertilization increased aphid densities and growth, this negative impact on the wheat plants was outweighed by the direct positive effect of fertilization on yield, only at a given nutritional state the negative effect of aphids on yield 


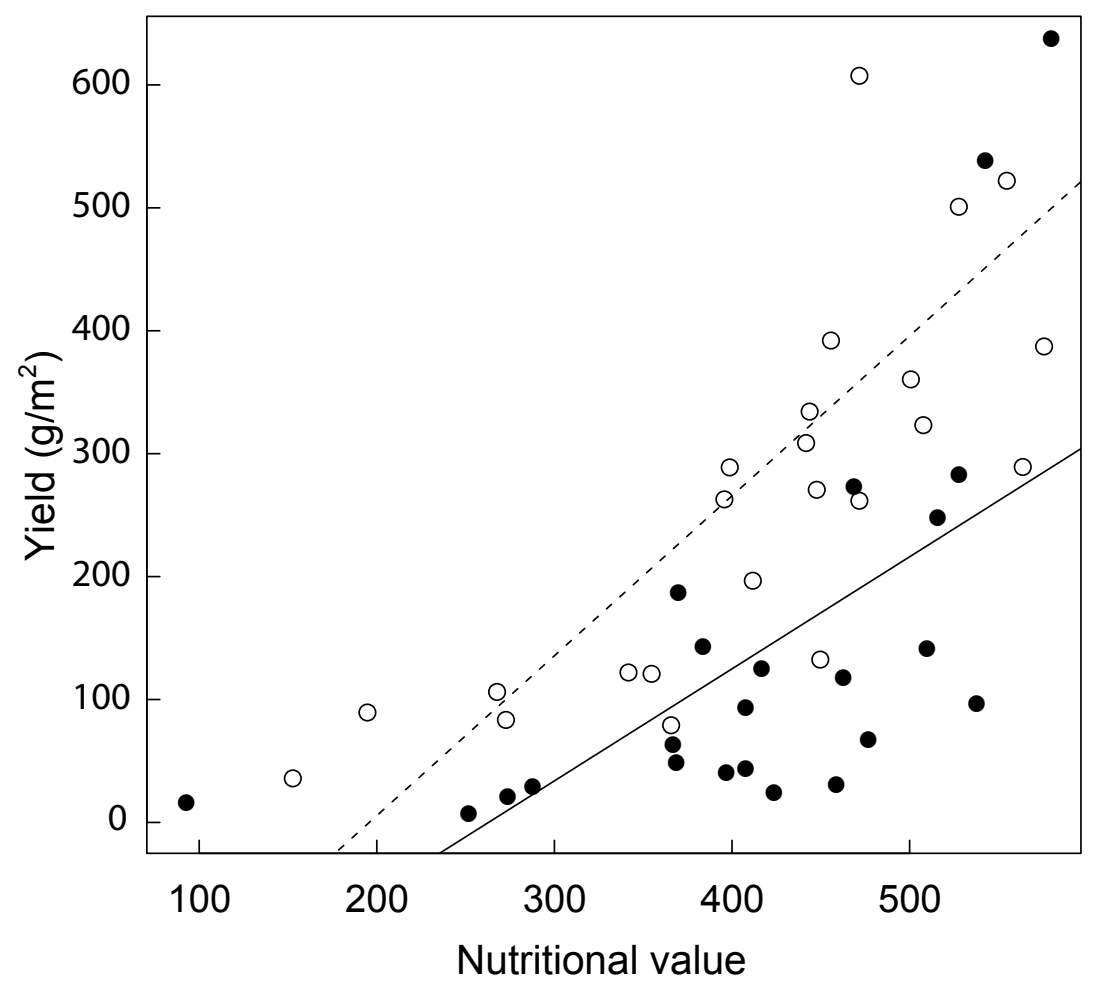

Figure 3.2. Higher nutritional state increased both, aphids (not shown in this graph) and yield. At a given nutritional state an increase of aphids negatively affects yield. Black points represent high aphid numbers, blank points low aphid numbers. For divisions in high and low aphid numbers nutritional value was divided into four discrete sections $\quad(0-300,300-400$, 400 - 500, $500-600)$ and aphid numbers within each section were distributed by value into two equal-sized groups. The regression lines are for low (broken) and high (solid) aphid numbers. Values of nutritional value are the transmission measures of the Hydro $\mathrm{N}$ tester.

was visible (Fig. 3.2).

Predator-prey ratios and parasitism rates were lower in fertilized plots than in unfertilized ones. As absolute numbers of mummies and predators tended to increase in fertilized plots, this reduction in potential biocontrol is due to an over proportional increase of aphid numbers with nutrititional value of the wheat plants. Yield in monocultures and mixed cultures differed only slightly, which seems to be unusual but may be the result of a combination of effects. In fertilized plots competition may not have severely affected wheat plants, as intercropped wheat was reported to gain competitive advance by fertilizing (Ghaley et al. 2005). Remaining handicaps due to competition may have been outweighed by improved reduction of aphids in mixed cultures. Furthermore yield in monocultures may be negatively affected by the application of herbicides, so that advantages and disadvantages were counterbalanced between the two systems in this study.

The significant interaction between time and the herbicide treatment indicates limited aphid growth in mixed cultures at higher densities. Non crop plants in mixed cultures impeded aphid distribution between wheat tillers by masking visual and olfactory cues, which has followup consequences: (1) Dispersing aphids are likely to die on non crop plants (Theunissen 1994). (2) Increased aphid aggregations on single tillers may have aggravated (local) competition (despite comparatively low numbers in the plot) and reduce aphid fertility. (3) Increased aggregations of aphids on single wheat tillers surrounded by non crop plants also may easier attract the more abundant predators (Harwood et al. 2003), which was shown by increased predator-prey ratios in mixed cultures. Spiders contributed particularly to predator-prey ratios (not shown) in mixed crops, which is in line with literature (Sunderland and Samu 2000) confirming the effective (spider) predation of aphids in mixed cultures. 
Table 3.1. Results of minimal adequate models for the given response variables. Two models were calculated for yield, the design model and another for the effect of aphids.

\begin{tabular}{|c|c|c|c|c|}
\hline & numDF & denDF & F-value & P-value \\
\hline \multicolumn{5}{|l|}{ a) Yield $/ \mathrm{m}^{2}$} \\
\hline herbicide & 1 & 5 & 1.07 & 0.348 \\
\hline fertilizer & 1 & 10 & 19.66 & 0.001 \\
\hline temperature & 1 & 20 & 2.78 & 0.111 \\
\hline herbicide $x$ fertilizer & 1 & 10 & 7.45 & 0.021 \\
\hline herbicide $\mathrm{x}$ temperature & 1 & 20 & 1.61 & 0.219 \\
\hline fertilizer $x$ temperature & 1 & 20 & 2.36 & 0.140 \\
\hline herbicide $\mathrm{x}$ fertilizer $\mathrm{x}$ temperature & 1 & 20 & 6.12 & 0.023 \\
\hline \multicolumn{5}{|l|}{$a^{1}$ ) Yield $/ m^{2}$} \\
\hline nutritional value & 1 & 21 & 37.36 & $<0.0001$ \\
\hline aphids $/ \mathrm{m}^{2}$ & 1 & 21 & 29.78 & $<0.0001$ \\
\hline nutritional value $\mathrm{x}$ aphids $/ \mathrm{m}^{2}$ & 1 & 21 & 16.40 & 0.001 \\
\hline \multicolumn{5}{|l|}{ b) Aphid growth } \\
\hline time & 1 & 68 & 17.68 & 0.000 \\
\hline herbicide & 1 & 5 & 5.63 & 0.064 \\
\hline fertilizer & 1 & 11 & 294.62 & $<0.0001$ \\
\hline temperature & 1 & 68 & 5.86 & 0.018 \\
\hline time $\mathrm{x}$ herbicide & 1 & 68 & 21.08 & $<0.0001$ \\
\hline herbicide $\mathrm{x}$ temperature & 1 & 68 & 3.00 & 0.088 \\
\hline \multicolumn{5}{|l|}{ c) Predator-prey } \\
\hline time & 2 & 108 & 28.03 & $<0.0001$ \\
\hline herbicide & 1 & 5 & 5.38 & 0.068 \\
\hline fertilizer & 1 & 10 & 9.40 & 0.012 \\
\hline temperature & 1 & 108 & 3.87 & 0.052 \\
\hline time $\mathrm{x}$ herbicide & 2 & 108 & 6.80 & 0.002 \\
\hline time $x$ fertilizer & 2 & 108 & 1.46 & 0.236 \\
\hline time $\mathrm{x}$ temperature & 2 & 108 & 1.12 & 0.329 \\
\hline herbicide $\mathrm{x}$ fertilizer & 1 & 10 & 0.13 & 0.723 \\
\hline herbicide $x$ temperature & 1 & 108 & 1.37 & 0.244 \\
\hline fertilizer $x$ temperature & 1 & 108 & 3.48 & 0.065 \\
\hline herbicide $\mathrm{x}$ fertilizer $\mathrm{x}$ temperature & 1 & 108 & 2.42 & 0.123 \\
\hline \multicolumn{5}{|l|}{ d) Parasitism rate } \\
\hline time & 2 & 118 & 7.11 & 0.001 \\
\hline herbicide & 1 & 5 & 8.57 & 0.033 \\
\hline fertilizer & 1 & 10 & 5.17 & 0.046 \\
\hline herbicide $\mathrm{x}$ fertilizer & 1 & 10 & 3.43 & 0.094 \\
\hline
\end{tabular}


Parasitism rates contributed little to biocontrol in mixed cultures, which is in contrast to other studies (e.g. Praslicka and Mistina 2004). Parasitoids (Hymenoptera: mainly Aphidiidae) are highly specialized on aphids in wheat fields (Sigsgaard 2002; Brewer and Elliott 2004; Thies et al. 2005) thus their host finding ability may have been diminished in mixed cultures. Furthermore monocultures had higher aphid densities, so resource concentration (Sheehan and Shelton 1989) may have positively affected parasitism rates.

\section{CROPPING SYSTEMS AT ELEVATED TEMPERATURES}

Warming caused higher predator-prey ratios and thereby, appeared to enhance top-down control (Fig. 3.3). The largest functional change between systems in ambient and elevated temperatures was the negative effect of aphids on yield (Fig. 3.3). In warmed conditions monocultures had a positive effect on aphids on one hand, but a less negative effect (than in non warmed plots) on biocontrol on the other, which led to increased impact of biocontrol on aphids (Fig. 3.3). However, these main tendencies counterbalance each other, which will be discussed subsequently.

Like in non-warmed plots fertilization was a major driver in the warmed systems. As stated in hypothesis (iii) responses of aphids and yield to other factors were stronger in fertilized plots. Capped responses in unfertilized plots (Fig. 3.1a,b) were possibly due to a lack of nutrients. However, our results from fertilized plots indicate increased risks of pest outbreaks with warming and a potential key role of mixed cultures in insect population management.

While yield was similar in mixed and monocultures in non-warmed plots, warming led to a reduction of yields in monocultures relative to mixed cultures. In warmed and fertilized plots aphids benefited from reduced development times (Bale et al. 2002; Holopainen and Kainulainen 2004; Adler et al. 2007; Currano et al. 2008) and increased growth rates (Fig. 3.1b) leading to particularly high aphid densities in monocultures (Appendix 3.1) and thereby reducing yield significantly (Fig 3.2, Fig 3.3). Limitation of aphids in mixed cultures may have counteracted potential negative yield effects of competition between wheat and non-crop plants. Higher abundance of biocontrol agents in warmed mixed cultures led to higher predator-prey ratios thus increasing potential biocontrol of aphids (Fig. 3.3). Higher activity of predators (Soares et al. 2003) may have contributed to improved and effective biocontrol.

However, this improved biocontrol potential is mainly due to ground living predators, as parasitism showed no response to warming, and contributed little to increased aphid reduction in warmed plots. As parasitoids are highly mobile (Powell and Poppy 1999) they could shift easily between warmed and non-warmed plots (which is also indicated by the somewhat erratic crossing of warming and no waming curves in Figure 3.1). Development times of mummies may decrease with temperature, and activity of adults is likely to increase when warming is not locally confined (Hance et al. 2006). As the warming treatment in our experiment was at the lower limit of expected future temperature elevation, the observed patterns may become even more apparent in the future than we showed. 


\section{CONCLUSIONS}

At actual temperatures an intensive field management maximizes yield although aphids profit likewise from monocultures and fertilized plants. It seems however, that in monocultures population growth of aphids will exceed suppression potential of predators at future warmer climates. In contrast the more complex systems proved to be a warrant for biocontrol, and intercropping may gain importance as an effective practice to prevent pest outbreaks in future warmer climate.

In general warming seemed to increase the strength of interactions between trophic levels (Fig. 3.3). This may lead to a higher sensitivity of whole ecosystems, because tighter links may cause even smaller shifts in population densities due to environmental changes, to cascade further up or down the food chains.

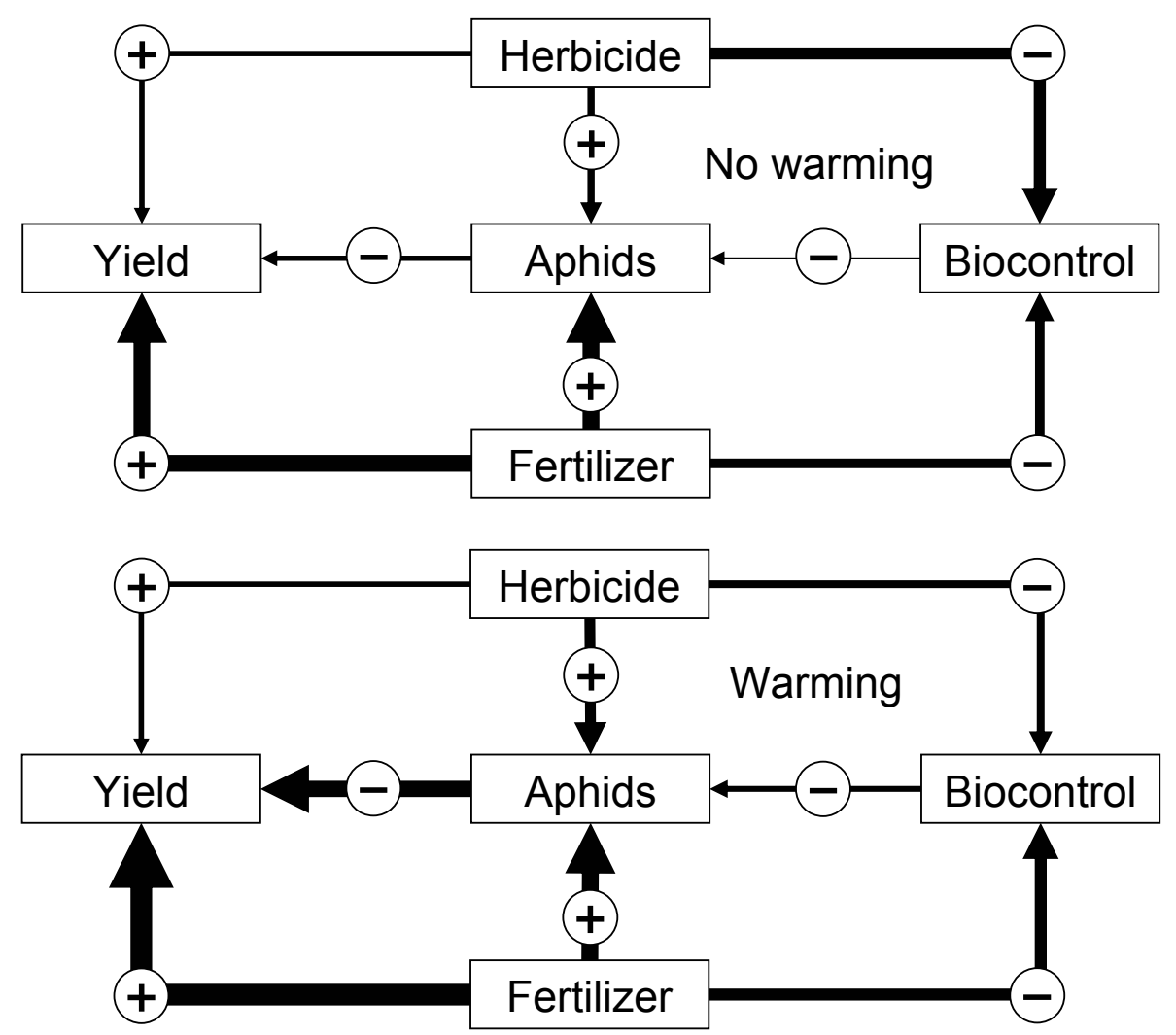

Figure 3.3. Intensity (thickness) and quality ("+" and "-“"Symbols) of interactions between trophic levels and treatments are plotted for warmed versus non-warmed systems. The quality of effects of herbicide and fertilizer are given with respect to the application of both factors. 


\section{APPENDIX}

CONTENT

Appendix 3.1. Plant species cover and occurrence in mixed- vs. monocultures Appendix 3.2. Temperature data for warming, no warming and field reference Appendix 3.3. Aphid densities per 100 tiller in different treatment combinations 
Appendix 3.1. Cover of the 10 most common plant species in plots. Percent values for presence in plots are given with respect to a total $n=24$. Minimum cover for all non crop species was zero.

\begin{tabular}{lccc}
\hline Plant species & $\begin{array}{c}\text { Present in mixed } \\
\text { culture plots (\%) }\end{array}$ & Mean cover & Maximum cover \\
\hline Triticum aestivum & 100.00 & 39.10 & 90.00 \\
Calystega sepium & 91.67 & 13.50 & 50.00 \\
Plantago lanceolata & 41.67 & 32.00 & 60.00 \\
Lotus corniculatus & 25.00 & 19.90 & 70.00 \\
Vicia hirsuta & 37.50 & 14.60 & 45.00 \\
Polygonum aviculare & 16.67 & 1.50 & 2.00 \\
Latyrus pratensis & 33.33 & 17.20 & 70.00 \\
Epilobium tetragonum & 29.17 & 7.00 & 30.00 \\
Poa spec. & 33.33 & 31.00 & 70.00 \\
Elymus repens & 33.33 & 19.20 & 45.00 \\
Plant species & Present in monoculture & Mean cover & Maximum cover \\
\hline Triticum aestivum & plots (\%) & 41.50 & 90.00 \\
Calystega sepium & 100.00 & 8.70 & 30.00 \\
Plantago lanceolata & 75.00 & 30.00 & 40.00 \\
Lotus corniculatus & 25.00 & 2.00 & 5.00 \\
Vicia hirsuta & 16.67 & 4.25 & 10.00 \\
Polygonum aviculare & 20.83 & 1.00 & 1.00 \\
Latyrus pratensis & 16.67 & 1.80 & 5.00 \\
Epilobium tetragonum & 25.00 & 3.00 & 40.00 \\
Poa spec. & 33.33 & 23.00 & \\
Elymus repens & 25.00 & & \\
\hline & 8.33 & & \\
\hline
\end{tabular}


Appendix 3.2. Temperature data are given for a reference without shield, as average over all plots with warming shields and gauze shields.

\begin{tabular}{lccc}
\hline & $\begin{array}{c}\text { Daily mean } \\
\left({ }^{\circ} \mathrm{C}\right)\end{array}$ & $\begin{array}{c}\text { Daily maximum } \\
\left({ }^{\circ} \mathrm{C}\right)\end{array}$ & $\begin{array}{c}\text { Night minimum } \\
\left({ }^{\circ} \mathrm{C}\right)\end{array}$ \\
\hline $\begin{array}{l}\text { Reference } \\
(\mathrm{n}=6)\end{array}$ & & & \\
\hline week 1 & 19,20 & 25,64 & 12,73 \\
week 2 & 16,04 & 21,37 & 11,53 \\
week 3 & 14,80 & 19,19 & 10,73 \\
week 4 & 21,01 & 27,06 & 14,01 \\
Warming & & & \\
(n=24) & & & 12,68 \\
week 1 & 20,37 & 28,92 & 11,63 \\
week 2 & 16,95 & 22,70 & 10,87 \\
week 3 & 15,68 & 20,10 & 13,98 \\
week 4 & 22,28 & 31,35 & 10,69 \\
No warming & & & 13,84 \\
( $\mathrm{n}=24)$ & & & 11,45 \\
week 1 & 18,95 & 25,14 & \\
week 2 & 15,94 & 21,17 & \\
week 3 & 14,75 & 19,08 & \\
week 4 & 20,78 & 26,59 & \\
\hline
\end{tabular}




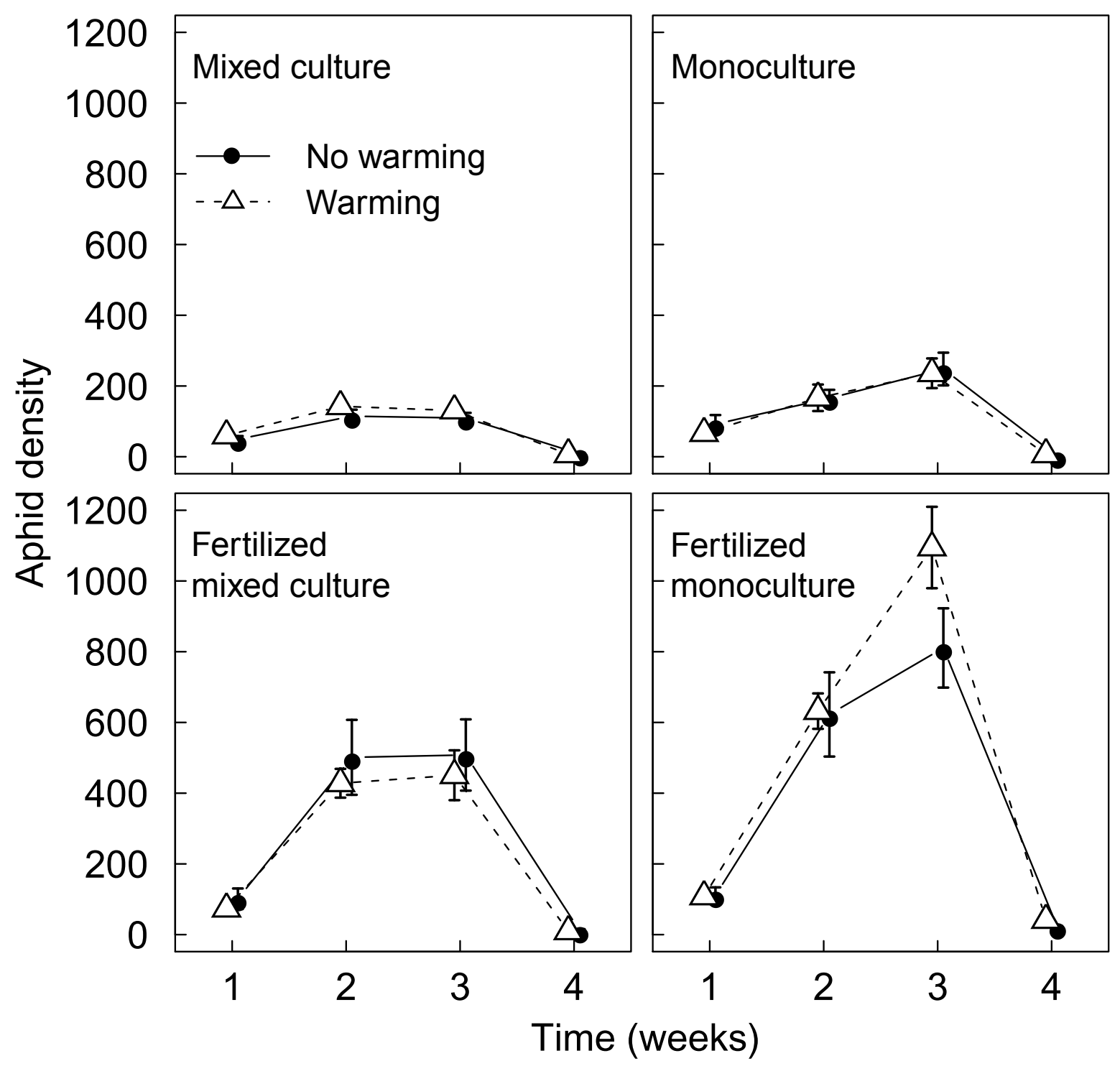

Supporting information 3.3. Aphid density is plotted as aphids per 100 tillers over time for the different management types. The different curves in each plot represent the temperature treatment, with $n=6$. 



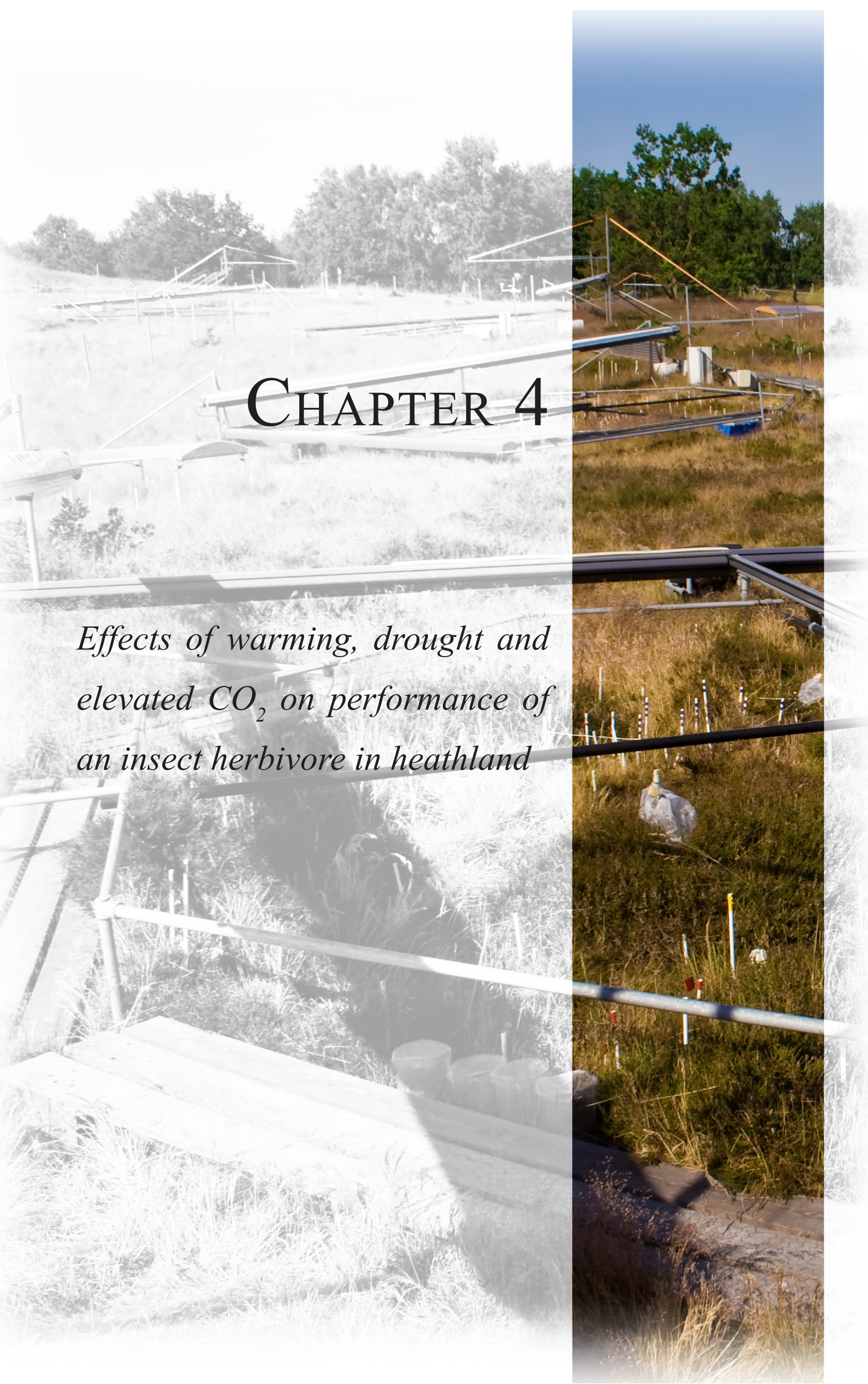




\begin{abstract}
The impact of climate change on herbivorous insects can have far-reaching consequences for ecosystem functioning. However, experiments investigating the combined effects of multiple climate change drivers on herbivorous insects are scarce. Here we independently manipulated three climate change drivers $\left(\mathrm{CO}_{2}\right.$, temperature, drought) in a Danish heathland ecosystem dominated by heather (Calluna vulgaris) and grasses. The experiment was a full factorial split-plot with 6 blocks $\times 2 \mathrm{CO}_{2}$ treatments $\times 4$ warming/drought treatments $=48$ plots. We exposed a total of 432 larvae ( $\mathrm{n}=9$ per plot) of the heather beetle (Lochmaea suturalis Thомsом), an important herbivore on heather, to ambient vs. elevated drought, temperature and $\mathrm{CO}_{2}$ (plus all combinations) for five weeks. Larval growth and survival were strongly and significantly negatively affected by elevated $\mathrm{CO}_{2}$ and drought. Warming had negative effects on growth but not on survival. Combined $\mathrm{CO}_{2}$ and drought significantly reduced growth, while interactions between warming, $\mathrm{CO}_{2}$ and drought had varying effects. Overall, our study shows that i) drought was the most important factor for this insect herbivore, ii) the effect of climate change drivers on the herbivore was dependent on other co-acting factors, iii) insect herbivore populations can respond negatively to future climate,
\end{abstract}

Key-words: multiple climate change drivers, FACE experiment, Lochmaea suturalis

Authors:

David J. Gladbach

Karen Stevnbak Andersen

Søren Christensen

Anders Michelsen

Kristian R. Albert

Teis Nørregard Mikkelsen

Claus Beier

Christoph Scherber 


\section{INTRODUCTION}

Herbivorous insects account for about one quarter of all extant organisms (Strong et al. 1984; Mayhew 2001) and are essential to ecosystem structure and functioning (Weisser and Siemann 2004). Ecosystem process rates such as herbivory may be altered significantly under climate change (Currano et al. 2008). The global mean surface air temperature is expected to increase by $1.8-5.8^{\circ} \mathrm{C}$ (2090 to 2099 relative to 1980 to 1999 ), with additional changes in other climate change drivers such as increasing $\mathrm{CO}_{2}$ levels or extreme weather events (IPCC 2007). In recent studies, effects of global change drivers on herbivorous insects have been studied mostly in single-factor manipulative experiments rather than multi-factorially. For example, studies have shown that increases in $\mathrm{CO}_{2}$ may alter plant-insect interactions in various ways (Lincoln et al. 1986; Lincoln and Couvet 1989; Stiling et al. 1999; Stiling and Cornelissen 2007). Elevated temperature (Bale et al. 2002) and altered water conditions (Mattson and Haack 1987; Morecroft et al. 2002) have also been considered independently. However, although several studies have started to investigate the combined effects of global change drivers on ecosystem processes (Shaw et al. 2002; Pritchard et al. 2007), studies on the joint consequences of different climate change drivers on herbivorous insects are scarce (but see Dury et al. 1998; DeLucia et al. 2008). Multifactor studies, however, will be key to a better mechanistic understanding of plantherbivore interactions and may function as basis for predicting trophic interactions with respect to climate change.

In the present study we independently manipulated atmospheric $\mathrm{CO}_{2}$ concentration, near-surface air temperature, and summer drought in a replicated field experiment (Mikkelsen et al. 2007). The experiments were conducted in nutrient-poor heather vegetation dominated by Calluna vulgaris (L.) and Deschampsia flexuosa (L.) Trin. We recorded growth and survival of larvae of an important specialist herbivore, the heather beetle Lochmaea suturalis (Chrysomelidae), which shows outbreaks and is a major threat to heather worldwide. We directly measured the response of insect individuals on heather to multiple climate change effects under field conditions. Elevated $\mathrm{CO}_{2}$ may alter the chemical composition of plants (Peñuelas and Estiarte 1998; Awmack and Leather 2002) and thus reduce the nutritive value for herbivores (Lincoln et al. 1986). Consequently, we tested the following hypotheses:

(i) Elevated atmospheric $\mathrm{CO}_{2}$-concentrations negatively affect growth and survival of $L$. suturalis larvae because of nitrogen dilution (Roth and Lindroth 1994; Goverde and Erhardt 2003).

(ii) Prolonged drought negatively affects plant quality (Brenes-Arguedas et al. 2009) and hence negatively affects larval growth and survival (Scriber and Slansky 1981).

(iii) Warming positively affects larval growth and survival due to higher metabolic rates (Netherer and Schopf 2010).

(iv) Interactive effects of global change drivers on herbivores may reinforce each other (e.g. $\mathrm{CO}_{2}$ and drought) or act antagonistically (e.g. temperature and $\mathrm{CO}_{2}$, temperature and drought). 


\section{MethodS}

\section{SITE DESCRIPTION}

The experiment was conducted at the CLIMAITE research site at Brandbjerg (55 $\left.53^{\circ} \mathrm{N}, 11^{\circ} 58^{\prime} \mathrm{E}\right)$, Denmark between $1^{\text {st }}$ June to $10^{\text {th }} \mathrm{July}$, 2008. The site is located on nutrient poor sandy soils with unmanaged dry heath/grassland mosaic consisting of heather shrubs (Calluna vulgaris, $30 \%$ cover) and grasses (Deschampsia flexuosa, $70 \%$ cover). The annual mean temperature was $8^{\circ} \mathrm{C}$ and the precipitation averaged $600 \mathrm{~mm}$ (www.DMI.dk).

\section{EXPERIMENTAL DESIGN AND TREATMENTS}

The Brandbjerg field site was designed as a full factorial experiment combining the effects warming (T), drought (D) and $\mathrm{CO}_{2}\left(\mathrm{CO}_{2}\right)$ to mimic a possible climate scenario in Denmark in the year 2075. Climate manipulations (T, D, $\mathrm{CO}_{2}$ ), an ambient control (A) and all combinations of them (TD, $\mathrm{TCO}_{2}, \mathrm{DCO}_{2}$ and $\mathrm{TDCO}_{2}$ ) were established in October 2005. The study design contained six blocks (replicates) consisting of two octagons (7 m diameter), each divided into four plots (split-plot design), yielding a total of 48 plots (Fig. 4.1a). $\mathrm{CO}_{2}$ was manipulated at the octagon level, while drought, elevated temperature, a combination of both treatments and a plot without drought or warming were applied within octagons (Fig. 4.1b).

$\mathrm{CO}_{2}$ was elevated to $510 \mathrm{ppm}$ using a free air carbon enrichment (FACE) system (Miglietta et al. 2001). Passive night time warming (Beier et al. 2004) with curtains (height $50 \mathrm{~cm}$ ) covering the vegetation from sunset to sunrise increased the average temperature (at 20 $\mathrm{cm}$ above ground surface) by $1-2^{\circ} \mathrm{C}$. The drought treatment was implemented using curtains (controlled by rain sensors) that were activated during May 2008 to simulate a prolonged summer drought. For further detailed information on the facility, treatments and the experimental design see Mikkelsen et al. (2007).

\section{STUDY ORGANISM AND MEASUREMENTS}

The heather beetle Lochmaea suturalis is a strictly monophagous insect herbivore which feeds on Calluna vulgaris both as larvae (Fig 4.1c) and as adults (Mohr 1966). Outbreaks have been reported from northern Europe (Gimingham 1972) in which larvae of L. suturalis can reach densities of up to 2000 individuals $/ \mathrm{m}^{2}$ and cause complete defoliation and death of heather (Brunsting 1982).

300 adults of $L$. suturalis were caught near Großalmerode (Germany, $55^{\circ} 15^{\prime} \mathrm{N}, 9^{\circ} 47^{\prime} \mathrm{E}$ ) in a Calluna heathland after they mated in April. The specimens were kept in 61 plastic boxes ("Faunabox", $27 \times 18 \times 18 \mathrm{~cm}$, Savic, Belgium) using standard protocols (Melber 1989) on the $5^{\text {th }}$ of May 2008. Females successively lay up to 300 eggs between end of April and August. Egg batches were transferred to petri dishes where the larvae hatched after 6-11 days and were fed on small pieces of Calluna branches. This was done until we transferred approximately 900 larvae to the field site in Denmark on the $28^{\text {th }}$ of May 2008. Before the start of the experiment on the $1^{\text {st }}$ of June heather beetle larvae were divided into classes according to their weight. Each of the 48 plots received the same amount of larvae from each weight class ( 9 in total). 

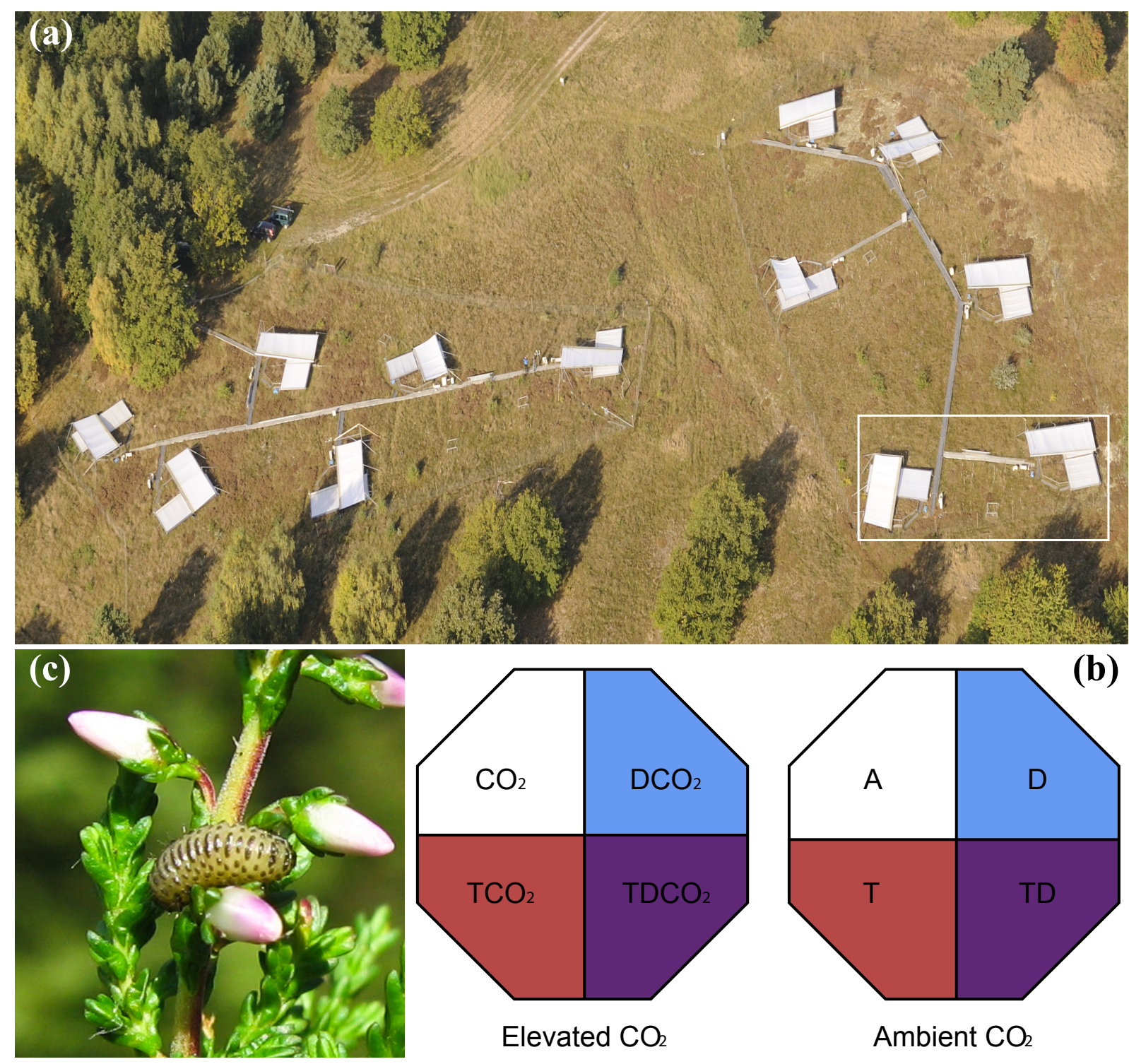

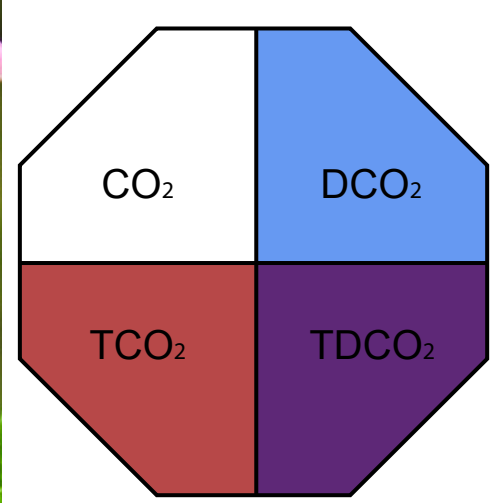

Elevated $\mathrm{CO}_{2}$

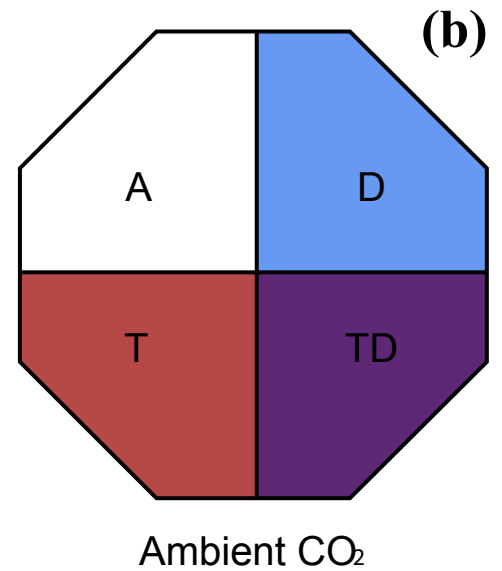

(b)

Figure 4.1. Aerial photograph (a, Copyright by Kim Pilegaard) of the experimental FACE site at Brandbjerg, DK. Curtains were drawn over the plots for illustrative purposes only; (b) split-plot design of the three treatments $\mathrm{CO}_{2}\left(\mathrm{CO}_{2}\right)$, drought (D) and warming (T) and all combinations, including an ambient control (A), adapted from Mikkelsen et al. (2007); (c) $2^{\text {nd }}$ instar larva of Lochmaea suturalis feeding on a Calluna plant (Copyright by C. Scherber).

Gauze mesh bags (length $30 \mathrm{~cm}$, diameter $13 \mathrm{~cm}$ ) were tied around individual heather twigs to prevent the L. suturalis larvae from leaving the plant during the experiment. For comparability between plots we used heather twigs of the same size (estimated with a scale paper). Larvae were collected from four plots within one octagon, weighed and returned to the plants before proceeding to the next octagon. This practice minimized the time during which the larvae were separated from the plants. Individuals lost were counted as alive for the survival analysis. For weighing we used a Mettler AJ100 fine scale accurate to $0.1 \mathrm{mg}$, placed on a granite block inside the field station. Measures of fresh weight and survival were recorded weekly during larval development. The experiment was terminated when larvae were close to pupation in the litter layer (after 5 weeks). All larvae being alive by the end of the experiment were recollected and kept in a freezer for further analyses. 
For additional information of the treatment effects structural equation models (not shown) were calculated with the following measures of June 2007: carbon and nitrogen content of green leaves from plant individuals in the same plots were analyzed using an Eurovector CN analyzer coupled to an Isoprime isotope ratio mass spectrometer (ambient $\mathrm{CO}_{2}: 26.46 \pm 0.74$, elevated $\mathrm{CO}_{2}: 30.45 \pm 0.90, \mathrm{~F}_{1,5}=13.897, \mathrm{P}=0.01$, Appendix 4.1). Condensed tannin of green leaves was extracted with methanol and analyzed with a spectrophotometer (ambient $\mathrm{CO}_{2}$ : $39.50 \pm 2.27 \mathrm{mg} / \mathrm{g}$, elevated $\mathrm{CO}_{2}: 45.74 \pm 2.60 \mathrm{mg} / \mathrm{g}, \mathrm{F}_{1,5}=10.23, \mathrm{P} \pm 0.02$, Appendix 4.2). Soil moisture was continuously measured in each plot using TDR-probes (see Mikkelsen et al. 2007).

\section{ANALYSES AND STATISTICS}

Larvae relative growth rates were calculated from larval weights as indicator of larval development (Hoffmann and Poorter 2002; Awmack et al. 2004) using the formula

$\mathrm{RGR}=\left(\ln \mathrm{W}_{\mathrm{t}(\mathrm{x})+1}-\ln \mathrm{W}_{\mathrm{t}(\mathrm{x})}\right) /\left(\mathrm{D}_{\mathrm{t}(\mathrm{x})+1-\mathrm{t}(\mathrm{x})}\right), \quad$ eqn 1

where RGR is relative growth rate (Stamp and Yang 1996), $\mathrm{W}_{\mathrm{t}(\mathrm{x})}$ and $\mathrm{W}_{\mathrm{t}(\mathrm{x})+1}$ the weights (in mg) for time step $\mathrm{x}$ and $\mathrm{D}$ the time between two time steps. Because of high larval mortality, the $5^{\text {th }}$ time step was excluded from the growth rate analyses to keep the design balanced. Larval weights were pooled for each plot and time step. Kaplan-Meier survivorship for each plot and time steps 1-5 was calculated using the survfit function from the survival package (version 2.35-7, 2008) in R 2.10.1 (R Development Core Team 2009). Survival rate and relative growth rate were taken as response variables in linear mixed effects models (lme models, Pinheiro et al. 2009) to account for the split-plot design of the experiment. The order of fixed effects terms was time, $\mathrm{CO}_{2}$, drought, temperature, plus two- and three-way interactions between all terms. Because plots were visited repeatedly over time, we included random intercepts for plots nested

Table 4.1. Performance of Lochmaea suturalis larvae. Start and end weights as well as number of remaining larvae are given as means of the six treatment replicates $(\mathrm{A}=$ ambient control, $\mathrm{T}=$ elevated temperature, $\mathrm{D}=$ elevated drought, $\mathrm{TD}=$ elevated temperature and drought, $\mathrm{CO}_{2}=$ elevated $\mathrm{CO}_{2}, \mathrm{CO}_{2} \mathrm{~T}=$ elevated $\mathrm{CO}_{2}$ and temperature, $\mathrm{CO}_{2} \mathrm{D}=$ elevated $\mathrm{CO}_{2}$ and drought, $\mathrm{CO}_{2} \mathrm{TD}=$ elevated $\mathrm{CO}_{2}$, temperature and drought). Overall values are grand means of all plots $(\mathrm{N}=48)$.

\begin{tabular}{lccc}
\hline Treatment & $\begin{array}{c}\text { Mean weight }[\mathrm{mg}] \pm \mathrm{SE} \\
\text { at experimental start }\end{array}$ & $\begin{array}{c}\text { Mean weight }[\mathrm{mg}] \pm \mathrm{SE} \\
\text { after } 4 \text { weeks }\end{array}$ & $\begin{array}{c}\text { Mean number of larvae } \\
\pm \text { SE after } 5 \text { weeks }\end{array}$ \\
\hline $\mathrm{A}$ & $1.96 \pm 0.05$ & $10.45 \pm 1.60$ & $6.33 \pm 0.33$ \\
$\mathrm{~T}$ & $2.01 \pm 0.09$ & $7.57 \pm 2.10$ & $6.33 \pm 0.84$ \\
$\mathrm{D}$ & $1.99 \pm 0.05$ & $4.20 \pm 1.62$ & $4.33 \pm 0.92$ \\
$\mathrm{TD}$ & $1.97 \pm 0.08$ & $9.40 \pm 0.9$ & $4.33 \pm 0.61$ \\
$\mathrm{CO}_{2}$ & $1.92 \pm 0.09$ & $5.83 \pm 1.17$ & $2.83 \pm 0.70$ \\
$\mathrm{CO}_{2} \mathrm{~T}$ & $1.98 \pm 0.06$ & $6.27 \pm 1.09$ & $5.83 \pm 0.71$ \\
$\mathrm{CO}_{2} \mathrm{D}$ & $1.94 \pm 0.06$ & $8.40 \pm 0.7$ & $2.50 \pm 0.72$ \\
$\mathrm{CO}_{2} \mathrm{TD}$ & $1.99 \pm 0.06$ & $4.80 \pm 1.28$ & $2.33 \pm 0.84$ \\
$\mathrm{Overall}$ & $1.99 \pm 0.03$ & $7.16 \pm 0.77$ & $4.70 \pm 0.67$ \\
\hline
\end{tabular}


in block and $\mathrm{CO}_{2}$ treatment, and random slopes for weeks 1 - 4(5). For 48 plots this yielded 192 (response variable: RGR) and 240 (response variable: survival rate) degrees of freedom for errors in the full model. Variance functions (Pinheiro and Bates 2000; Zuur et al. 2009) were used to account for heteroscedasticity. A modified version of the stepAIC function (Venables \& Ripley 2002), corrected for small sample sizes (Burnham and Anderson 2002), was used to find the minimal adequate model for each response variable.

\section{RESULTS}

\section{GROWTH}

At the beginning of the experiment, larvae weighed approximately $2.0 \mathrm{mg}$ and reached an average final weight of $7.2 \mathrm{mg}$ (Tab. 4.1). Elevated $\mathrm{CO}_{2}$, prolonged drought, and elevated temperature all significantly decreased larval weight (Tab. 4.1).

Relative growth rates increased significantly over time and peaked after three weeks (Tab. 4.2, Fig. 4.2). Relative growth in elevated $\mathrm{CO}_{2}\left(\mathrm{~F}_{1,5}=15.20, \mathrm{P}<0.05\right)$, drought and warming plots were significantly lower compared to the ambient plots (Tab. 4.2, Fig. 4.2). In addition, there were significant two-way interactions between time and $\mathrm{CO}_{2}$, time and drought and time and warming (Tab.4.2, Fig. 4.2). In combined $\mathrm{CO}_{2}$ and drought conditions larvae grew slowly (Average RGR in week 1 and 2: $\mathrm{D} 0.027 \pm 0.01 ; \mathrm{DCO}_{2} 0.045 \pm 0.01$ ) particularly in weeks three and four ( $0.01 \pm 0.01 ; \mathrm{DCO}_{2} 0.00 \pm 0.02$, Appendix 4.3). Larvae in plots with combined elevation of drought and warming gained on average $0.03 \pm 0.06 \mathrm{mg}$ per day. This is less than in plots with warming, but more than in drought-only plots in the second half of the experiment (drought $\times$ temperature $\mathrm{F}_{1,107}=5.18, \mathrm{P}<0.05$; time $\times$ drought $\times$ temperature $\mathrm{F}_{3,107}=5.87, \mathrm{P}<0.001$, Appendix 4.3).
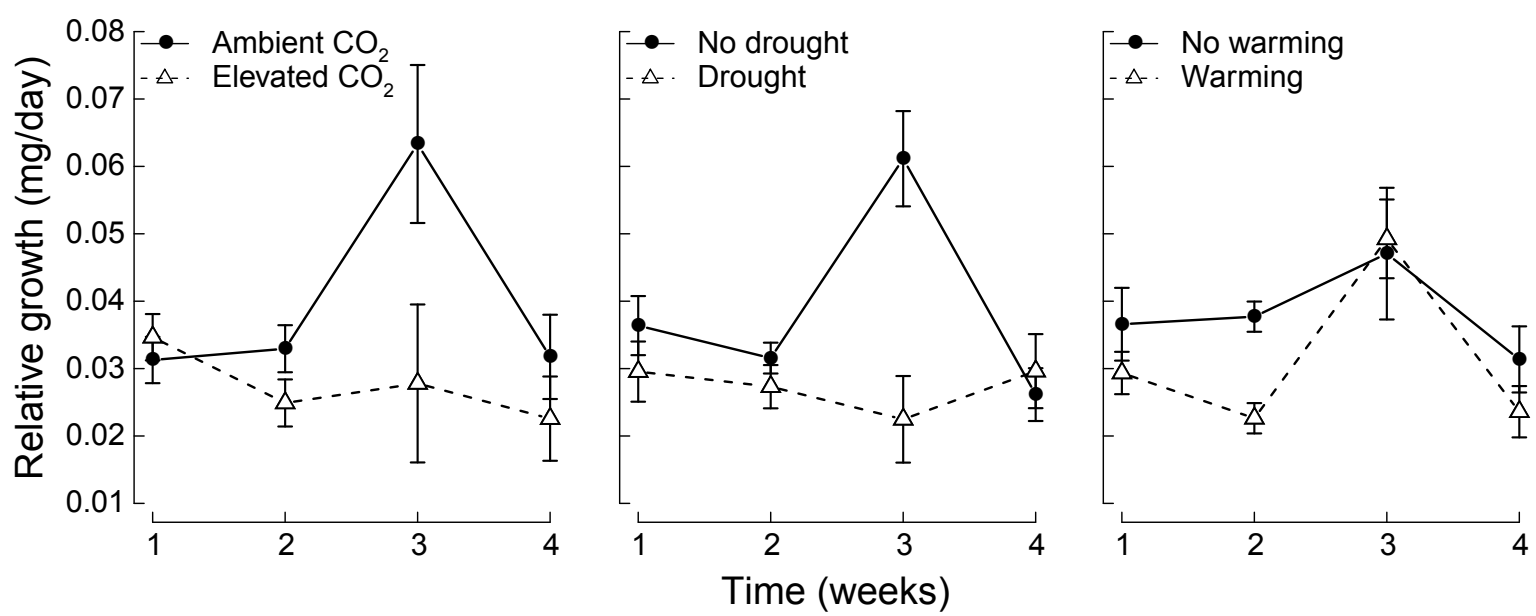

Figure 4.2. Relative growth rate of Lochmaea suturalis larvae over time for all plots with elevated treatments $(\mathrm{n}=24$, broken lines) and controls $(\mathrm{n}=24$, solid lines). 
Table 4.2. ANOVA tables of the minimal adequate models for relative growth rate (RGR) and survival rate.

\begin{tabular}{|c|c|c|c|c|}
\hline Response variable: RGR & numDF & denDF & F-Value & P-value \\
\hline time (weeks) & 3 & 107 & 6.953 & $<0.0001$ \\
\hline $\mathrm{CO}_{2}$ & 1 & 5 & 15.201 & 0.011 \\
\hline drought & 1 & 107 & 11.464 & 0.001 \\
\hline warming & 1 & 107 & 26.597 & $<0.0001$ \\
\hline time $\times \mathrm{CO}_{2}$ & 3 & 107 & 4.978 & 0.002 \\
\hline time $\times$ drought & 3 & 107 & 5.995 & $<0.0001$ \\
\hline time $\times$ warming & 3 & 107 & 3.001 & 0.033 \\
\hline $\mathrm{CO}_{2} \times$ drought & 1 & 107 & 7.996 & 0.005 \\
\hline $\mathrm{CO}_{2} \times$ warming & 1 & 107 & 2.085 & 0.151 \\
\hline drought $\times$ warming & 1 & 107 & 5.182 & 0.024 \\
\hline time $\times \mathrm{CO}_{2} \times$ drought & 3 & 107 & 2.030 & 0.114 \\
\hline time $\times$ drought $\times$ warming & 3 & 107 & 5.887 & $<0.0001$ \\
\hline $\mathrm{CO}_{2} \times$ drought $\times$ warming & 1 & 107 & 3.811 & 0.053 \\
\hline \multicolumn{5}{|c|}{ Response variable: Survival rate } \\
\hline time (weeks) & 4 & 210 & 38.101 & $<0.0001$ \\
\hline $\mathrm{CO}_{2}$ & 1 & 5 & 8.476 & 0.033 \\
\hline drought & 1 & 210 & 65.911 & $<0.0001$ \\
\hline warming & 1 & 210 & 3.161 & 0.076 \\
\hline time $\times \mathrm{CO}_{2}$ & 4 & 210 & 1.325 & 0.261 \\
\hline time $\times$ drought & 4 & 210 & 5.032 & $<0.0001$ \\
\hline $\mathrm{CO}_{2} \times$ drought & 1 & 210 & 0.450 & 0.498 \\
\hline $\mathrm{CO}_{2} \times$ warming & 1 & 210 & 16.186 & $<0.0001$ \\
\hline drought $\times$ warming & 1 & 210 & 0.430 & 0.508 \\
\hline $\mathrm{CO}_{2} \times$ drought $\times$ warming & 1 & 210 & 16.555 & $<0.0001$ \\
\hline
\end{tabular}


SURVIVAL

Five weeks after the start of the experiment an average of $4.7 \pm 0.67$ Lochmaea suturalis larvae still remained in the plots (Tab. 4.1). While both, elevated $\mathrm{CO}_{2}$ and prolonged drought had negative effects on larval abundance after 5 weeks, abundance was slightly higher under elevated than ambient temperature (but only when warming was combined with elevated $\mathrm{CO}_{2}$, Tab. 4.1).

Resembling a type II response (Pearl 1928), Kaplan-Meier survivorship declined significantly with time (Tab 4.2, Fig 4.3). Type III responses of survival were observed in elevated $\mathrm{CO}_{2}$, and drought (Tab. 4.2, Fig: 4.3). Survival rates in drought plots dropped significantly in the second week (Tab. 4.2, Fig. 4.3). Warming increased survival only slightly (Fig. 4.3). However, warming increased survival rates to levels of ambient plots in combination with $\mathrm{CO}_{2}$ (Tab. 4.2, Appendix 4.4). Finally the three-way interaction of $\mathrm{CO}_{2}$, drought and temperature yielded the lowest survival rates in the experiment $(0.25 \pm 0.059$ after 5 weeks, Tab. 4.1, 4.2, Appendix 4.4).
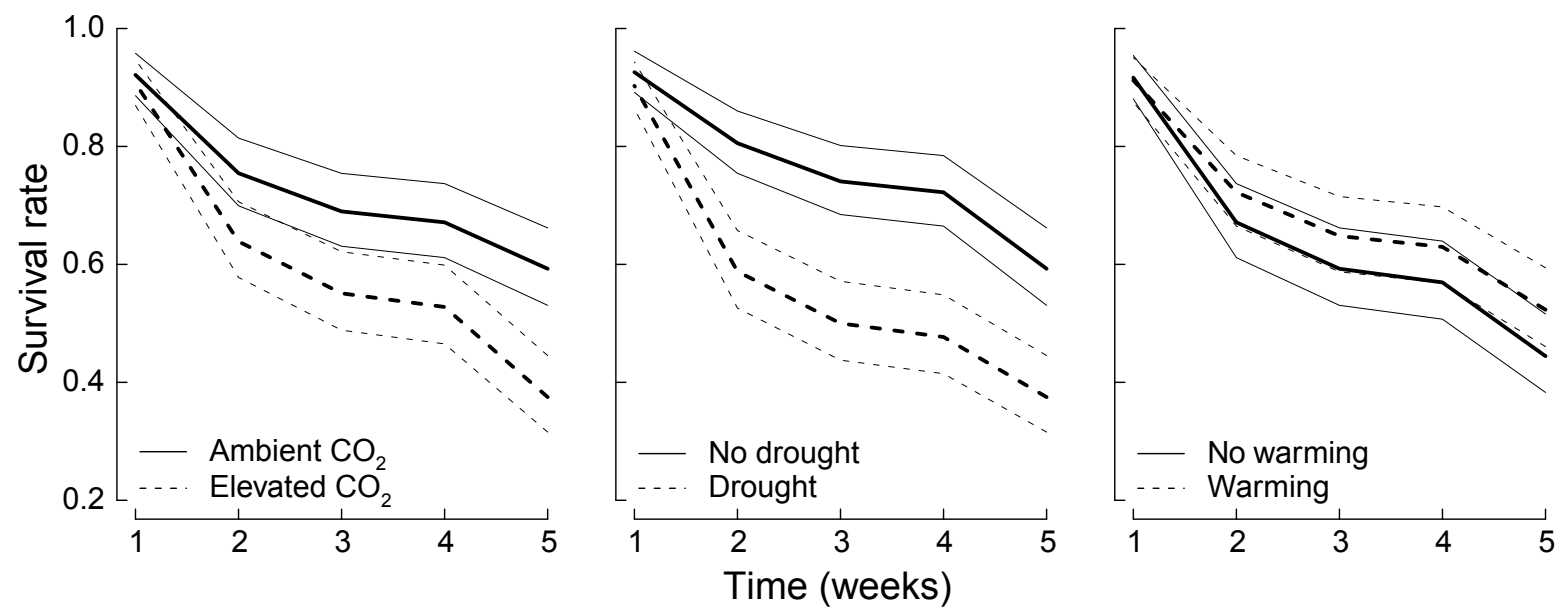

Figure 4.3. Survival rate of Lochmaea suturalis larvae over time for all plots with elevated treatments $(\mathrm{n}=24$, solid lines) and ambient plots ( $\mathrm{n}=24$, broken lines). Thin lines show the confidence intervals at $5 \%$ and $95 \%$.

\section{DISCUSSION}

We investigated main effects and interactions of the climate change drivers $\mathrm{CO}_{2}$, warming and drought on growth and survival of larvae of a chrysomelid beetle. Insect larval stages are generally considered most sensitive to environmental changes. Given the strong treatment effects on larval stages, it can further be assumed that fecundity and fitness correlates in herbivorous insects may shift considerably under global change.

All global change drivers adversely affected growth and survival of Lochmea suturalis larvae, with the exception of temperature, which only affected growth. Two- and three-way interactions of global change drivers in most cases amplified the negative impacts of main effects on growth or survival. 


\section{$\mathrm{CO}_{2}$ AND DROUGHT EFFECTS}

In general, growth was particularly strong at intermediate larval stages and reduced when larvae were closer to pupation. This result is consistent with studies on different insect herbivores (e.g. Berger et al. 2006). Confirming our hypotheses (i) and (ii), elevated $\mathrm{CO}_{2}$ and drought reduced growth rates. Analyses of leaf carbon and nitrogen content indicated that $\mathrm{CO}_{2}$ increased the $\mathrm{C} / \mathrm{N}$ ratios of $C$. vulgaris leaves and thus reduced food plant quality for L. suturalis (comp. Scriber and Slansky 1981). It is likely that nitrogen dilution due to enhanced plant growth in elevated $\mathrm{CO}_{2}$ (Lincoln et al. 1986) may have lowered food conversion efficiency of L. suturalis, resulting in slower development (Roth and Lindroth 1994; Lawler et al. 1996; Goverde and Erhardt 2003).

There was no effect of drought on leaf $\mathrm{C} / \mathrm{N}$, but plants under drought stress (reduced soil water content) often build tougher and therefore harder digestible leaf structures (Lincoln et al. 1993; Awmack and Leather 2002; Rouault et al. 2006), which may be an explanation for reduced larval growth in drought plots. However, consumption of plant material by the larvae was too small to record differences in the field.

Nitrogen dilution effects on growth rates may also be responsible for reduced larval survival (Brunsting and Heil 1985) because of elongated development times (Coviella and Trumble 1999). Analyses of tannins showed that the heather plants growing under elevated $\mathrm{CO}_{2}$ contained higher concentrations of leaf tannins than those in ambient $\mathrm{CO}_{2}$. In combination with prolonged small larval stages, which are most sensitive to foliar quality (Rouault et al. 2006), higher tannin concentrations may additionally have increased mortality, particularly among smaller larvae. Reduced soil water content under drought conditions may also have affected leaf water content negatively (Mattson and Haack 1987). In consequence, survival rates in drought plots dropped in week one and two, as particularly young developmental stages of $L$. suturalis depend on elevated levels of microclimatic humidity (Melber and Heimbach 1984; Melber 1989).

Confirming the sensivity of small larval stages to food plant quality survival rates in the first two weeks were similar in combined $\mathrm{CO}_{2}$ and drought and in plots with $\mathrm{CO}_{2}$ or drought applied separately. Obviously the negative effect of these main effects was at a maximum for small larvae. Only as larvae outgrew the first stage during the progress of the experiment, the negative effects of the combined $\mathrm{CO}_{2}$ and drought treatment further reduced survival. However, in combined $\mathrm{CO}_{2}$ and drought larvae ceased to grow in week three. Hence, low nutritive values of $C$. vulgaris may lead to lowered food conversion efficiency, which in combination with low consumption rates may be insufficient to yield energy in excess to what is required for foraging.

\section{WARMING EFFECTS}

Warming had no effect on leaf nitrogen or tannin concentration in heather. In insects, increased temperature causes higher metabolic rates and can thereby increase growth, fecundity and survival. However, warming effects on L. suturalis larvae in our study were less pronounced 
than the distinct effects of $\mathrm{CO}_{2}$ and drought, and depended on presence and absence of the other climate change drivers. For instance, and in contrast to hypothesis (iii), warming adversely affected larval growth, but reductions remained moderate in comparison to $\mathrm{CO}_{2}$ or drought effects. These results are in line with findings of Melber (1989), who reported that at high temperatures larvae move closer to the (cooler) ground in order to evade unfavourable conditions. However, while warming may increase consumption and metabolic rates, it also leads to faster tannin accumulation in the larvae. In the face of unchanged survival rates, increased detoxification of tannins may take place at the cost of growth (Barbehenn et al. 2009). This assumption is supported by increased survival in combined $\mathrm{CO}_{2}$ and warming. We suggest that the detoxification efficiency of defensive metabolites increases with temperature (Mattson and Haack 1987), but becomes significant only when concentrations of carbon-based toxic agents increase (Lawler et al. 1996).

However, the negative effects of warming increased in combination with $\mathrm{CO}_{2}$ and drought, and survival of $L$. suturalis larvae dropped to the lowest levels of the study. Possibly larvae could compensate only certain levels of tannin or nitrogen dilution that were exceeded in the three-way interaction of all climate change drivers. Warming may on the one hand increase metabolism rates and thus benefit insect herbivores, but on the other for example greatly reduce relative air humidity when combined with drought. Although we could not exactly determine the mechanism, warming may have introduced unexplored side effects of the climate change factors that lead to qualitatively different impacts on herbivore insects.

This is supported by the fact that the combination of drought and warming increased growth relative to the drought-only treatment, while all other combinations or main effects of climate change drivers lead to reduced growth.

CONCLUSIONS

In the present experiment, drought effects were slightly stronger than $\mathrm{CO}_{2}$ and clearly dominated over those of warming. $\mathrm{CO}_{2}$ and drought always negatively affected survival and growth. Warming was less consistent - main effects were not obvious or slightly positive, while particularly interactions with drought had negative impacts on insect herbivores.

We showed clearly that complexity of insect responses increases with the number of combined climate change drivers that may enhance or weaken each others effects. Thus our results are in contrast to earlier hypotheses that e.g. assumed warming to result in increasing insect populations (Coley 1998; Himanen et al. 2008; Klapweijk et al. 2010). According to our results climate change may not promote but reduce insect populations. Increasing plant $\mathrm{C} / \mathrm{N}$ ratios may increase the duration of insect developmental stages that are particularly sensitive to drought conditions and may particularly suffer from so called "extreme weather" events with predicted prolonged drought periods, which may be aggravated by warming (Rouault et al. 2006). However, generalisations of the effects of single climate change drivers should be handled with care, as the effect of a climate change driver demonstrably depends on the concert of co-acting global change drivers. 


\section{APPENDIX}

CONTENT

Appendix 4.1. Carbon to nitrogen ratio in leaves of heather (Calluna vulgaris) in dependence $\mathrm{CO}_{2}$, drought, and warming and all treatment combinations

Appendix 4.2. Leaf tannin concentration of heather (Calluna vulgaris) in dependence $\mathrm{CO}_{2}$, drought, and warming and all treatment combinations

Appendix 4.3. Relative growth rate of Lochmaea suturalis larvae in dependence $\mathrm{CO}_{2}$, drought, and warming and all treatment combinations

Appendix 4.4. Survival rate of Lochmaea suturalis larvae in dependence $\mathrm{CO}_{2}$, drought, and warming and all treatment combinations 


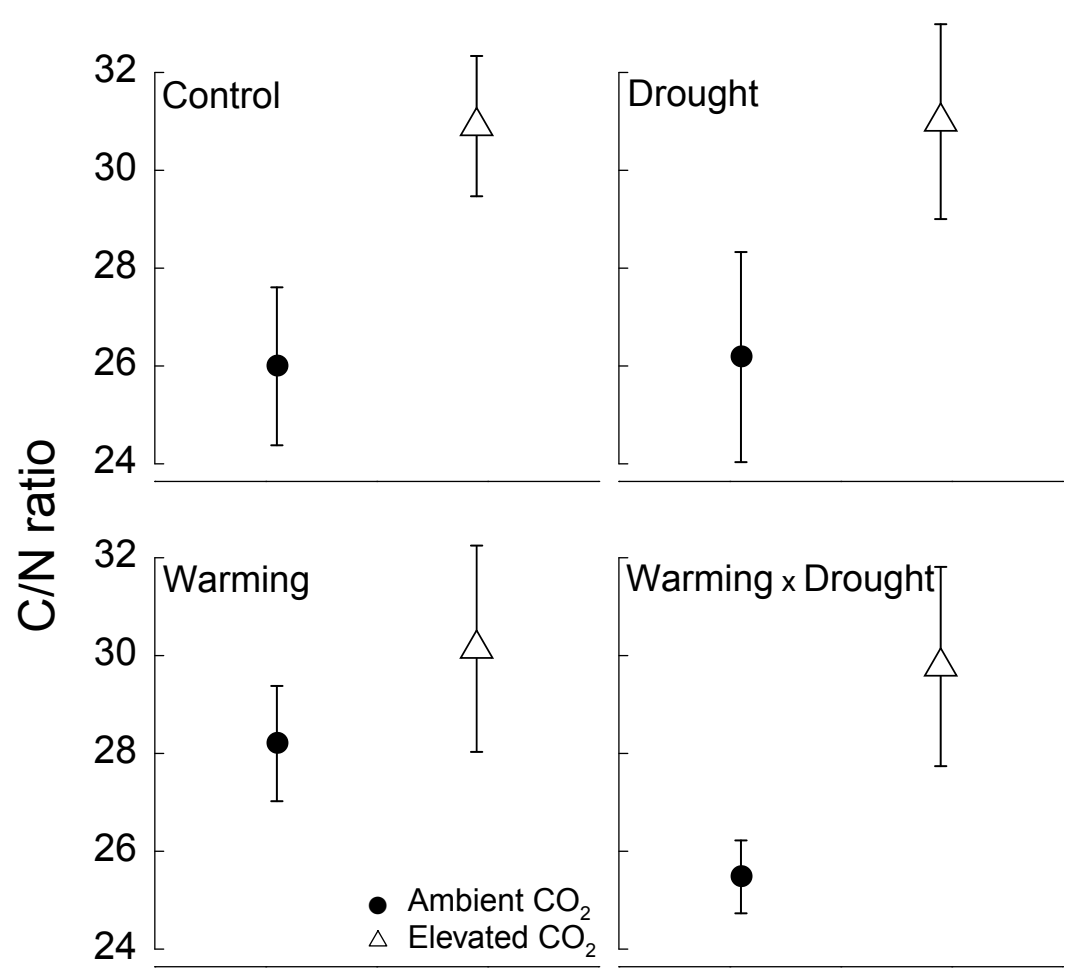

Appendix 4.1. Carbon to nitrogen ratio in leaves of heather (Calluna vulgaris). The graph panels are ordered according to the splitplot design of the experiment. $\mathrm{C} / \mathrm{N}$ ratios are given for each treatment in elevated (open triangles) and ambient (solid circles) $\mathrm{CO}_{2}$ octagons. Thus each graph includes only the subset of plots $(n=6)$ with the respective treatment. The single $\mathrm{CO}_{2}$ effect is obtained when comparing both symbols in the control panel. Other single effects are obtained when comparing the solid circles of different panels. Two and three way interactions with $\mathrm{CO}_{2}$ can be taken from the open triangles in all but the upper left panel.

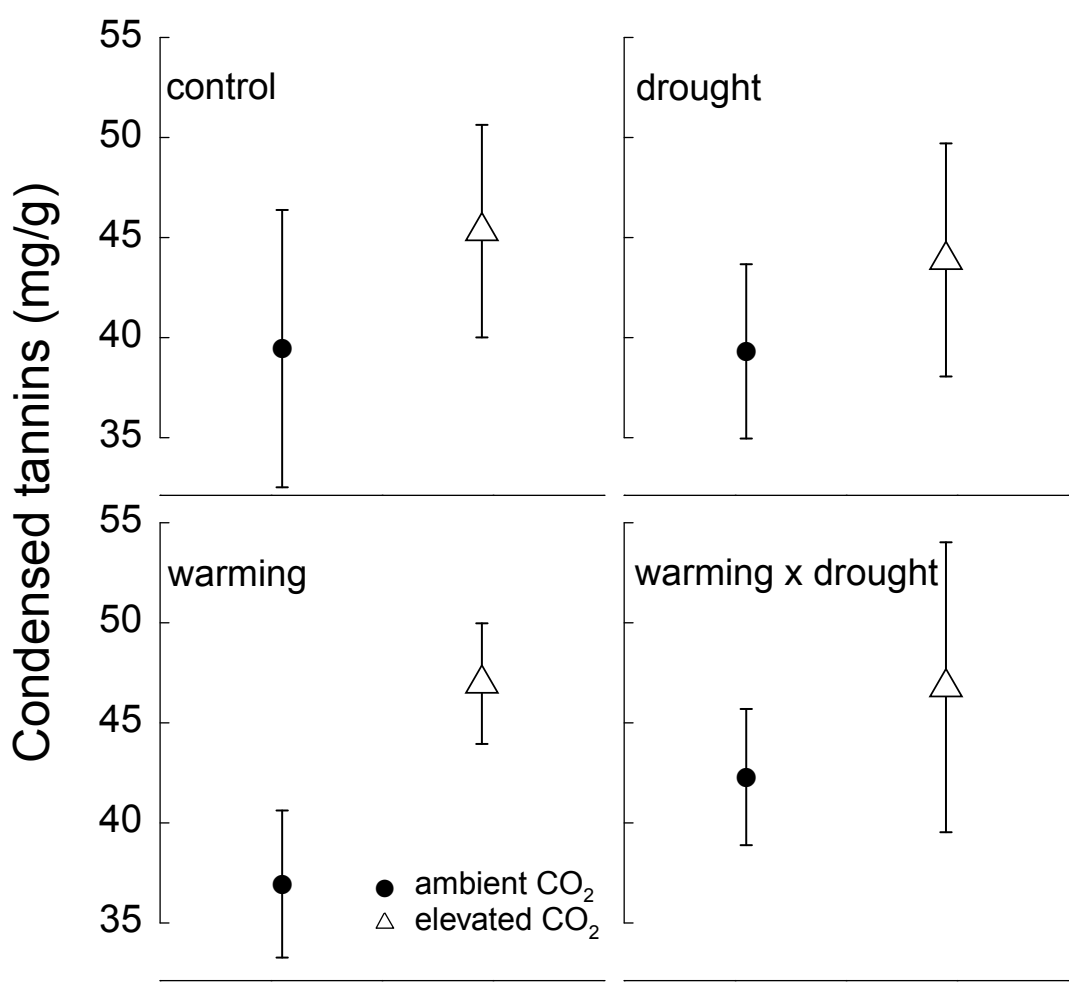

Appendix 4.2. Leaf tannin concentration of heather (Calluna vulgaris). The graph panels are ordered according to the splitplot design of the experiment. Tannin concentrations are given as $\mathrm{mg}$ per $\mathrm{g}$ for each treatment in elevated (open triangles) and ambient (solid circles) $\mathrm{CO}_{2}$ octagons. Thus each graph includes only the subset of plots $(n=6)$ with the respective treatment. The single $\mathrm{CO}_{2}$ effect is obtained when comparing both symbols in the control panel. Other single effects are obtained when comparing the solid circles of different panels. Two and three way interactions with $\mathrm{CO}_{2}$ can be taken from the open triangles in all but the upper left panel. 


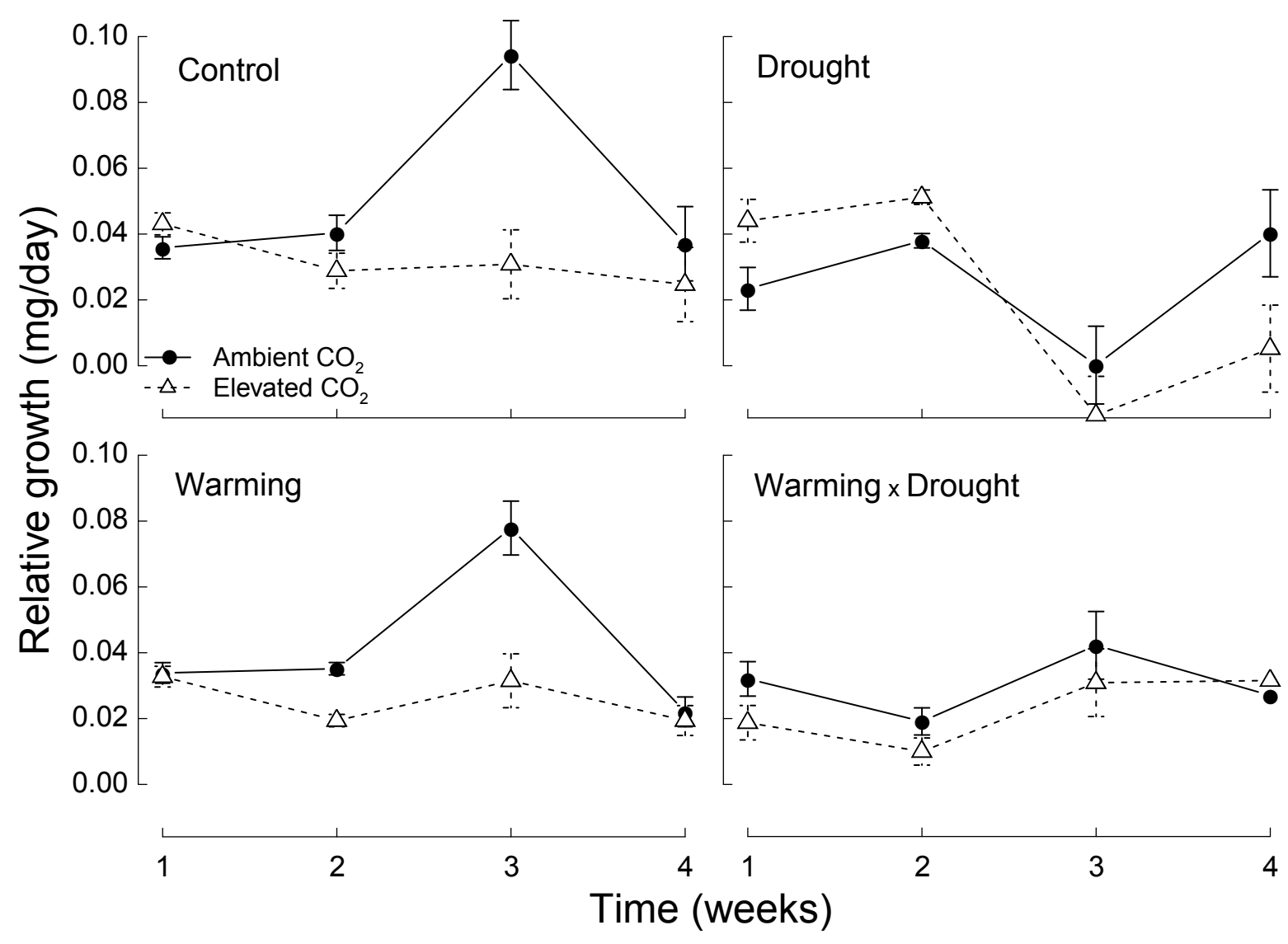

Appendix 4.3. Relative growth rate of Lochmaea suturalis larvae. The graph panels are ordered according to the split-plot design of the experiment. Relative growth rates are given for each treatment in elevated (broken lines) and ambient (solid lines) $\mathrm{CO}_{2}$ octagons. Thus each graph includes only the subset of plots $(\mathrm{n}=6)$ with the respective treatment. The single $\mathrm{CO}_{2}$ effect is obtained when comparing both curves in the control panel. Other single effects are obtained when comparing the solid lines of different panels. Interactions with time can be seen along each curve. Two and three way interactions with $\mathrm{CO}_{2}$ can be taken from the broken curves in all but the upper left panel. 


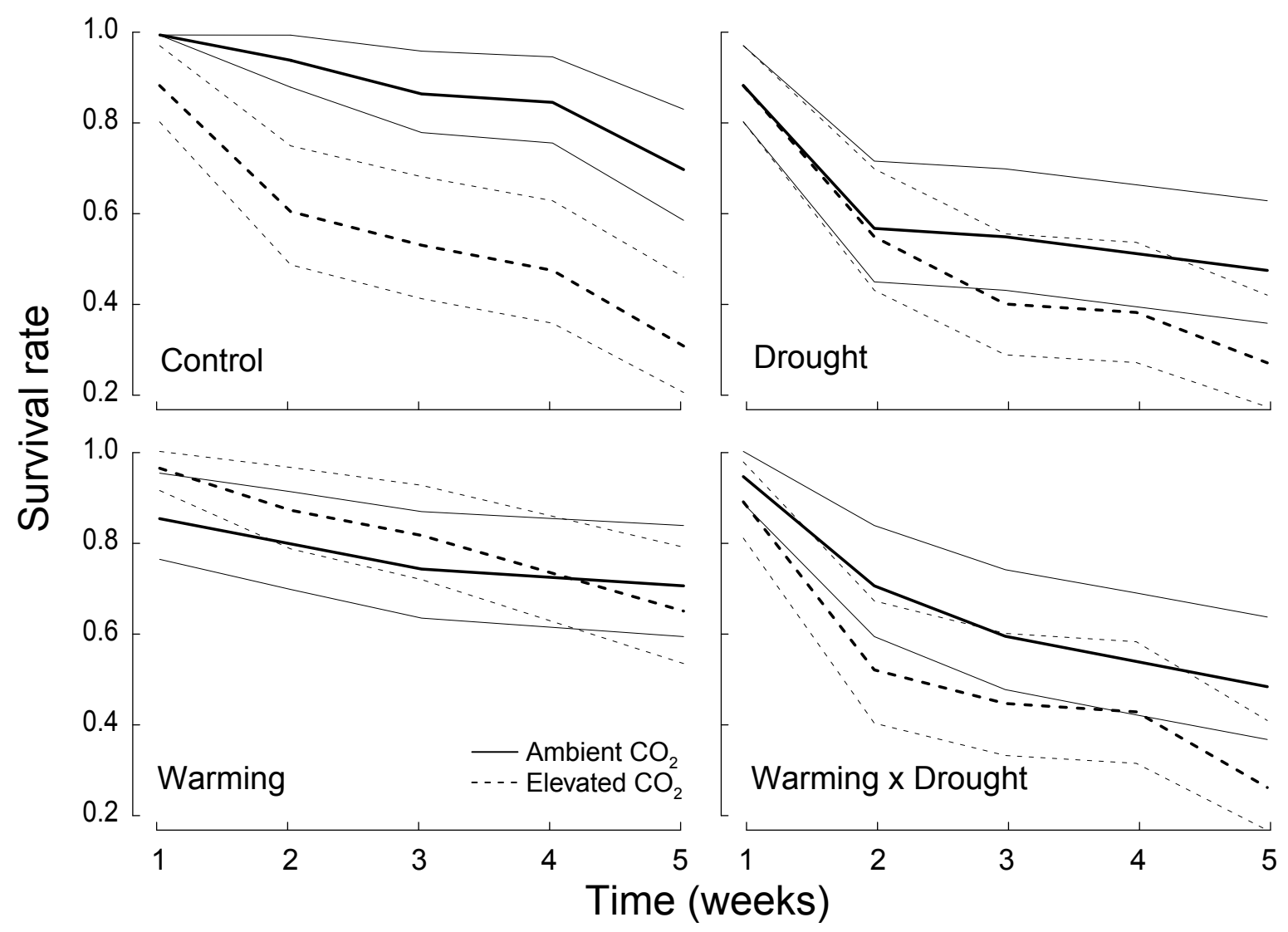

Appendix 4.4. Survival rate of Lochmaea suturalis larvae. The graph panels are ordered according to the split-plot design of the experiment. Survival rates are given for each treatment in elevated (broken lines) and ambient (solid lines) $\mathrm{CO}_{2}$ octagons. Thus each graph includes only the subset of plots $(\mathrm{n}=6)$ with the respective treatment. The single $\mathrm{CO}_{2}$ effect is obtained when comparing both curves in the control panel. Other single effects are obtained when comparing the solid lines of different panels. Interactions with time can be seen along each curve. Two and three way interactions with $\mathrm{CO}_{2}$ can be taken from the broken curves in all but the upper left panel. Thin lines show the confidence intervals at $5 \%$ and $95 \%$. 



\section{SUMMARY}

Plant-insect interactions are essential to structure and functioning of terrestrial ecosystems. Shifts within interactions, or their removal from ecosystems due to human caused environmental changes, can have far-reaching consequences for agroecosystems and near-natural systems. Environmental change in this context has three aspects: (1) The expansion of agricultural land decreases structural complexity and habitat diversity on a landscape level. (2) Agricultural intensification due to the application of fertilizers and pesticides often reduces biodiversity within habitats and alters local conditions for insects. (3) Climate change modifies abiotic (e.g. temperature, $\mathrm{CO}_{2}$ concentration, relative air humidity) and biotic (e.g. concentration of defensive metabolites in plants, nutritional value of plants) conditions for insects on different levels. Predictions about the quality of future ecosystem functions require mechanistic studies of how trophic interactions respond to environmental changes. This thesis comprises three studies approaching the mentioned aspects of change:

(1) In eight landscapes sectors in the vicinity of Göttingen we investigated how landscape composition affects spillover of rape pollen beetles and their parasitoids from oilseed rape fields on wild mustard phytometer plants in cropland habitats (wheat fields and field margin) and noncrop habitats (fallow, grassland, wood margin). Parasitism rates were not related to landscape simplification, but benefited from increasing proportions of oilseed rape. In contrast, rape pollen beetles benefited from simple landscape structure, presumably due to multi-annual population buildup resulting from long-term oilseed rape planting (as part of the crop rotation). We showed that parasitoid spillover from cropland affects trophic cascades on related wild plants outside cropland, which has been not shown so far, but can be expected to be a widespread effect shaping noncrop food webs.

(2) We tested effects of elevated temperature (using shields for passive warming) in fertilized vs. unfertilized wheat and wheat monocultures vs. wheat diversified with undersowings in a full factorial split-plot ( 8 treatments, 6 replicates, $n=48$ plots). We measured number of cereal aphids and their natural enemies in relation to yield of wheat plants. Fertilization increased yield, but also aphid density, which negatively affected yield. Predator-prey ratios were highest in diversified wheat and related to reduced aphid population growth. Elevated temperature enhanced aphid growth strongest in fertilized monocultures, leading to reduced yield. Our results show that diversified crops and reduced fertilization may become an important tool to prevent pest outbreaks in future warmer climates.

(3) We independently manipulated three climate change drivers $\left(\mathrm{CO}_{2}\right.$, temperature, drought) in a Danish heathland ecosystem dominated by heather (Calluna vulgaris) and grasses. The experiment was a full factorial split-plot with 6 blocks $\times 2 \mathrm{CO}_{2}$ treatments $\times 4$ warming/ drought treatments $=48$ plots. We exposed a total of $432(\mathrm{~N}=9$ per plot $)$ larvae of heather beetle (Lochmaea suturalis THOMSON) to ambient vs. elevated drought, temperature and $\mathrm{CO}_{2}$ 
(plus all combinations) for five weeks. Overall, this study shows i) that drought was the most important factor for insect herbivores, ii) how the effect of climate change drivers depend on other co-acting factors, iii) that insect herbivore populations may respond negatively to future climate.

In this experimental series we showed clear shifts within trophic interactions as a result of environmental changes. While effects of landscape and local management varied with specialisation of organisms, climate change (i.e. temperature) benefited insects with shorter generation cycles. Extrapolating from local field management effects we may conclude that large scale patterns such as landscape structure may interact with climate change drivers and can be used as a tool for insect population management in future. However, species specific responses to experimentally controlled changes highlight the complexity with which future environmental change affects ecosystems. 


\section{ACKNOWLEDGEMENTS}

This research certainly would not have been possible without my supervisors Professor Dr. Teja Tscharntke and Dr. habil. Carsten Dormann. Sincere thanks for discussion, criticism and providing the framework for a finally fruitful $\mathrm{PhD}$. A special thank for patience and tolerance when I took my time for parental leave and research on the Falklands. Thank you, Carsten, for initiating the BESS project - source of my funding. Also thank you for an open word whenever needed.

I acknowledge Professor Dr. Stefan Vidal and Professor Dr. Johannes Isselstein for being part of my defence committee.

I am greatly indebted to my friend and colleague Dr. Christoph Scherber who has initiated the collaboration with the Danish colleagues of CLIMAITE. I never felt more like a real scientist than in this Denmark project - it certainly was one of the best times I had during my PhD. Nothing compares to the night in the ferry lounge with a stop over at Malmø after we agreed with Søren and Karen about the project outline. Thank you for uncounted lections and help in $\mathrm{R}$ - particularly towards PhD's end when you actually did not help anymore - as.is $=\mathrm{T}$ to say that my now profound knowledge in $\mathrm{R}$ is owed to your tireless efforts. Beyond this, there is little in this thesis that has not been discussed or been criticized with and by Scherberus. It is almost certain, that MS I would have been finished earlier without his support, but in the end this has taught me so much and paid for the subsequent work. I truly aspire your scientific "question everything" approach. Thanks for brain taking scientific discussions and also for wasting time with non-statistical software and sharing photography.

I appreciate all my Danish colleagues who gave us a warm welcome and helped wherever they could. Thanks to Professor Dr. Søren Christensen and Karen Stevnbak for their effort and hospitality and their collaboration in my $\mathrm{PhD}$ and another project. Project leader Dr. Claus Beier and all other responsible scientists at CLIMAITE deserve recognition for deciding to give us the opportunity to conduct a research with that heather threatening Lochmaea beetle. Thank you, Dr. Inger Kappel Schmidt for extensive help and inviting us to the hederens workshop. Thanks also to Dr. Anders Michelsen for providing additional data. I further acknowledge the funding of travel and overnight costs by the CLIMAITE project.

Thanks to my colleagues of the Agroecology group for a good working atmosphere and scientific discussions. Not directly involved, but somehow key to a successful field season Susanne Schiele always knew where everything or -body was and why. Thank you for being that frank and good humoured master of disaster. Dr. Carsten Thies and Dr. Andrea Holzschuh are acknowledged for help during fieldwork and developing part of the ideas for MS I (C.T.,A. H.) and II (C.T:). Great thanks to Kristin Krewenka, also working in the BESS research group, 
for sharing data, help in the field and always having time to listen (and talk). Katharina (the marathon animal) Eckel, Gitte Hornemann, Ines Vollhardt, and Jochen Fründ helped during field work - thank you. Thanks to fellow father Yann Clough for counsel and statistical advice. Special thanks to the now Swiss Arno Kuhn, who shared race biking, showed me the nicest tracks in the vicinity of Göttingen and finally took me to my first Tour de Energie. My office mates are thanked for company and aerating work. Patrick Hoehn was great fun with his political incorrectness. Kathrin Stenchly was abroad or in the laboratory most of the time - thank you for letting the David work (and also thank you for coffee and having discussions about things one would normally not think about).

Sincere gratitude goes to Ian, Maria and Georgina Strange from Stanley and New Island for this fantastic time. You greatly contributed to my scientific experience. Thank you for friendship and that remote little treasure that I now call my own. Particularly to mention is Georgina Strange in her task as my short tempered muse for the best nature photographer contest. Also thanks for buying my postcards. Until we meet again.

I greatly appreciate Monique Liesenjohann, Axel Strauss and Dagmar Lorch for sticking with me although we have dispersed widely since the Jena days. Thank you for recreational holidays and moments and also for backing when you were needed.

Finally I want to thank my family: My parents Hermann-Josef and Hella-Maria always supported and still do not fail to educate me. Thank you for our talks arising and inspired from your interest and non-scientific view in and on the things that I worked with. Often it made me review what I was actually doing. Thank you also for the comment that the development of terms like ecosystem services requires a lot of an anthropocentric way of thinking. Thank you, Lotte, for understanding that I sometimes had to go away for working at an age when you called "Arbeit" "Eibat". Thank you also for being patient in the past few weeks and a caring sister to Gerda. Anja! Thank you for being at my side - you shared climate change in every aspect. I could not have desired a more reliable backing, particularly, but not only during the last period of writing. Thank you for action science, the little adventures that we had and the big ones that we started in the Falklands. Most of all I am grateful for our family. 


\section{REFERENCES}

Alford DV, Nilsson C, Ulber B (2005) Insect pests of oilseed rape crops. In: Biocontrol of Oilseed Rape Pests (ed Alford DV), pp. 9-42 Blackwell Pub Professional, Oxford.

Adler L, Harte J, Call J, De Valpine P (2007) Effects of long-term experimental warming on aphid density in the field. Journal of the Kansas Entomological Society, 80, 156-168.

Arbuckle J (2007) Amos. SPSS, Chicago.

Awmack CS, Leather SR (2002) Host plant quality and fecundity in herbivorous insects. Annual Review of Entomology, 47, 817-844.

Awmack CS, Harrington R, Lindroth RL (2004) Aphid individual performance may not predict population responses to elevated $\mathrm{CO}_{2}$ or $\mathrm{O}_{3}$. Global Change Biology, 10, 1414-1423.

Bale JS, Masters GJ, Hodkinson ID, et al. (2002) Herbivory in global climate change research: direct effects of rising temperature on insect herbivores. Global Change Biology, 8, $1-16$.

Balvanera P, Daily GC, Ehrlich PR, et al. (2001) Conserving biodiversity and ecosystem services. Science, 291, 2047-2047.

Barbehenn RV, Jaros A, Lee G, Mozola C, Weir Q, Salminen J-P (2009) Hydrolyzable tannins as "quantitative defenses": Limited impact against Lymantria dispar caterpillars on hybrid poplar. Journal of Insect Physiology, 55, 297-304.

Beier C, Emmett B, Gundersen P, et al. (2004) Novel approaches to study climate change effects on terrestrial ecosystems in the field: drought and passive nighttime warming. Ecosystems, 7, 583-597.

Berger D, Walters R, Gotthard K (2006) What keeps insects small? —-Size dependent predation on two species of butterfly larvae. Evolutionary Ecology, 20, 575-589.

Bianchi F, Booij CJH, Tscharntke T (2006) Sustainable pest regulation in agricultural landscapes: a review on landscape composition, biodiversity and natural pest control. Proceedings of the Royal Society B: Biological Sciences, 273, 1715. 
Billqvist A, Ekbom B (2001) The influence of host plant species on parasitism of pollen beetles (Meligethes spp.) by Phradis morionellus. Entomologia Experimentalis et Applicata, 98, 41-47.

Bolker BM, Brooks ME, Clark CJ, Geange SW, Poulsen JR, Stevens MHH, White J-SS (2009) Generalized linear mixed models: a practical guide for ecology and evolution. Trends in Ecology \& Evolution, 24, 127-135.

Brenes-Arguedas T, Coley PD, Kursar TA (2009) Pests vs. drought as determinants of plant distribution along a tropical rainfall gradient. Ecology, 90, 1751-1761.

Brewer MJ, Elliott NC (2004) Biological control of cereal aphids in North America and mediating effects of host plant and habitat manipulations. Annual Review of Entomology, 49, 219242.

Bromand B (1983) Possibility of continuous rearing of Meligethes aeneus Fabr. (Col.). Journal of Applied Entomology, 96, 419-422.

Bruce DM, Farrent JW, Morgan CL, Child RD (2002) Precision agriculture: determining the oilseed rape pod strength needed to reduce seed loss due to pod shatter. Biosystems Engineering, 81, 179-184.

Brunsting AMH (1982) The influence of the dynamics of a population of herbivorous beetles on the development of vegetational patterns in a heathland system. Proceedings of the 5th conference insect-plant relationships, 215-223.

Brunsting AMH, Heil GW (1985) The role of nutrients in the interactions between a herbivorous beetle and some competing plant species in heathlands. Oikos, 44, 23-26.

Büchi R (2002) Mortality of pollen beetle (Meligethes spp.) larvae due to predators and parasitoids in rape fields and the effect of conservation strips. Agriculture, Ecosystems and Environment, 90, 255-263.

Burnham KP, Anderson DR (2002) Information and likelihood theory: a basis for model selection and inference. In: Model Selection and Multimodel Inference, pp. 49-97.

Carpenter SR, Mooney HA, Agard J, et al. (2009) Science for managing ecosystem services: Beyond the Millennium Ecosystem Assessment. Proceedings of the National Academy of Sciences, 106, 1305-1312. 
Casula P, Wilby A, Thomas MB (2006) Understanding biodiversity effects on prey in multienemy systems. Ecology Letters, 9, 995-1004.

Chapin FS, Walker BH, Hobbs RJ, Hooper DU, Lawton JH, Sala OE, Tilman D (1997) Biotic Control over the Functioning of Ecosystems. Science, 277, 500-504.

Coley PD (1998) Possible effects of climate change on plant/herbivore interactions in moist tropical forests. Climatic Change, 39, 455-472.

Cook SM, Smart LE, Martin JL, Murray DA, Watts NP, Williams IH (2006) Exploitation of host plant preferences in pest management strategies for oilseed rape (Brassica napus). Entomologia Experimentalis et Applicata, 119, 221-229.

Coviella CE, Trumble JT (1999) Review: effects of elevated atmospheric carbon dioxide on insect-plant interactions. Conservation Biology, 13, 700-712.

Currano ED, WilfP, Wing SL, Labandeira CC, Lovelock EC, Royer DL (2008) Sharply increased insect herbivory during the paleocene-eocene thermal maximum. Proceedings of the National Academy of Sciences, 105, 1960-1964.

Cushman SA, McGarigal K (2004) Patterns in the species-environment relationship depend on both scale and choice of response variables. Oikos, 105, 117-124.

Dauber J, Purtauf T, Allspach A, Frisch J, Voigtländer K, Wolters V (2005) Local vs. landscape controls on diversity: a test using surface-dwelling soil macroinvertebrates of differing mobility. Global Ecology and Biogeography, 14, 213-221.

den Belder E, Elderson J, van den Brink WJ, Schelling G (2002) Effect of woodlots on thrips density in leek fields: a landscape analysis. Agriculture, Ecosystems and Environment, 91, 139-145.

DeLucia EH, Casteel CL, Nabity PD, O’Neill BF (2008) Insects take a bigger bite out of plants in a warmer, higher carbon dioxide world. Proceedings of the National Academy of Sciences, 105, 1781-1782.

Dixon AFG (1997) Aphid Ecology - An optimization approach, Second Edition. Chapman and Hall, London.

Dury SJ, Good JEG, Perrins CM, Buse A, Kaye T (1998) The effects of increasing $\mathrm{CO}_{2}$ and temperature on oak leaf palatability and the implications for herbivorous insects. 
Global Change Biology, 4, 55-61.

Ekbom B (1998) Clutch size and larval performance of pollen beetles on different host plants. Oikos, 83, 56-64.

Ekbom B, Borg A (1996) Pollen beetle (Meligethes aeneus) oviposition and feeding preference on different host plant species. Entomologia Experimentalis et Applicata, 78, 291299.

Elzinga JA, van Nouhuys S, van Leeuwen DJ, Biere A (2007) Distribution and colonisation ability of three parasitoids and their herbivorous host in a fragmented landscape. Basic and Applied Ecology, 8, 75-88.

Flynn DFB, Sudderth EA, Bazzaz FA (2006) Effects of aphid herbivory on biomass and leaf-level physiology of Solanum dulcamara under elevated temperature and $\mathrm{CO}_{2}$. Environmental and Experimental Botany, 56, 10-18.

Foley JA, DeFries R, Asner GP, et al. (2005) Global consequences of land use. Science, 309, 570-574.

Gardiner MM, Landis DA, Gratton C, et al. (2009) Landscape diversity enhances biological control of an introduced crop pest in the north-central USA. Ecological Applications, 19, 143-154.

Grace JB, Bollen KA (2005) Interpreting the results from multiple regression and structural equation models. Bulletin of the Ecological Society of America, 86, 283-295.

Ghaley B, Hauggaard-Nielsen H, Høgh-Jensen H, Jensen E (2005) Intercropping of wheat and pea as influenced by nitrogen fertilization. Nutrient Cycling in Agroecosystems, 73, 201-212.

Gimingham CH (1972) Ecology of Heathlands. Chapman \& Hall, London.

Grilli MP, Bruno M (2007) Regional abundance of a planthopper pest: the effect of host patch area and configuration. Entomologia Experimentalis et Applicata, 122, 133-143.

Goverde M, Erhardt A (2003) Effects of elevated $\mathrm{CO}_{2}$ on development and larval food-plant preference in the butterfly Coenonympha pamphilus (Lepidoptera, Satyridae). Global Change Biology, 9, 74-83. 
Gurr GM, Wratten SD, Luna JM (2003) Multi-function agricultural biodiversity: pest management and other benefits. Basic and Applied Ecology, 4, 107-116.

Hance T, van Baaren J, Vernon P, Boivin G (2006) Impact of extreme temperatures on parasitoids in a climate change perspective. Annual Review of Entomology, 52, 107-126.

Harwood JD, Sunderland KD, Symondson WOC (2003) Web-location by linyphiid spiders: Prey-specific aggregation and foraging strategies. Journal of Animal Ecology, 72, 745756.

Hassell MP, May RM (1974) Aggregation of predators and insect parasites and its effect on stability. Journal of Animal Ecology, 13, 567-594.

Haynes KJ, Dillemuth FP, Anderson BJ, Hakes AS, Jackson HB, Elizabeth Jackson S, Cronin JT (2007) Landscape context outweighs local habitat quality in its effects on herbivore dispersal and distribution. Oecologia, 151, 431-441.

Hennekens SM, Schaminée JHJ (2001) TURBOVEG, a comprehensive data base management system for vegetation data. Journal of Vegetation Science, 589-591.

Himanen SJ, Nissinen A, Dong W-X, Nerg A-M, Stewart CN, Poppy GM, Holopainen JK (2008) Interactions of elevated carbon dioxide and temperature with aphid feeding on transgenic oilseed rape: Are Bacillus thuringiensis (Bt) plants more susceptible to nontarget herbivores in future climate? Global Change Biology, 14, 1437-1454.

Hoffmann WA, Poorter H (2002) Avoiding bias in calculations of relative growth rate. Annals of Botany, 90, 36-42.

Hokkanen HMT (2000) The making of a pest: recruitment of Meligethes aeneus onto oilseed brassicas. Entomologia Experimentalis et Applicata, 95, 141-149.

Holland JM, Thomas SR (1997) Quantifying the impact of polyphagous invertebrate predators in controlling cereal aphids and in preventing wheat yield and quality reductions. Annals of Applied Biology, 131, 375-397.

Holopainen JK, Kainulainen P(2004) Reproductive capacity of the grey pine aphid and allocation response of Scots pine seedlings across temperature gradients: a test of hypotheses predicting outcomes of global warming. Canadian Journal of Forest Research, 34, 94-102. 
Holt RD, Lawton JH, Polis GA, Martinez ND (1999) Trophic rank and the species-area relationship. Ecology, 80, 1495-1504.

Hooper DU, Chapin FS, Ewel JJ, et al. (2005) Effects of biodiversity on ecosystem functioning: a consensus of current knowledge. Ecological Monographs, 75, 3-35

Hopkins RJ, Ekbom B (1996) Low oviposition stimuli reduce egg production in the pollen beetle Meligethes aeneus. Physiological Entomology, 21, 118-122.

Hothorn T, Bretz F, Westfall P (2008) Simultaneous inference in general parametric models. Biometrical Journal, 50, 346-363.

IPCC (2007) Climate Change 2007: The Physical Science Basis. Contribution of Working Group I to the Fourth Assessment Report of the Intergovernmental Panel on Climate Change (eds Solomon S, Qin D, Manning M, Chen Z, Marquis M, Averyt KB, Tignor M, Miller HL). Cambridge University Press, Cambridge, United Kingdom and New York, NY, USA.

Jones TH (1998) Impacts of Rising Atmospheric Carbon Dioxide on Model Terrestrial Ecosystems. Science, 280, 441-443.

Jonsen ID, Fahrig L (1997) Response of generalist and specialist insect herbivores to landscape spatial structure. Landscape Ecology, 12, 185-197.

Jonsson M, Lindkvist A, Anderson P (2005) Behavioural responses in three ichneumonid pollen beetle parasitoids to volatiles emitted from different phenological stages of oilseed rape. Entomologia Experimentalis et Applicata, 115, 363-369.

Jourdheuil P (1960) Influence de quelques facteurs écologiques sur les fluctuations de population d'une biocénose parasitaire. Etude à quelques hymenoptère parasites de divers coléoptères inféodés aux crucifères. Annales Epiphytes, 445-660.

Kareiva P, Wennergren U (1995) Connecting landscape patterns to ecosystem and population processes. 373, 299-302.

Klapweijk MJ, Gröbler BC, Ward K, Wheeler D, Lewis OT (2010) Influence of experimental warming and shading on host-parasitoid synchrony. Global Change Biology, 16, 102112.

Klug T, Gathmann A, Poehling HM, Meyhofer R (2003) Area-dependent effects of landscape 
structure on the colonisation of spinach cultures by the silver Y moth Autographa gamma (L., Lepidoptera: Noctuidae) in Western Germany. In: IOBC/wprs Bulletin Vol. 4 (eds Rossing WAH, Poehling H-M, Burgio G), pp. 77-83.

Kruess A, Tscharntke T (1994) Habitat fragmentation, species loss, and biological control. Science, 264, 1581-1584.

Lancashire PD, Bleiholder H, van den Boom T, Langelüdeke P, Stauss R, Weber E, Witzenberger A (1991) A uniform decimal code for growth stages of crops and weeds. Annals of Applied Biology, 119, 561-601.

Lawler IR, Foley WJ, Woodrow IE, Cork SJ (1996) The effects of elevated $\mathrm{CO}_{2}$ atmospheres on the nutritional quality of Eucalyptus foliage and its interaction with soil nutrient and light availability. Oecologia, 109, 59-68.

Lehrman A, Åhman I, Ekbom B (2008) Effect of pea lectin expressed transgenically in oilseed rape on pollen beetle life-history parameters. Entomologia Experimentalis et Applicata, 127, 184-190.

Lewis WJ, Tumlinson JH (1988) Host detection by chemically mediated associative learning in a parasitic wasp. Nature, 331, 257-259.

Lincoln DE, Couvet D (1989) The effect of carbon supply on allocation to allelochemicals and caterpillar consumption of peppermint. Oecologia, 78, 112-114.

Lincoln DE, Couvet D, Sionit N (1986) Response of an insect herbivore to host plants grown in carbon dioxide enriched atmospheres. Oecologia, 69, 556-560.

Lincoln DE, Fajer ED, Johnson RH (1993) Plant-insect herbivore interactions in elevated $\mathrm{CO}_{2}$ environments. Trends in Ecology \& Evolution, 8, 64-68.

Lumley T (2008) survival: Survival analysis, including penalised likelihood. $R$ package version 2.34-1,

Matson PA, Parton WJ, Power AG, Swift MJ (1997) Agricultural intensification and ecosystem properties. Science, 277, 504-509.

Matter SF, Roland J (2002) An experimental examination of the effects of habitat quality on the dispersal and local abundance of the butterfly Parnassius smintheus. Ecological Entomology, 27, 308-316. 
Mattson WJ, Haack RA (1987) The role of drought in outbreaks of plant-eating insects. Bioscience, 37, 110-118.

Mayhew PJ (2001) Herbivore host choice and optimal bad motherhood. Trends in Ecology \& Evolution, 16, 165-167.

Melber A (1989) Der Heideblattkäfer (Lochmaea suturalis) in nordwestdeutschen CallunaHeiden. Informationsdienst Naturschutz Niedersachsen, 9, 101-124.

Melber A, Heimbach U (1984) Massenvermehrungen des Heideblattkäfers Lochmaea suturalis (Thoms.) (Col., Chrysomelidae) in nordwestdeutschen Calluna-Heiden in diesem Jahrhundert. Journal of Pest Science, 57, 87-89.

Meyer B, Jauker F, Steffan-Dewenter I (2009) Contrasting resource-dependent responses of hoverfly richness and density to landscape structure. Basic and Applied Ecology, 10, 178-186.

Miglietta F, Peressotti A, Vaccari FP, Zaldei A, deAngelis P, Scarascia-Mugnozza G (2001) Free-air $\mathrm{CO}_{2}$ enrichment (FACE) of a poplar plantation: the POPFACE fumigation system. New Phytologist, 150, 465-476.

Migui SM, Lamb RJ (2007) Trophic interactions between three species of cereal aphid (Hemiptera: Aphididae) and spring wheat (Poaceae): implications for pest management. The Canadian Entomologist, 139, 850-863.

Mikkelsen TN, Beier C, Jonasson S, et al. (2008) Experimental design of multifactor climate change experiments with elevated $\mathrm{CO}_{2}$, warming and drought: the CLIMAITE project. Functional Ecology, 22 185-195.

Mohr KH (1966) Chrysomelidae. In: Die Käfer Mitteleuropas, Bd. 9: CerambycidaeChrysomelidae, Freude, H., Harde, K.W. \& G.A. Lohse (Ed.) Vol. 9. Spektrum Akademischer Verlag, Krefeld.

Morecroft MD, Bealey CE, Howells O, Rennie S, Woiwod IP (2002) Effects of drought on contrasting insect and plant species in the UK in the mid-1990s. Global Ecology \& Biogeography, 11, 7-22.

Müller HJ (1941) Weitere Beiträge zur Biologie des Rapsglanzkäfers Meligethes aeneus F. (Über das Winterlager und die Massenbewegung im Frühjahr). Zeitschrift für Pflanzenkrankheiten, Pflanzenpathogene und Pflanzenschutz, 51, 529-595. 
Murray K, Conner MM (2009) Methods to quantify variable importance: implications for the analysis of noisy ecological data. Ecology, 90, 348-355.

Naud C, Makowski D, Jeuffroy M-H (2009) Leaf transmittance measurements can improve predictions of the nitrogen status for winter wheat crop. Field Crops Research, 110, 27-34.

Netherer S, Schopf A Potential effects of climate change on insect herbivores in European forests--General aspects and the pine processionary moth as specific example. Forest Ecology and Management, 259, 831-838.

Nilsson C (1988) The pollen beetle (Meligethes aeneus F.) in winter and spring rape at Alnarp 1976-1978. III. Mortality factors. Växtskyddsnotiser, 52, 145-150.

Nilsson C (2003) Parasitoids of pollen beetles. In: Biocontrol of Oilseed Rape Pests (ed Alford DV), pp. 73-86 Blackwell Publishing, Oxford.

Olivier M, Goffart J-P, Ledent J-F (2006) Threshold value for chlorophyll meter as decision tool for nitrogen management of potato. Agronomy Journal, 98, 496-506.

Peñuelas J, Estiarte M (1998) Can elevated $\mathrm{CO}_{2}$ affect secondary metabolism and ecosystem function? Trends in Ecology \& Evolution, 13, 20-24.

Perrin RM (1976) Pest management in multiple cropping systems. Agro-Ecosystems, 3, 93118.

Pinheiro J, Bates D, DebRoy S, Sarkar D, the R Developement Core Team (2009) nlme: Linear and Nonlinear Mixed Effects Models, R package version 3.1-92.

Pinheiro JC, Bates DM (2000) Theory and computational methods for linear mixed-effects models. In: Mixed-Effects Models in S and S-PLUS (eds Pinheiro JC, Bates DM), pp. 57-96. Springer, New York.

Powell W, Poppy GM (1999) Host location by parasitoids. In: Insect Movement: Mechanisms and Consequences (eds Woiwood I, Reynolds D, Thomas C), pp. 111-129 CABI Publishing, Wallingford.

Praslicka J, Mistina T (2004) Influence of parasitization on cereal aphids (Sternorrhyncha: Aphidoidea) in various field management. Plant Protection Science, 40, 49-53. 
Pritchard J, Griffiths B, Hunt EJ (2007) Can the plant-mediated impacts on aphids of elevated $\mathrm{CO}_{2}$ and drought be predicted? Global Change Biology, 13, 1616-1629.

Rand TA, Louda SM (2006) Spillover of agriculturally subsidized predators as a potentia threat to native insect herbivores in fragmented landscapes. Conservation Biology, 20, 17201729.

Rand TA, Tscharntke T (2007) Contrasting effects of natural habitat loss on generalist and specialist aphid natural enemies. Oikos, 116, 1353.

Rand TA, Tylianakis JM, Tscharntke T (2006) Spillover edge effects: the dispersal of agriculturally subsidized insect natural enemies into adjacent natural habitats. Ecology Letters, 9, 603-614.

R Development Core Team (2010) R: A language and environment for statistical computing. $\mathrm{R}$ Foundation for statistical Computing, Vienna, Austria.

Renwick JAA (2002) The chemical world of crucivores: lures, treats and traps. Entomologia Experimentalis et Applicata, 104, 35-42

Ricketts TH, Regetz J, Steffan-Dewenter I, et al. (2008) Landscape effects on crop pollination services: are there general patterns? Ecology Letters, 11, 499-515.

Risch SJ, Andow D, Altieri MA (1983) Agroecosystem diversity and pest control: Data, tentative conclusions, and new research directions. Environmental Entomology, 12, 625-629.

Root RB (1973) Organization of a plant-arthropod association in simple and diverse habitats: The fauna of collards (Brassica oleracea). Ecological Monographs, 43, 95-124.

Rotem KA, Agrawal AA (2003) Density dependent population growth of the two-spotted spider mite, Tetranychus urticae, on the host plant Leonurus cardiaca. Oikos, 103, 559-565.

Roth SK, Lindroth RL (1994) Effects of $\mathrm{CO}_{2}$-mediated changes in paper birch and white pine chemistry on gypsy moth performance. Oecologia, 98, 133-138.

Rouault G, Candau J-N, Lieutier F, Nageleisen L-M, Martin J-C, Warzée N (2006) Effects of drought and heat on forest insect populations in relation to the 2003 drought in Western Europe. Annals of Forest Science, 63, 613-624.

Sarker P, Rahman M, Das B (2009) Effect of intercropping with mustard with onion and garlic 
on aphid population and yield. Journal of Bio-Science, 15, 35-40.

Schmitz OJ (2009) Effects of predator functional diversity on grassland ecosystem function. Ecology, 90, 2339-2345.

Schweiger O, Maelfait JP, Wingerden W, et al. (2005) Quantifying the impact of environmental factors on arthropod communities in agricultural landscapes across organizational levels and spatial scales. Journal of Applied Ecology, 42, 1129-1139.

Scriber JM, Slansky F (1981) The nutritional ecology of immature insects. Annual Review of Entomology, 26, 183-211.

Shaw MR, Zavaleta ES, Chiariello NR, Cleland EE, Mooney HA, Field CB (2002) Grassland responses to global environmental changes suppressed by elevated $\mathrm{CO}_{2}$. Science, 298 , 1987-1990.

Sheehan W, Shelton AM (1989) Parasitoid response to concentration of herbivore food plants: Finding and leaving plants. Ecology, 70, 993-998.

Sigsgaard L (2002) A survey of aphids and aphid parasitoids in cereal fields in Denmark, and the parasitoids role in biological control. Journal of Applied Entomology, 126, 101107.

Smith JG (1976) Influence of crop background on natural enemies of aphids on Brussels sprouts. Annals of Applied Biology, 83, 15-29.

Soares AO, Coderre D, Schanderl H (2003) Effect of temperature and intraspecific allometry on predation by two phenotypes of Harmonia axyridis Pallas (Coleoptera: Coccinellidae). Environmental Entomology, 32, 939-944.

Stamp NE, Yang Y (1996) Response of insect herbivores to multiple allelochemicals under different thermal regimes. Ecology, 77, 1088-1102.

Stiling P, Cornelissen T (2007) How does elevated carbon dioxide $\left(\mathrm{CO}_{2}\right)$ affect plant-herbivore interactions? A field experiment and meta-analysis of $\mathrm{CO}_{2}$-mediated changes on plant chemistry and herbivore performance. Global Change Biology, 13, 1823-1842.

Stiling P, Rossi AM, Hungate B, Dijkstra P, Hinkle CR, Knott Iii WM, Drake B (1999) Decreased leaf-miner abundance in elevated $\mathrm{CO}_{2}$ : reduced leaf quality and increased parasitoid attack. Ecological Applications, 9, 240-244. 
Straub CS, Finke DL, Snyder WE (2008) Are the conservation of natural enemy biodiversity and biological control compatible goals? Biological Control, 45, 225-237.

Straub CS, Snyder WE (2006) Experimental approaches to understanding the relationship between predator biodiversity and biological control. In: Trophic and Guild in Biological Interactions Control (eds Brodeur J, Boivin G), pp. 221-239. Springer, New York.

Strong DR, Southwood R, Lawton JH (1984) Insects on Plants : Community Patterns and Mechanisms. Blackwell Scientific, Oxford.

Sunderland K, Samu F (2000) Effects of agricultural diversification on the abundance, distribution, and pest control potential of spiders: a review. Entomologia Experimentalis et Applicata, 95, 1-13.

Theunissen J (1994) Intercropping in field vegetable crops: Pest management by agrosystem diversification - an overview. Pesticide Science, 42, 65-68.

Thies C, Roschewitz I, Tscharntke T (2005) The landscape context of cereal aphid-parasitoid interactions. Proceedings of the Royal Society B: Biological Sciences, 272, 203-210.

Thies C, Steffan-Dewenter I, Tscharntke T (2003) Effects of landscape context on herbivory and parasitism at different spatial scales. Oikos, 101, 18-25.

Thies C, Steffan-Dewenter I, Tscharntke T (2008) Interannual landscape changes influence plant-herbivore-parasitoid interactions. Agriculture, Ecosystems and Environment, 125, 266-268.

Thies C, Tscharntke T (1999) Landscape structure and biological control in agroecosystems. Science, 285, 893-895.

Tscharntke T, Rand TA, Bianchi F (2005) The landscape context of trophic interactions: insect spillover across the crop-noncrop interface. Annales Zoologici Fennici, 42, 421-432.

Turner MG (1989) Landscape ecology: the effect of pattern on process. Annual review of ecology and systematics, 20, 171-197.

Turner MG, Gardner RH (1991) Quantitative methods in landscape ecology: an introduction. In: Quantitative Methods in landscape ecology, pp. 3-14 Springer, New York.

Van Emden HF, Williams GF (1974) Insect stability and diversity in agroecosystems. Annual 
Review of Entomology, 19, 455-475.

Vandermeer J, van Noordwijk M, Anderson J, Ong C, Perfecto I (1998) Global change and multi-species agroecosystems: Concepts and issues. Agriculture, Ecosystems \& Environment, 67, 1-22.

Venables WN, Ripley BD (2002) Modern Applied Statistics with S. Springer, New York.

Vet LEM, Lewis WJ, Carde RT (1995) Parasitoids foraging and learning. In: Chemical Ecology of Insects 2 (eds Carde RT, Bell WJ), pp. 65-104. Chapmann and Hall, New York.

Wackers FL (2004) Assessing the suitability of flowering herbs as parasitoid food sources: flower attractiveness and nectar accessibility. Biological Control, 29, 307-314.

Weibull J (1987) Seasonal changes in the free amino acids of oat and barley phloem sap in relation to plant growth stage and growth of Rhopalosiphum padi. Annals of Applied Biology, 111, 729-737.

Web of Science ${ }^{\circledR}$ Citation Report (2010) Topic=(climate change ecosystem function), www. isiknowledge.com. Download 15.05.2010

Weisser WW, Siemann E (2004) Insects and Ecosystem Function, pp 3-26. Springer, Berlin.

White TCR (1993) The Inadequate Environment: Nitrogen and the Abundance of Animals. Springer-Verlag, Berlin, New York.

Wilf P, Labandeira CC (1999) Response of Plant-Insect Associations to Paleocene-Eocene Warming. Science, 284, 2153-2156.

Williams IH (2004) Advances in insect pest management of oilseed rape in europe. In: Insect Pest Management - Field and Protected Crops (eds Horowitz A, Ishaaya I), pp. 181208. Springer-Verlag, Heidelberg.

Williams IH (2006) Integrating parasitoids into management of pollen beetle on oilseed rape. Agronomy Research, 4, 465-470

Wrbka T, Erb K-H, Schulz NBNB, Peterseil J, Hahn C, Haberl H (2004) Linking pattern and process in cultural landscapes. An empirical study based on spatially explicit indicators. Land Use Policy, 21, 289-306.

Zadoks JC, Chang TT, Konzak CF (1974) A decimal code for the growth stages of cereals. 
Weed Research, 14, 415-421.

Zaller JG, Moser D, Drapela T, Schmoger C, Frank T (2008a) Effect of within-field and landscape factors on insect damage in winter oilseed rape. Agriculture Ecosystems \& Environment, 123, 233-238.

Zaller JG, Moser D, Drapela T, Schmöger C, Frank T (2008b) Insect pests in winter oilseed rape affected by field and landscape characteristics. Basic and Applied Ecology, 9, 682-690.

Zehnder CB, Hunter MD (2008) Effects of nitrogen deposition on the interaction between an aphid and its host plant. Ecological Entomology, 33, 24-30.

Zhang W, Ricketts TH, Kremen C, Carney K, Swinton SM (2007) Ecosystem services and disservices to agriculture. Ecological Economics, 64, 253-260.

Zuur AF, Ieno EN, Walker NJ, Saveliev AA, Smith GM (2009) Mixed Effects Models and Extensions in Ecology with R, pp. 71-100. Springer, Berlin

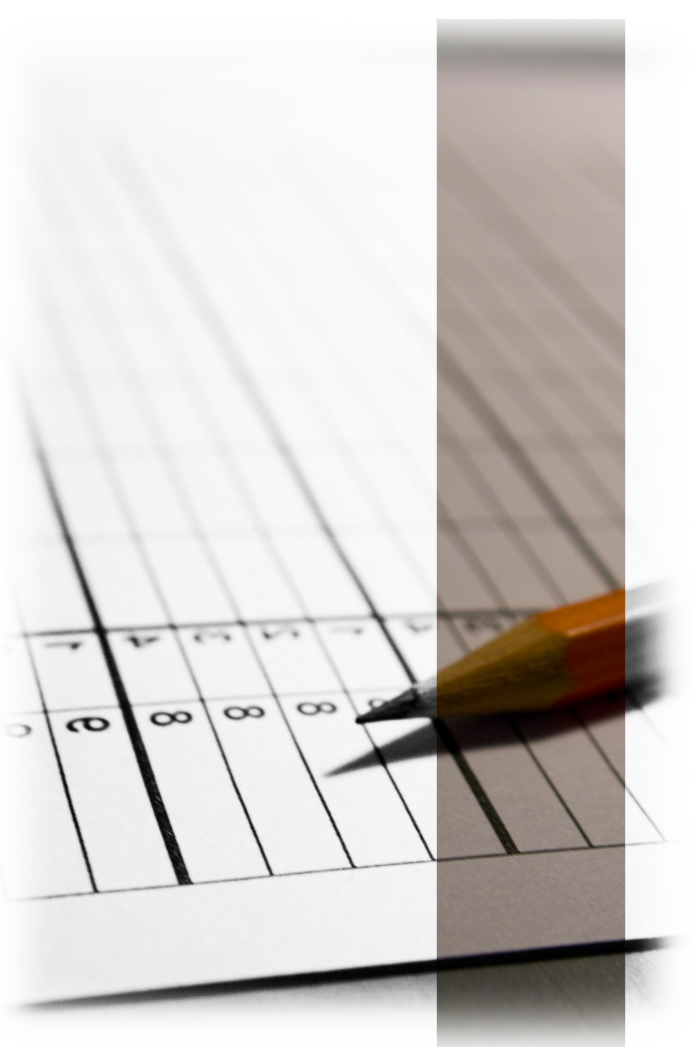




\section{Publications}

MANUSCRIPTS

Krewenka K, Gladbach DJ, Holzschuh A, Evaars J, Dormann CF, Tschartnke T (in prep.) Spatiotemporal patterns of hoverflies in crop vs. non-crop habitat types - implications of functional traits.

Krewenka K, Holzschuh A, Gladbach DJ, Hellmich S, Dormann CF, Tscharntke T (in prep.) Spatiotemporal patterns of bees and predatory wasps in different habitat types.

Stevnbak K, Gladbach DJ, Scherber C, Christensen S, Mikkelsen TN, Beier C (in prep. for Nature) Grasshoppers eat less at future $\mathrm{CO}_{2}$ but stimulate belowground activity more, due to relieved N-limitation.

Gladbach DJ, Stevnbak K, Christensen S, Michelsen A,. Mikkelsen TN, Beier C, Tscharntke T, Scherber C (submitted to Global Change Biology, May 2010) Effects of warming, drought and elevated $\mathrm{CO}_{2}$ on performance of an insect herbivore in heathland.

Gladbach DJ, Thies, C, Tscharntke T, Dormann CF (submitted to Global Change Biology, May 2010) Heating up trophic interactions in crops with low vs. high intensity management.

Gladbach DJ, Holzschuh A., Scherber C, Thies C, Dormann CF, Tscharntke T (submitted to Oecologia, May 2010) Spillover cascades: crops affect trophic interactions on wild plants in surrounding habitats.

Gladbach A, Gladbach DJ, Quillfeldt P (submitted to Journal of Avian Biology, February 2010) Male achromatic wing colouration is related to body condition and female reproductive investment in a dichromatic species, the Upland goose Chloephaga picta leucoptera.

Gladbach A, Gladbach DJ, Kempenaers B, Quillfeldt P (accepted) Female-specific colouration, carotenoids and reproductive investment in a dichromatic species, the Upland goose Chloephaga picta leucoptera. Behavioral Ecology and Sociobiology.

Gladbach A, Gladbach DJ, Quillfeldt P (2010) Seasonal clutch size decline and individual variation in the timing of breeding are related to female body condition in a non-migratory species, the Upland goose Chloephaga picta leucoptera. Journal of Ornithology. 
Gladbach A, Gladbach DJ, Quillfeldt P (2010) Variations in leucocyte profiles and plasma biochemistry are related to different aspects of parental investment in male and female Upland geese Chloephaga picta leucoptera. Comparative Biochemistry and Physiology.

\section{CONTRIBUTIONS TO CONFERENCES}

Gladbach DJ, Thies C, Scherber C, Holzschuh A, Dormann CF, Tscharntke T (2009) Effects of local and landscape features on multitrophic plant-insect interactions. Poster, Conference of the German Society of General and Applied Entomology, Göttingen.

Gladbach DJ, Scherber C, Stevnbak K, Christensen S, Tscharntke T, Mikkelsen TN, Beier C (2009) Effects of climate change on aboveground trophic interactions. Poster, Conference of the German Society of General and Applied Entomology, Göttingen.

Stevnbak K, Scherber C, Gladbach DJ, Christensen S (2009): Climate change strongly affects interaction between herbivorous insects, plants, and rhizosphere biota. Poster, Conference „Climate change: global risks, challenges and decisions“, Copenhagen, Denmark.

Gladbach A, Gladbach DJ, Quillfeldt P (2009) Tarsus colouration as a signal of individual quality in Upland Geese (Chloephaga picta leucoptera). Vortrag, 7th EOU (European Ornithological Union) conference, Zürich.

Gladbach A, Gladbach DJ, Quillfeldt P (2008), Zuviel der Sorge tut nicht gut, macht bleich und dürr und dünnt das Blut": Untersuchung zum Stresslevel von Magellangänsen anhand hämatologischer Parameter. Talk, 141. Conference of the DO-G (Deutsche Ornithologen-Gesellschaft), Bremen.

Halle S, Gladbach DJ (2005) Spatial and temporal short-term responses of common voles (Microtus arvalis) in experimentally fragmented habitats. Talk, Ninth International Mammalogical Congress of the Science Council of Japan and the Mammalogical Society of Japan, Sapporo, Japan.

Gladbach DJ, Halle S (2004) Emigrationsraten und Bewegungsmuster von abwandernden Wühlmäusen (Microtus arvalis) - Eine experimentelle Gehegestudie. Talk, 78. Annual Meeting of the German Society of Mammaology, Bonn. 
OTHER

Gladbach DJ, Scherber C (2009) Climate change effects on growth and survival of herbivorous insects. Invited talk, Heathland ecology and management workshop, Copenhagen, Denmark.

Scherber C, Gladbach D (2008) Effects of climate change on aboveground insects, Research presentation at the 12-13 March CLIMAITE meeting, Brorfelde, DK

Gladbach DJ (2006) Biocontrol and pest management in landscape context. Talk, Research Presentation at the Ceter for Environmental Research - UFZ, Leipzig.

Gladbach DJ (2006) Short-term effects of habitat fragmentation. Talk at the Department of Crop Science, Agroecology, Georg-August-University, Göttingen.

Gladbach DJ (2005) Experimental study of dispersal and immigration behaviour in common voles, Microtus arvalis. Diploma Thesis. Friedrich-Schiller-University, Jena.

Gladbach DJ (2004) Where have all the vo-oles gone? Talk, Annual Christmas Symposium, Institute of Ecology, Friedrich-Schiller-University, Jena.

Gladbach DJ (2004) Mäuse in Bewegung - Ein Modellexperiment mit Microtus arvalis. Talk, Institute Seminar, Institute of Ecology, Friedrich-Schiller-University, Jena.

Gladbach DJ (2004) Between scientific projects and every day living - summer on an Antarctic research station. Talk, Antarctic Expedition of Oceanwide Expeditions, Cruisehip vessel Grigory Mikheev, Drake Passage.

Gladbach DJ, Gross S, Lange A, Lauterbach D, Lorch D, Manthej S, Tittmann S, Peter HU (2001) FFH Gebiet 122, Nerkewitzer Grund- Klingelsteine. Report to the Thüringer Landesanstalt für Umwelt - TLU in the scope of declaration of FFH-Schutzgebiete. 



\section{Curriculum vitae}

DAVID GLADBACH

BORN IN COLOGNE, $14^{\text {TH }}$ MAY 1977

2006 - 2010 PhD study at the Department of Crop Sciences, Agroecology, Georg-AugustUniversity in Göttingen, funded by the Helmholz Association (VH-NG-247) under supervision of Prof. Dr. Teja Tscharntke

„Plant-insect interactions in changing environments"

2000 - 2005 Diploma studies in Biology at the Friedrich-Schiller-University in Jena, Main subject: Ecology, Minor subjects: Zoology, Environmental Law

Diploma thesis (2004 - 2005) at the Institute of Ecology, FriedrichSchiller University in Jena, under supervision of Prof. Dr. Stefan Halle „Experimental study of dispersal and immigration behaviour in common voles, Microtus arvalis"

Erasmus Exchange Study (2001 - 2002) at the University of Wales in Bangor, UK

$1998-2000$ Undergraduate studies at the Friedrich-Schiller-University in Jena

1997 - 1998 Civil service at „Schullandheim Ratsgymnasium Bielefeld“ on Langeoog

1988 - 1997 Grammar school, „Marienschule Opladen“, Leverkusen-Oplanden

1984 - 1988 Primary school, „Ernst Moritz Arndt Schule“, Burscheid-Hilgen 



\section{DECLARATION OF ORIGINAL AUTHORSHIP}

I, David Gladbach am the overall author of this thesis including the manuscripts presented in chapters 2 to 4 . Development of main ideas, data collection, statistical analysis, and writing of the manuscripts is my original work. The respective co-authors contributed to various parts of the studies and provided comments on the manuscripts. Any material from other resources has been properly and fully acknowledged.

Göttingen, May 2010 